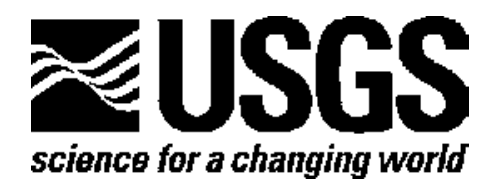

\title{
Effects of Equipment Performance on Data Quality from the National Atmospheric Deposition Program/National Trends Network and the Mercury Deposition Network
}

By Gregory A. Wetherbee and Mark F. Rhodes

Open-File Report 2013-1031

U.S. Department of the Interior

U.S. Geological Survey 


\section{U.S. Department of the Interior \\ KEN SALAZAR, Secretary}

\section{U.S. Geological Survey \\ Suzette M. Kimball, Acting Director}

U.S. Geological Survey, Reston, Virginia: 2013

For more information on the USGS-the Federal source for science about the Earth, its natural and living resources, natural hazards, and the environment-visit http://www.usgs.gov or call 1-888-ASK-USGS

For an overview of USGS information products, including maps, imagery, and publications, visit $h$ ttp://www.usgs.gov/pubprod

To order this and other USGS information products, visit http://store.usgs.gov

Suggested citation:

Wetherbee, G.A., and Rhodes, M.F., 2013, Effects of equipment performance on data quality from the National Atmospheric Deposition Program/National Trends Network and the Mercury Deposition Network: U.S. Geological Survey Open-File Report 2013-1031, 53 p. pamphlet

Any use of trade, product, or firm names is for descriptive purposes only and does not imply endorsement by the U.S. Government.

Although this report is in the public domain, permission must be secured from the individual copyright owners to reproduce any copyrighted material contained within this report. 


\section{Contents}

Terms and Abbreviations used in this report.............................................................................. viii

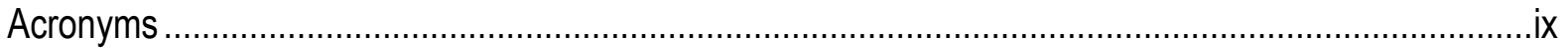

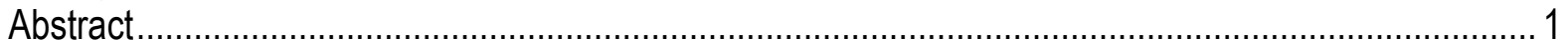

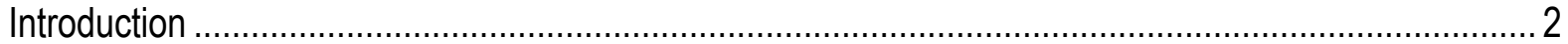

Precipitation Chemistry Quality Assurance............................................................................ 4

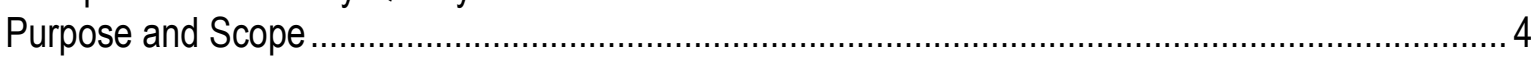

Study 1. Sample Evaporation in NTN Collector....................................................................... 4

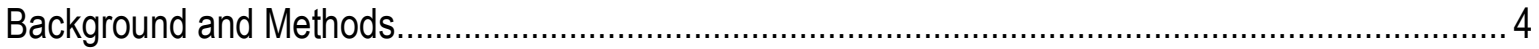

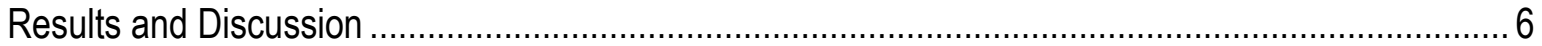

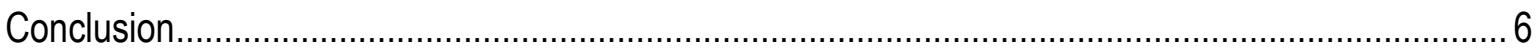

Study 2. MDN Sample Loss Study ......................................................................................... 9

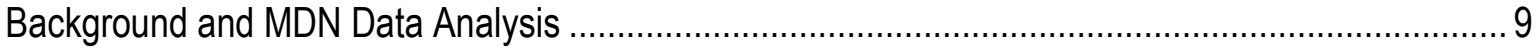

Phase 1 of Study -Extent of MDN Sample Loss ................................................................... 10

Phase 2 of Study_Factors that Affect MDN Sample Loss ....................................................... 13

Phase 2 Methodology ................................................................................................. 13

Phase 3 of Study-Effects of Sample Loss on Mercury Concentrations......................................... 18

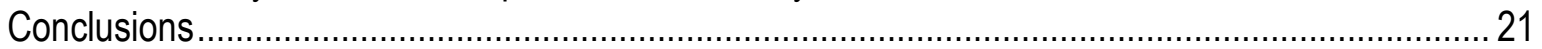

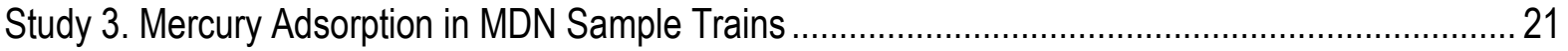

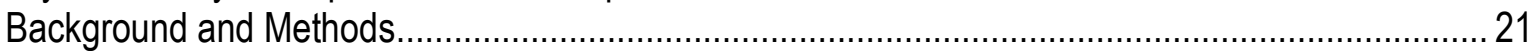

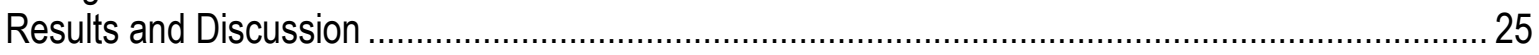

Study 4. Sensitivity of NTN and MDN Collector Sensors ............................................................. 25

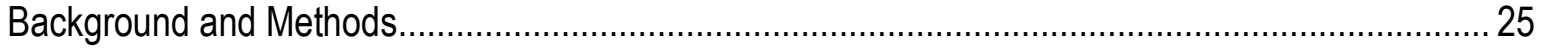

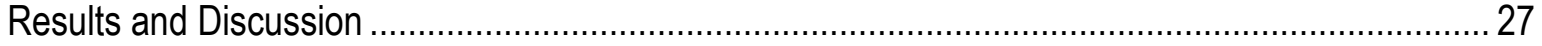

Study 5. Catch Efficiency of NTN Collector with Wind Shield......................................................... 31

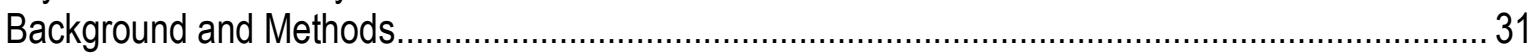

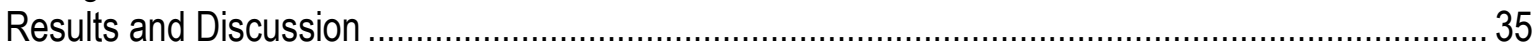

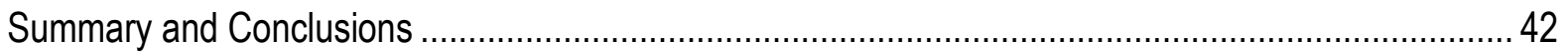

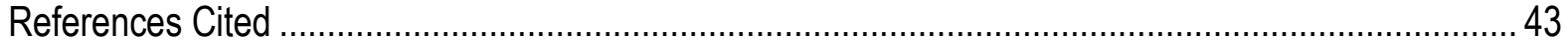

\section{Figures}

1. Map showing active and formerly active National Atmospheric Deposition Program/National

Trends Network (NTN) sites, 2010 ......................................................................... 2

2. Map showing active (2010) and formerly active National Atmospheric Deposition

Program/Mercury Deposition Network (MDN) sites, 2010 ................................................. 3

3. Graph showing active National Atmospheric Deposition Program/National Trends Network and Mercury Deposition Network sites, 1978-2009............................................................. 3

4. Graph showing weekly sample evaporation from a National Trends Network Aerochem Metrics Model 301 wet-deposition collector and weekly pan evaporation at Arvada, Colorado, May 16-September 5, 2006.

5. Graph showing weekly sample evaporation from a National Trends Network Aerochem Metrics Model 301 wet-deposition collector and weekly mean wind direction from north and wind speed at Arvada, Colorado, May 16-September 5, 2006. 
6. Graph showing weekly sample evaporation from a National Trends Network Aerochem Metrics Model 301 wet-deposition collector and weekly mean air temperature at Arvada, Colorado, May 16-September 5, 2006.

7. Graph showing relation of weekly mean relative humidity and mean barometric pressure to weekly sample evaporation from a National Trends Network Aerochem Metrics Model 301 wet-deposition collector at Arvada, Colorado, May 16-September 5, 2006.

8. Graph showing weekly sample evaporation from a National Trends Network Aerochem Metrics Model 301 wet-deposition collector and initial sample volumes at Arvada, Colorado, May 16-September 5, 2006.

9. Map showing Mercury Deposition Network samples with preservative volume loss in modified ACM and N-CON precipitation collectors during weeks with no precipitation, March 1996November 2010.

10. Map showing Mercury Deposition Network percent preservative volume loss in modified ACM and N-CON precipitation collectors during weeks with no precipitation, March 1996November 2010.

11. Photographs of bad lid seal configuration for the modified ACM collector (top) and the N-CON collector (bottom)

12. Graph showing field sample volume lost (percent) over weekly periods in N-CON and modified Aerochem Metrics (ACM) precipitation collectors and maximum weekly temperatures of the air inside the collectors, December 1, 2009-May 7, 2010.

13. Graph showing percentages of initial sample volumes lost over weekly periods in $\mathrm{N}-\mathrm{CON}$ and modified Aerochem Metrics (ACM) precipitation collectors and corresponding integrity of collector-lid seals, December 1, 2009-May 7, 2010.

14. Graph showing percentages of initial sample volumes lost over weekly periods in N-CON and modified Aerochem Metrics (ACM) precipitation collectors and corresponding configurations of air flow inside the collectors, March 1, 2010-October 29, 2010

15. Graph showing percentages of initial sample volumes lost over weekly periods in $\mathrm{N}-\mathrm{CON}$ and modified Aerochem Metrics (ACM) precipitation collectors and corresponding internal collector temperature, lid seal integrity, and internal air flow configurations for the collectors, December 1, 2009-November 17, 2010

16. Graph showing relation of percent sample volume loss and mercury concentration difference for three MDN collector types: N-CON, modified Aerochem Metrics (ACM), and Loda Electronics ACM.

17. Graph showing relation of sample volume loss to percent mercury mass loss for three MDN collector types: N-CON, modified Aerochem Metrics (ACM), and Loda Electronics ACM........ 20

18. Thistle-tube configurations used with the modified N-CON collector and the ACM collector............ 22

19. Flowchart of the sample-train study for the Mercury Deposition Network.................................... 24

20. Mercury Deposition Network 11-grid sensor and National Trends Network 7-grid sensor for Aeorchem Metrics precipitation collectors

21. Graphs showing comparison of number of precipitation events when 7- and 11-grid sensors opened and closed their respective collectors first at 20 co-located National Trends Network (NTN) and Mercury Deposition Network (MDN) sites.

22. Graphs showing comparison of wet- and dry-exposure differences and collector cycle differences for 7- and 11-grid sensors at 20 co-located National Trends Network and Mercury Deposition Network sites.

23. Co-located sampler installation at Marshall Field, Colorado showing placement of standard and wind-shielded ACM collectors and location of precipitation gage. 
24. Graphs showing time series of unshielded-minus-shielded collector catch differences for colocated wet-deposition collectors operated at Marshall Field, Colorado during water years 2008-2009 (WY08--WY09).

25. Graphs showing relation of shielded and unshielded collector catch for co-located wetdeposition collectors operated at Marshall Field, Colorado during water years 2008-2009 (WY08-WY09).

26. Graphs showing sample-volume differences for co-located standard and wind-shielded wetdeposition collectors, with maximum and average wind speed during precipitation at Marshall Field, Colorado during water years 2008-2009 (WY08-WY09)

27. Graph showing catch efficiency and sample-volume differences, for co-located wind-shielded and standard wet-deposition collectors, related to average wind direction and wind direction relative standard deviation during precipitation at Marshall Field, Colorado during water years 2008-2009

28. Graph showing sample-volume differences for co-located standard and wind-shielded wetdeposition collectors related to average and minimum air temperature during precipitation at Marshall Field, Colorado during water years 2008-2009 (WY08-WY09)

29. Graph showing specific conductance of precipitation samples obtained by co-located windshielded and standard wet-deposition collectors at Marshall Field, Colorado during water years 2008-2009

30. $\mathrm{pH}$ of precipitation samples obtained by co-located wind-shielded and unshielded wetdeposition collectors at Marshall Field, Colorado during water years 2008-2009 (WY08WY09) 


\section{Tables}

1. Kendall's Tau and associated statistical significance for correlation of meteorological data and weekly evaporation of synthetic precipitation samples sealed in an Aerochem Metrics Model 301 precipitation collector in Arvada, Colorado, May 16-September 5, 2006

2. Preservative volume loss for MDN samples collected between March 1996 and November 2010 ... 47

3. Weekly Mercury Deposition Network (MDN) samples with preservative volume loss and individual MDN sites where sample loss was observed, March 1996-November 2010

4. Specifications of the cooling fan used in the original modified Aerochem Metrics (ACM) collector and the Loda Electronics version of the ACM collector

5. Results from evaporation tests with Aerochem Metrics version of the modified ACM collector.

6. Results from evaporation tests with Loda Electronics version of the modified ACM collector.

7. Results from evaporation tests with $\mathrm{N}-\mathrm{CON}$ single-chimney collector.

8. Total mercury concentration analyses for sample-train study samples processed after a week with rain or snow at selected Mercury Deposition Network sites

9. Co-located National Trends Network (NTN) and Mercury Deposition Network (MDN) sites and periods of record for comparison of 7- and 11-grid Aerochem Metrics precipitation sensors... 53 


\section{Conversion Factors}

SI to Inch/Pound

\begin{tabular}{lcl}
\hline \multicolumn{1}{c}{ Multiply } & By & \multicolumn{1}{c}{ To obtain } \\
\hline centimeter $(\mathrm{cm})$ & 0.3937 & inch (in.) \\
\hline millimeter $(\mathrm{mm})$ & 0.0394 & inch (in.) \\
\hline & Volume & \\
\hline milliliter $(\mathrm{mL})$ & 0.03381 & ounce, fluid \\
liter $(\mathrm{L})$ & 1.057 & quart $(\mathrm{qt})$ \\
cubic meter $\left(\mathrm{m}^{3}\right)$ & 35.31 & cubic foot $\left(\mathrm{ft}^{3}\right)$ \\
\hline & Acceleration & \\
\hline meter per second $(\mathrm{m} / \mathrm{s})$ & 2.237 & miles per hour $(\mathrm{mi} / \mathrm{hr})$ \\
\hline & Mass & \\
\hline gram $(\mathrm{g})$ & 0.03527 & ounce, avoirdupois $(\mathrm{oz})$ \\
micrograms per square meter $\left(\mu \mathrm{g} / \mathrm{m}^{2}\right)$ & $2.049 \times 10^{-10}$ & pounds per square foot $\left(\mathrm{lbs} / \mathrm{ft}^{2}\right)$ \\
nanograms $(\mathrm{ng})$ & $3.527 \times 10^{-11}$ & ounce $(\mathrm{oz})$ \\
\hline
\end{tabular}

Temperature in degrees Celsius $\left({ }^{\circ} \mathrm{C}\right)$ may be converted to degrees Fahrenheit $\left({ }^{\circ} \mathrm{F}\right)$ as follows:

${ }^{\circ} \mathrm{F}=\left(1.8 x^{\circ} \mathrm{C}\right)+32$

Specific conductance is given in microsiemens per centimeter at 25 degrees Celsius $\left(\mu \mathrm{S} / \mathrm{cm}\right.$ at $\left.25^{\circ} \mathrm{C}\right)$.

Concentrations of chemical constituents in water are given either in milligrams per liter ( $\mathrm{mg} / \mathrm{L}$ ) micrograms per liter $(\mu \mathrm{g} / \mathrm{L})$, or nanograms per liter (ng/L). 


\section{Terms and Abbreviations Used in This Report}

absolute value of $x=|x|$, where $x$ takes the form of numerical values or algebraic expressions

cubic feet per minute $\left(\mathrm{ft}^{3} / \mathrm{min}\right)$

decibel $(\mathrm{dB})$

$\operatorname{gram}(\mathrm{g})$

grams per cubic centimeter $\left(\mathrm{g} / \mathrm{cm}^{3}\right)$

grams per milliliter $(\mathrm{g} / \mathrm{mL})$

maximum probability of incorrectly rejecting the null hypothesis when it is true $(p)$

meters per second $(\mathrm{m} / \mathrm{s})$

microgram $(\mu \mathrm{g})$

microequivalents per liter $(\mu \mathrm{eq} / \mathrm{L})$

microsiemens per centimeter at 25 degrees Celsius $(\mu \mathrm{S} / \mathrm{cm})$

milligrams per liter $(\mathrm{mg} / \mathrm{L})$

millimeter (mm)

nanograms per liter (ng/L)

revolutions per minute $(\mathrm{rpm})$

square centimeters $\left(\mathrm{cm}^{2}\right)$

statistical significance level $(\alpha)$

water year $=$ October 1 -September 30 of following year, designated by ending year 


\section{Abbreviations and Acronyms}

\begin{tabular}{ll}
\hline \multicolumn{1}{c}{ Abbreviation } & \multicolumn{1}{c}{ Full name } \\
\hline ACM & Aerochem Metrics Model 301 collector \\
BQS & Branch of Quality Systems \\
CAL & Central Analytical Laboratory \\
CDPHE & Colorado Department of Public Health and Environment \\
DC & Direct Current \\
DFC & Denver Federal Center \\
DFIR & Dual Fence Inter-comparison Reference wind shield \\
HAL & Mercury Analytical Laboratory at Frontier Global Sciences, Inc. \\
HCl & Hydrochloric acid \\
Hg & Mercury \\
MDN & Mercury Deposition Network \\
Mod-ACM & Modified Aerochem Metrics precipitation collector \\
MOF & Mercury Observer Form \\
MPV & most probable value \\
NADP & National Atmospheric Deposition Program \\
NCAR & National Center for Atmospheric Research \\
N-CON & N-CON Systems, Incorporated \\
NTN & National Trends Network \\
PCQA & Precipitation Chemistry Quality Assurance \\
pH & Negative log of hydrogen ion concentration in equivalents per liter \\
PO & Program Office (of the National Atmospheric Deposition Program) \\
QC & Quality control \\
SC & Specific Conductance \\
URL & Universal Resources Locator \\
USGS & United States Geological Survey \\
\hline
\end{tabular}




\title{
Effects of Equipment Performance on Data Quality from the National Atmospheric Deposition Program/National Trends Network and the Mercury Deposition Network
}

\author{
By Gregory A. Wetherbee ${ }^{1}$ and Mark F. Rhodes ${ }^{2}$ \\ 1 U.S. Geological Survey \\ 2 University of Illinois, Prairie Research Institute
}

\begin{abstract}
The U.S. Geological Survey Branch of Quality Systems operates the Precipitation Chemistry Quality Assurance project (PCQA) to provide independent, external qualityassurance for the National Atmospheric Deposition Program (NADP). NADP is composed of five monitoring networks that measure the chemical composition of precipitation and ambient air. PCQA and the NADP Program Office completed five short-term studies to investigate the effects of equipment performance with respect to the National Trends Network (NTN) and Mercury Deposition Network (MDN) data quality: sample evaporation from NTN collectors; sample volume and mercury loss from MDN collectors; mercury adsorption to MDN collector glassware, grid-type precipitation sensors for precipitation collectors, and the effects of an NTN collector wind shield on sample catch efficiency.

Sample-volume evaporation from an NTN Aerochem Metrics (ACM) collector ranged between 1.1-33 percent with a median of 4.7 percent. The results suggest that weekly NTN sample evaporation is small relative to sample volume. MDN sample evaporation occurs predominantly in western and southern regions of the United States (U.S.) and more frequently with modified ACM collectors than with N-CON Systems Inc. collectors due to differences in airflow through the collectors. Variations in mercury concentrations, measured to be as high as 47.5 percent per week with a median of 5 percent, are associated with MDN sample-volume loss. Small amounts of mercury are also lost from MDN samples by adsorption to collector glassware irrespective of collector type. MDN 11-grid sensors were found to open collectors sooner, keep them open longer, and cause fewer lid cycles than NTN 7-grid sensors. Wind shielding an NTN ACM collector resulted in collection of larger quantities of precipitation while also preserving sample integrity.
\end{abstract}




\section{Introduction}

The National Atmospheric Deposition Program (NADP) National Trends Network (NTN) was initiated in 1978 by the Association of State Agricultural Experiment Stations to monitor long-term atmospheric chemistry and the effects pollutants have on aquatic and terrestrial systems (Nilles, 2000). The number of sites increased from 21 in 1978 to 261 in 2006. As of 2010, precipitation samples were collected from a total of 251 sites in the United States (including Alaska, Puerto Rico, U.S. Virgin Islands) and Canada (fig. 1).

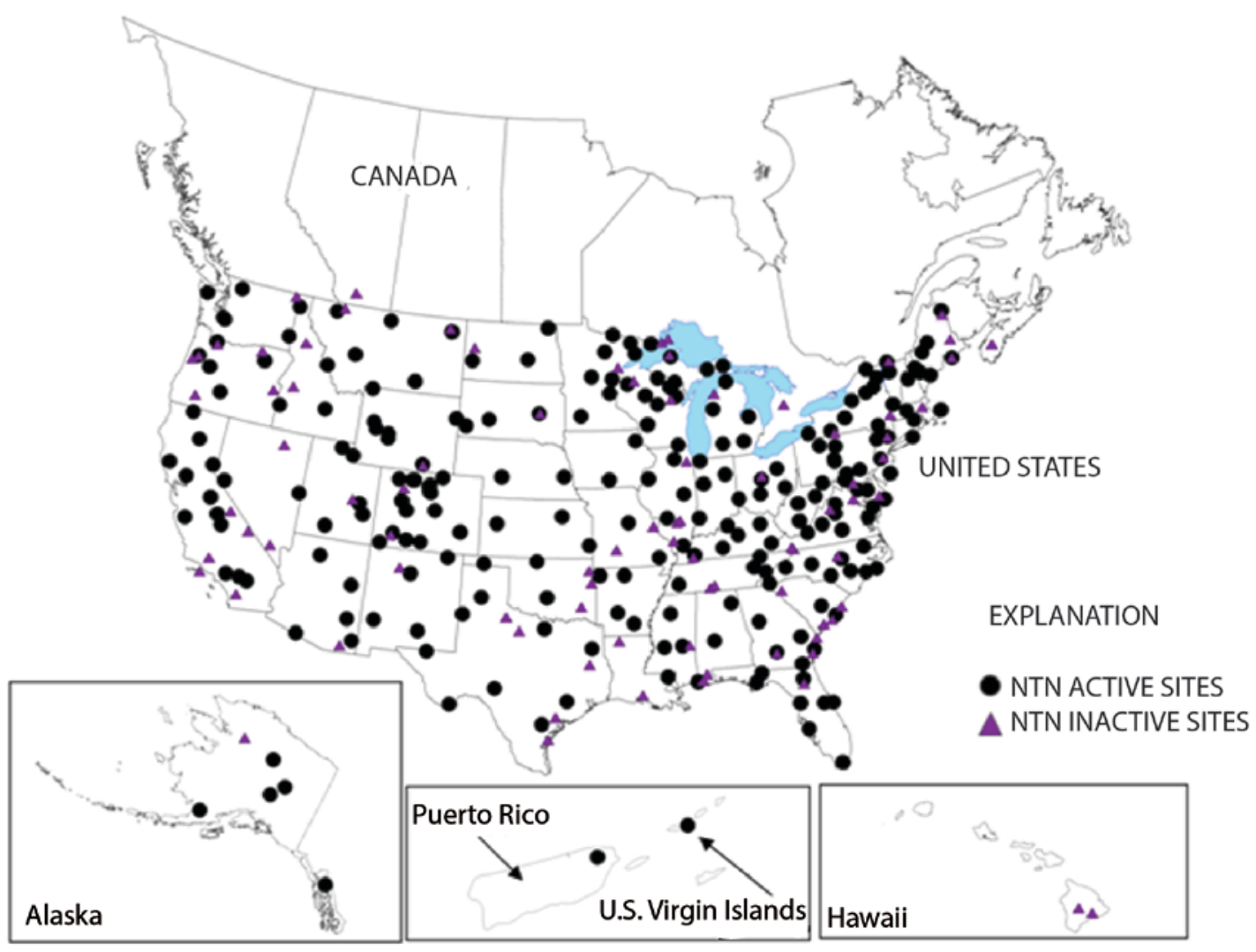

Figure 1. Active and formerly active National Atmospheric Deposition Program / National Trends Network (NTN) sites, 2010.

The NADP Mercury Deposition Network (MDN) was established in 1996 to monitor long-term atmospheric wet-deposition of mercury $(\mathrm{Hg})$ and to aid in understanding the effects of mercury pollution on aquatic and terrestrial systems (Vermette and others, 1995). The number of sites increased from 18 in 1996 to a maximum of 117 in 2008. As of winter 2010, precipitation was being collected from 111 sites in the United States (including Alaska and Puerto Rico) and Canada (fig. 2). The chronology of the number of active sites in the NTN and MDN is shown in figure 3. 


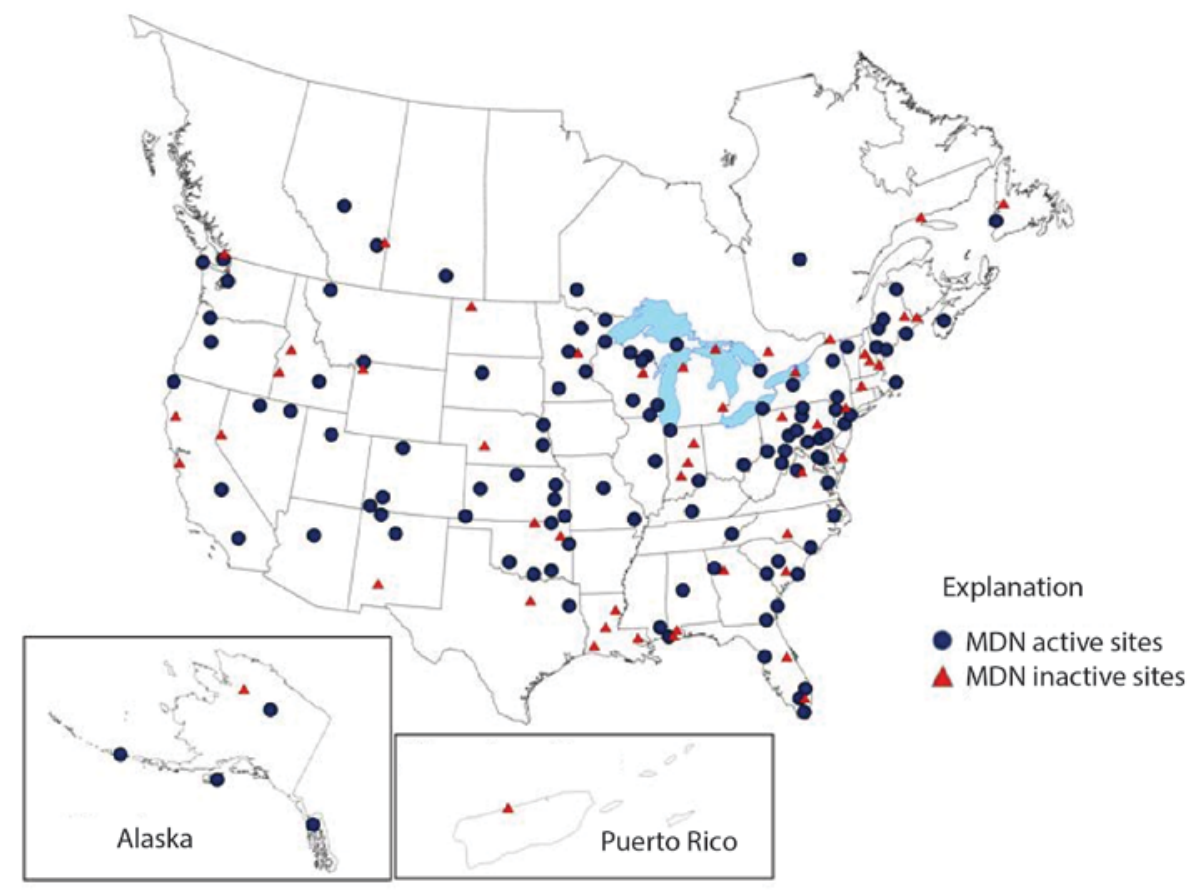

Figure 2. Active (2010) and formerly active National Atmospheric Deposition Program/Mercury Deposition Network (MDN) sites, 2010.

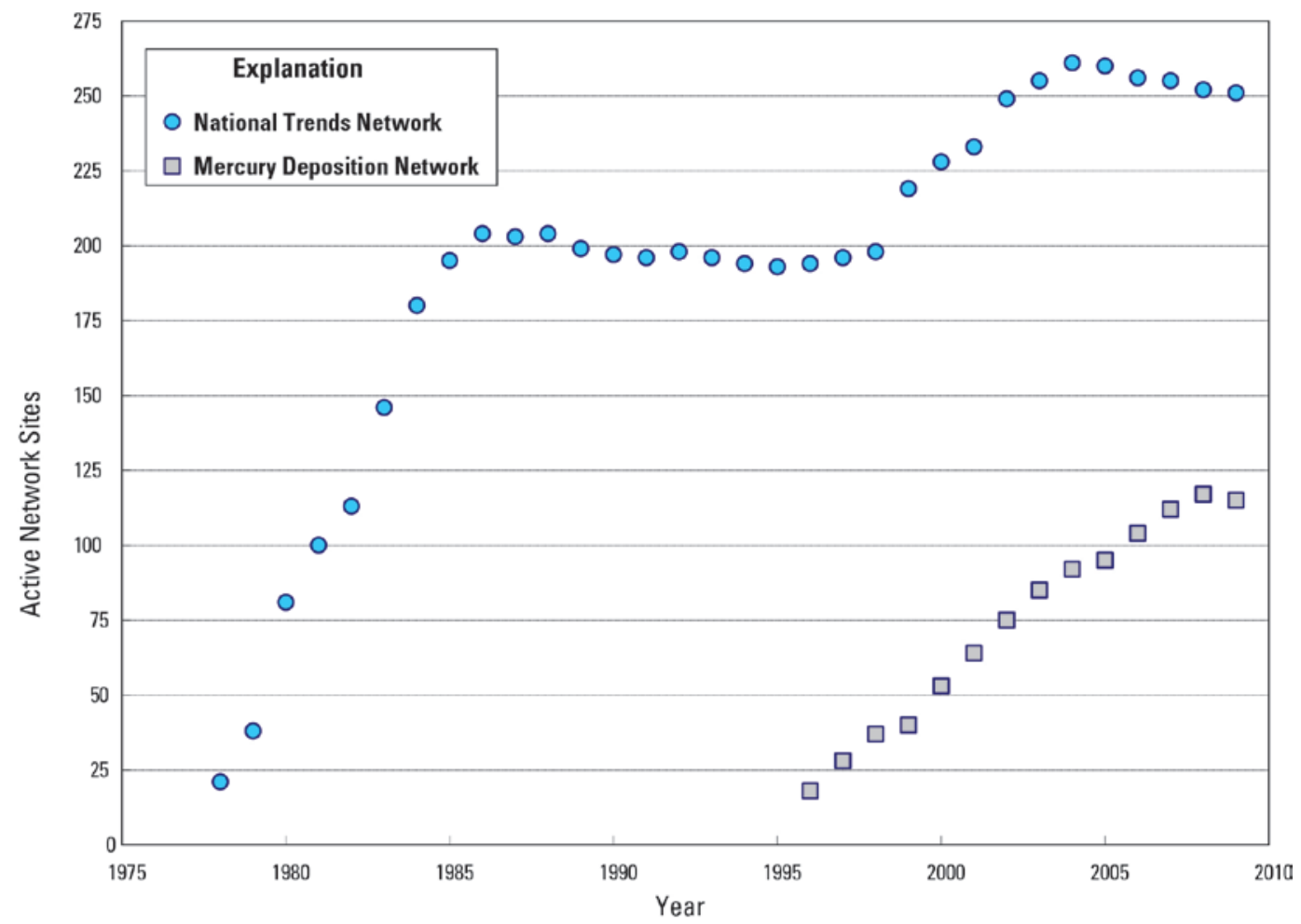

Figure 3. Active National Atmospheric Deposition Program/National Trends Network and Mercury Deposition Network sites, 1978-2009. 


\section{Precipitation Chemistry Quality Assurance}

The U.S. Geological Survey (USGS) Branch of Quality Systems (BQS) began operating external quality-assurance programs under the Precipitation Chemistry Quality Assurance Project (PCQA) for the NADP/NTN in 1978 and for the NADP/MDN in 2004 (Latysh and others, 2005 and 2007). In addition to long-term quality-assurance programs, PCQA implements short-term equipment performance studies. PCQA works closely with the NADP Program Office (PO) and Central Analytical Laboratory (CAL) located at the Illinois State Water Survey in Champaign, Illinois, and with the Mercury Analytical Laboratory (HAL) located at Frontier Global Sciences, Inc. in Bothell, Washington. CAL analyzes all weekly NTN precipitation samples, and HAL analyzes all weekly MDN precipitation samples.

Many technical questions about the integrity and representativeness of NTN measurements have been addressed by PCQA throughout the past 33 years of network operation. Results of studies to address NTN sample integrity were completed by Graham and others (1987 and 1990), See and others (1989), Willoughby and others (1989 and 1990), Gordon (1997 and 1999), and Latysh and Gordon (2004). MDN has been the subject of quality assurance studies by Vermette and others (1995) and Wetherbee and others $(2004,2005,2006,2009$, and 2010).

\section{Purpose and Scope}

The purpose of this report is to provide information about five studies of equipment performance effects on NADP data quality. Findings from these five studies have been presented at semi-annual NADP Technical Committee meetings, and may be accessed at http://nadp.isws.illinois.edu/committees/minutes.aspx. This report documents the information in a citable form.

The five studies of equipment performance effects on NADP data quality are:

1. Sample evaporation in NTN collector (2006),

2. MDN sample loss study (2009-2011),

3. Mercury adsorption in MDN sample trains (2009-2010),

4. Sensitivity of NTN and MDN collector sensors (2007-2010), and

5. Catch efficiency of NTN collector with wind shield (2008-2009).

\section{Study 1. Sample Evaporation in NTN Collector}

\section{Background and Methods}

This study evaluated sample evaporation from one model of NTN collector and compared the observed sample evaporation to nearby meteorological measurements of pan evaporation, wind direction, wind speed, air temperature, relative humidity, and barometric pressure. The hypothesis was that sample evaporation rate was related to one or more of these factors, in which case, algorithms could be developed to correct sample concentrations for evaporation using such measurements. This study did not address the effects of sample evaporation on sample chemistry. Tang and others (1987) measured weekly Aerochem Metrics Model 301 collector (ACM) sample evaporation ranging from 0.6-5 percent with negligible effects on sample chemistry. 
Synthetic precipitation samples were added to empty, pre-weighed NTN buckets and deployed in ACM collectors for one-week periods during May 16-September 5, 2006 at a field site in Arvada, Colorado. Initial sample depth was determined immediately prior to field deployment of the buckets. Sample depth was calculated from the sample mass as:

$$
\text { Sample depth, in centimeters }=\left(\frac{m_{\text {sample }} \times P^{-1}}{A}\right),
$$

where, $m_{\text {sample }}=$ mass of sample in grams,

$P^{-1}=$ reciprocal of density of water ( 1 cubic centimeter / gram), and $A=$ area of bucket orifice (678.9 square centimeters).

The collector lid sealed the bucket orifice, and power was disconnected from the ACM collector so that it would not open during the week. At week's end, the bucket containing the sample was removed from the ACM collector, and the final sample mass and depth were once again determined immediately using the same balance. Sample evaporation depth was calculated as the initial depth minus the final depth. Calculated sample evaporation was compared to onsite measurement of pan evaporation, which was done using a Class-A evaporation pan monitored manually on a weekly basis and every 4 hours electronically using a float gage and Campbell Scientific CR-10 data logger (fig. 4).

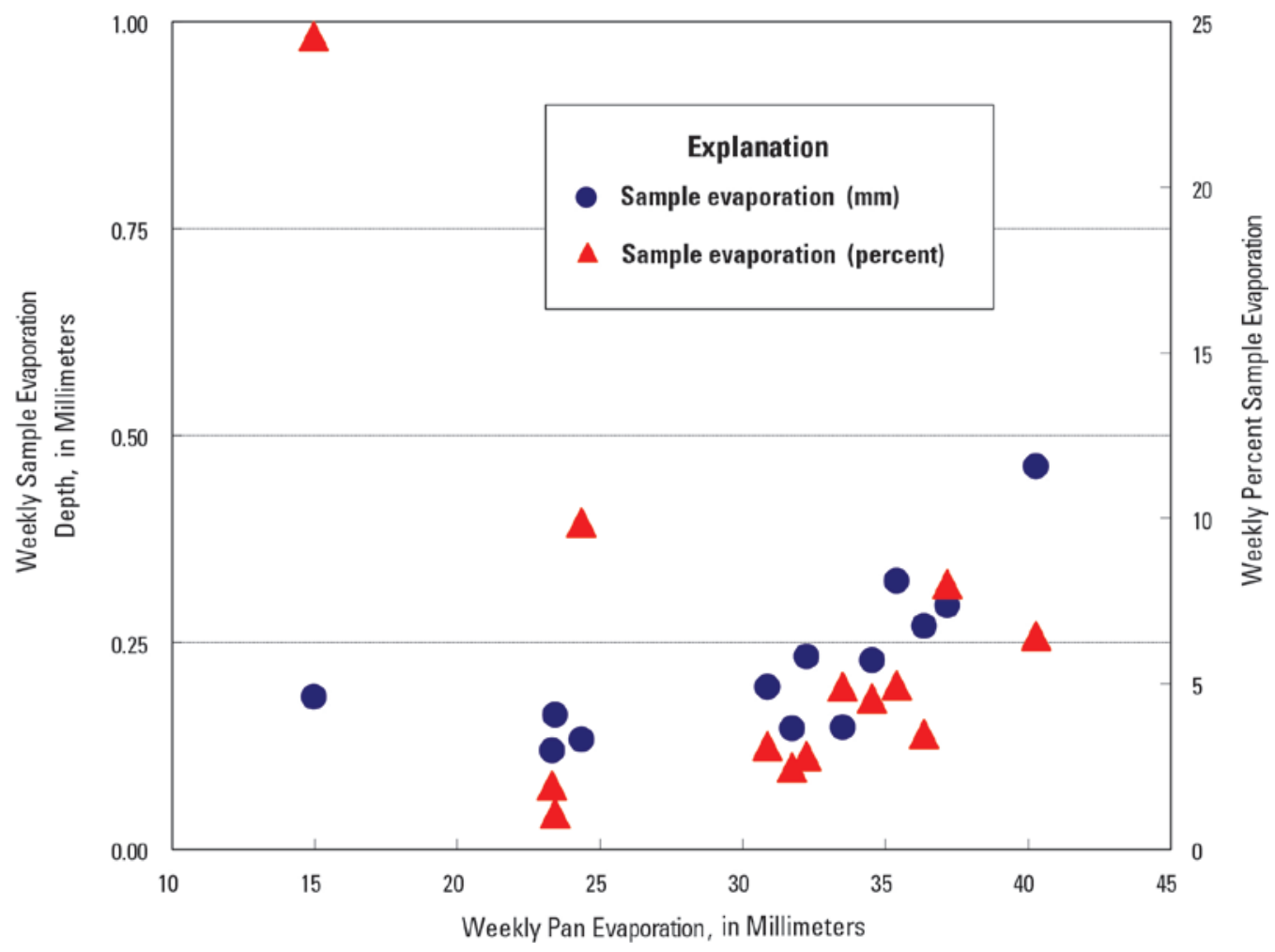

Figure 4. Weekly sample evaporation from a National Trends Network Aerochem Metrics Model 301 wet-deposition collector and weekly pan evaporation at Arvada, Colorado, May 16September 5, 2006. 
Hourly air temperature, wind speed, and wind direction were measured onsite using instrumentation operated by the Colorado Department of Public Health and Environment (CDPHE), Air Quality Control Division. Hourly CDPHE data for the Arvada site were provided by Frank Martelli (CDPHE, written commun., 2006). Relative humidity and barometric pressure were measured nearby at the Citizen Weather Observer Program site AR893 in Arvada, Colorado. Weekly mean wind direction ranged from southeast to southwest for this study, which was done during summer. The data were analyzed graphically to identify relations between the meteorological parameters and sample evaporation. Kendall's Tau (T) correlation coefficients (Helsel and Hirsch, 1992) were estimated to describe relations of sample evaporation to meteorological data using $\mathrm{R}$ software version 12.2.2 (available at URL: http://CRAN.R-project.org/). Statistically significant $(\alpha=0.05$ significance level) correlations with $\mathrm{T}$ greater than 0.5 were considered relevant.

\section{Results and Discussion}

Sample evaporation correlated with pan evaporation (Kendall Tau $=0.69$, $p=0.0003$ ), but no evidence of correlation was found between sample evaporation and wind direction, wind speed, air temperature, or barometric pressure (figs. 5-7), all with Kendall Tau less than 0.5 as indicated in table 1 . However, figure 7 illustrates a significant $(\alpha=0.05)$, strong correlation (Kendall Tau $=-0.77$ ) between weekly sample evaporation and mean relative humidity whereby sample evaporation increases with decreasing relative humidity. Weekly sample evaporation depth is not correlated with the initial sample volume at the time of deployment to the field (fig. 8).

Weekly NTN sample-volume evaporation from the ACM collector ranged between 1.1-33 percent with a median of 4.7 percent. This is a site-specific study performed during summer at an altitude of approximately 1,660 meters (m). Results might not be representative of the entire NTN, but they are indicative of changes in NTN samples that occur after collection.

There are other important differences between the study protocol and normal NTN samples. A fixed sample volume was added to the collector on the first day of each week of the study, and the collector did not open for the week. Many NTN samples are a composite of more than one rainfall event that does not always start on the first Tuesday of bucket deployment.; the collector may open and close several times during a week.

\section{Conclusion}

Sample evaporation is strongly correlated with mean relative humidity (Kendall $\mathrm{Tau}=-0.77$ at $\alpha=0.0001$ significance level), but not air temperature, wind speed, wind direction, or barometric pressure (figs. 5-7). A weak correlation (Kendall Tau $=-0.38$ at $\alpha=0.041$ ) between weekly percent sample evaporation and initial sample volume was observed despite the fact that evaporation occurs at the liquid-air interface of the sample surface area, which is independent of volume in the cylindrical NTN bucket. 

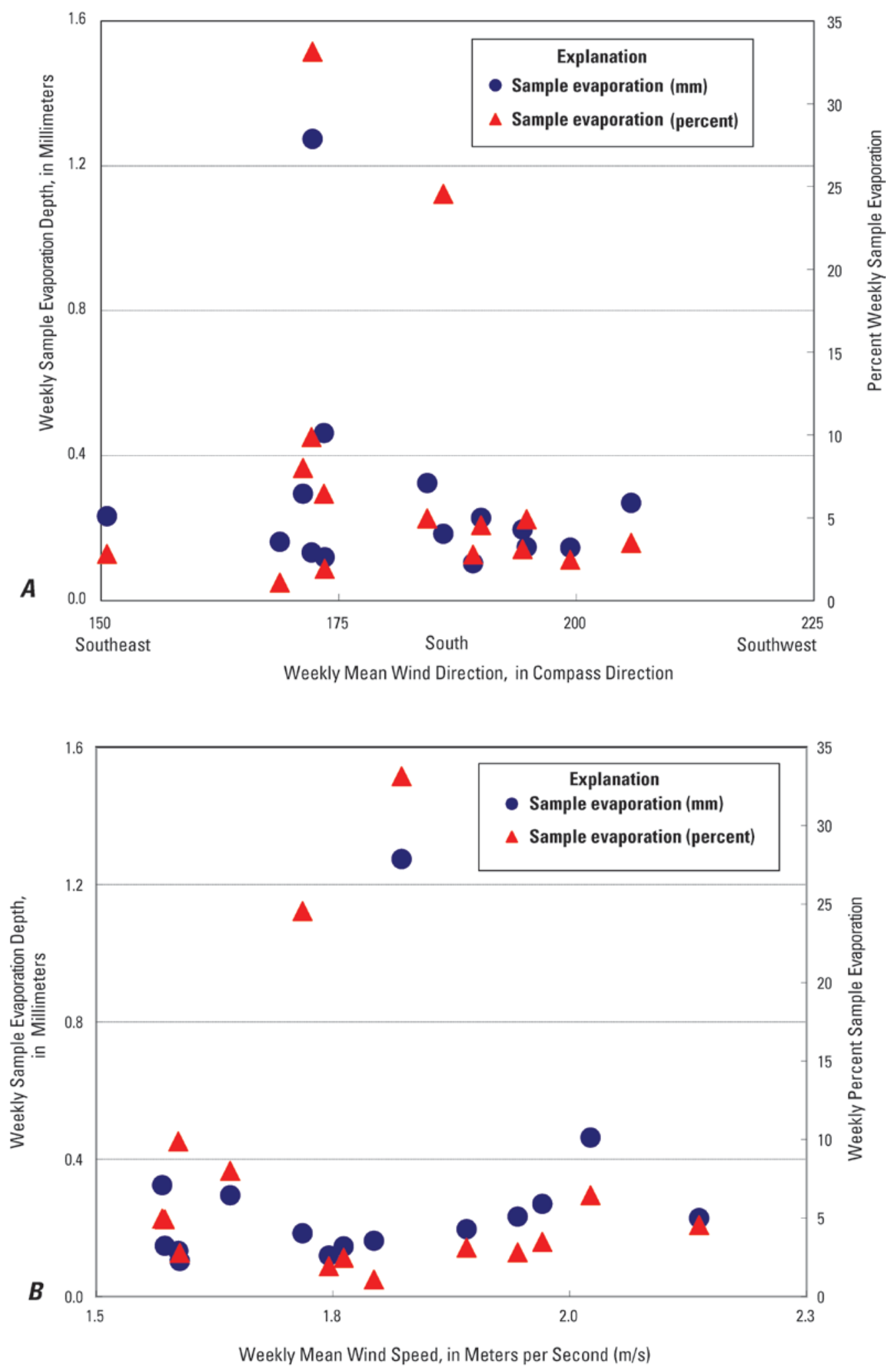

Figure 5. Weekly sample evaporation from a National Trends Network Aerochem Metrics Model 301 wet-deposition collector and weekly mean wind direction from north and wind speed at Arvada, Colorado, May 16-September 5, 2006. 


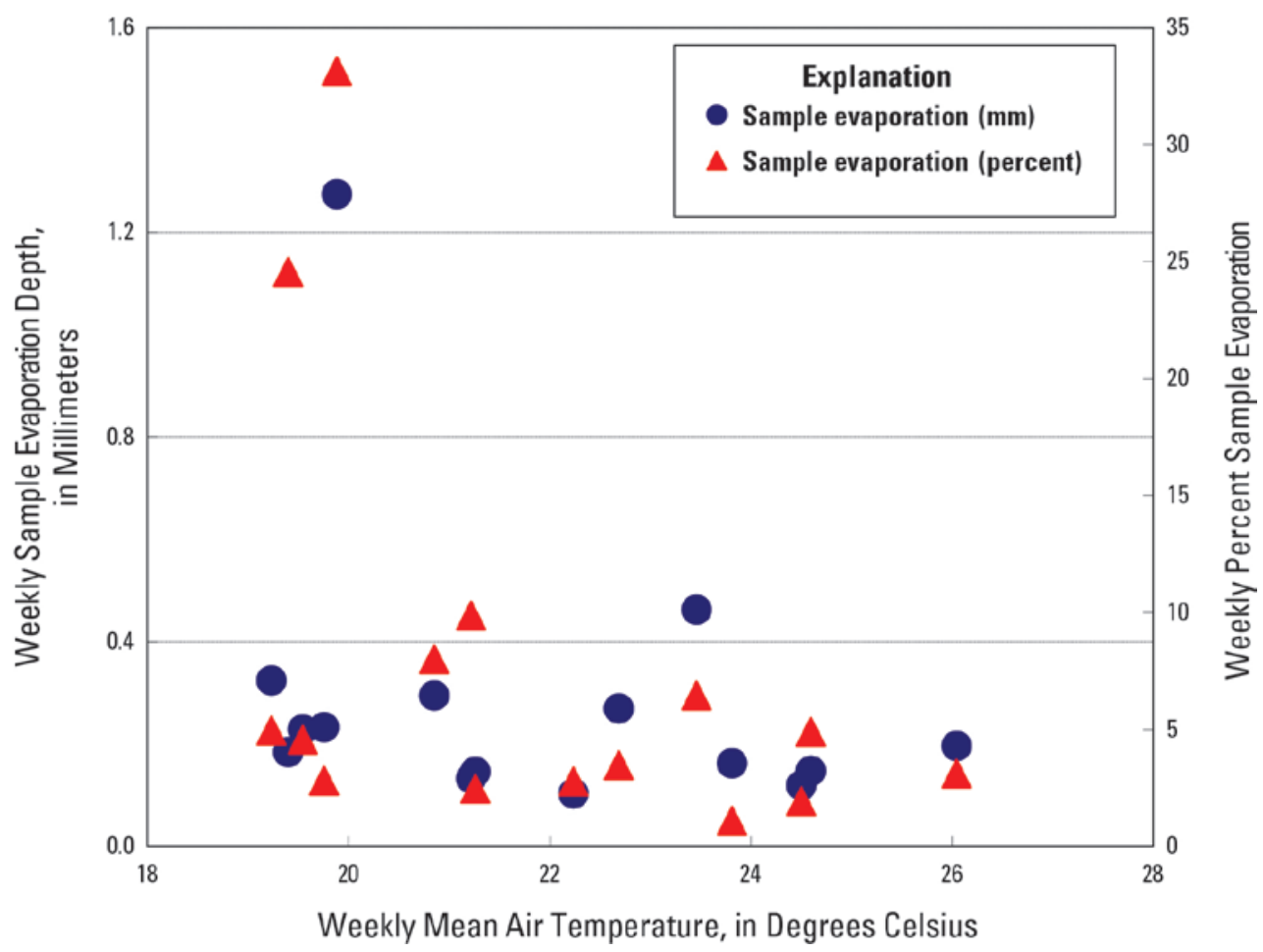

Figure 6. Weekly sample evaporation from a National Trends Network Aerochem Metrics Model 301 wet-deposition collector and weekly mean air temperature at Arvada, Colorado, May 16September 5, 2006.

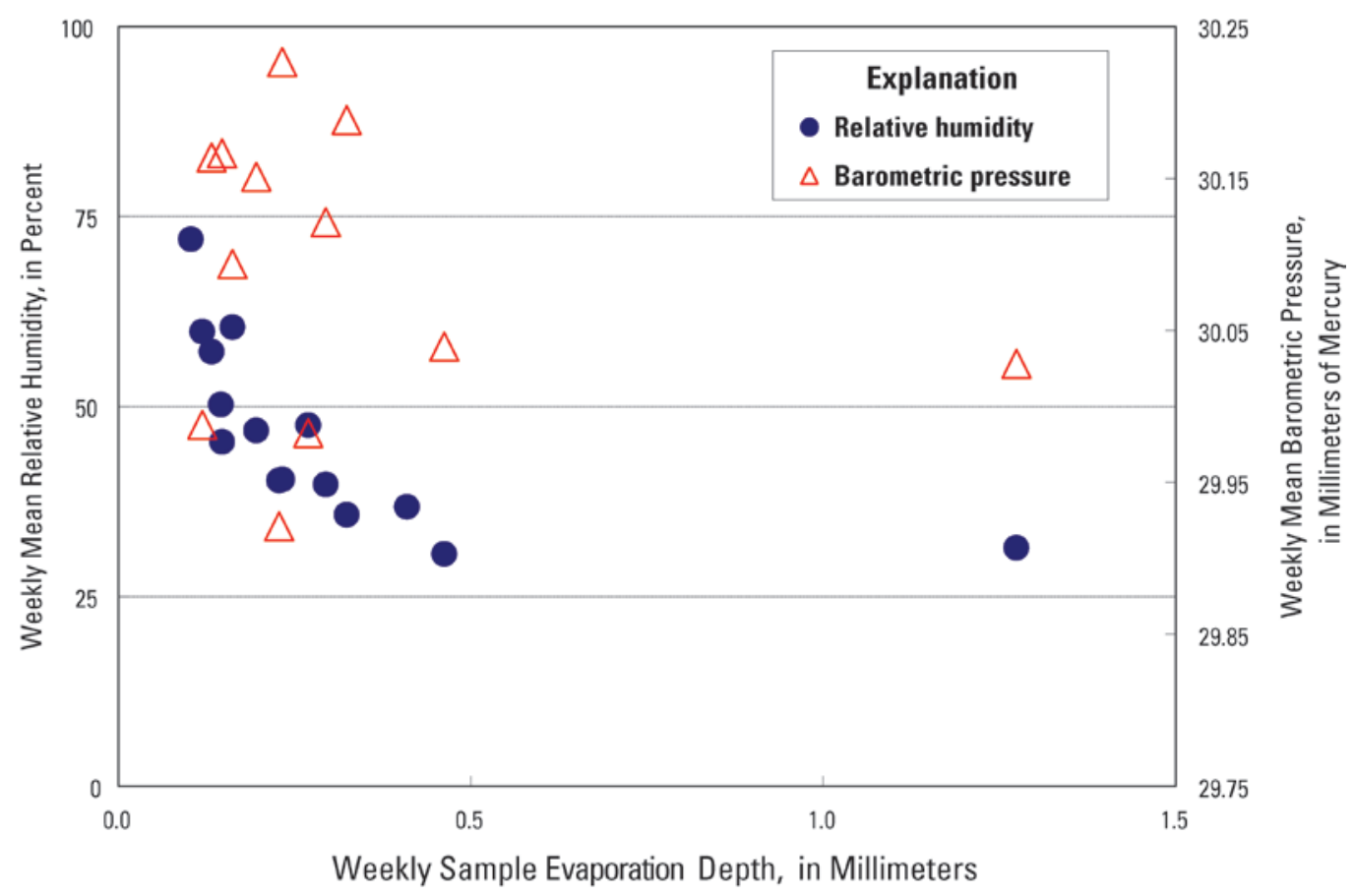

Figure 7. Relation of weekly mean relative humidity and mean barometric pressure to weekly sample evaporation from a National Trends Network Aerochem Metrics Model 301 wetdeposition collector at Arvada, Colorado, May 16-September 5, 2006. 


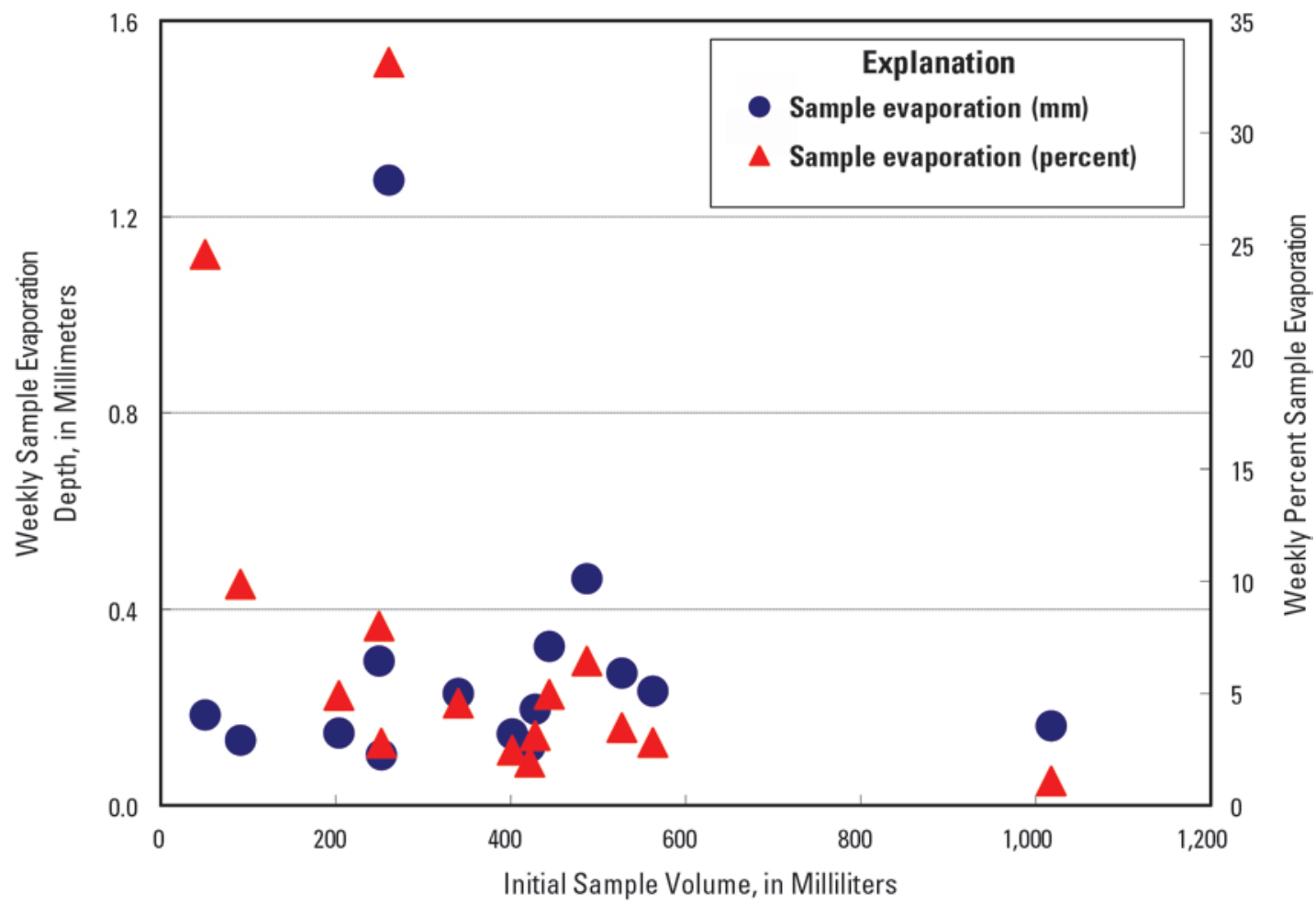

Figure 8. Weekly sample evaporation from a National Trends Network Aerochem Metrics Model 301 wet-deposition collector and initial sample volumes at Arvada, Colorado, May 16September 5, 2006.

\section{Study 2. MDN Sample Loss Study}

\section{Background and MDN Data Analysis}

NADP/MDN weekly wet-deposition samples are analyzed for total mercury $(\mathrm{Hg})$ and, in some instances, for methyl mercury. In order to preserve $\mathrm{Hg}$ in the collected sample, MDN sample bottles contain $20 \mathrm{~mL}$ of one-percent (volume/volume) hydrochloric acid $(\mathrm{HCl})$ preservative when deployed to field sites.

The MDN glass sample-collection train and collector housings are designed to reduce exposure of the collected sample to the open atmosphere and thus minimize sample loss by evaporation. Despite these efforts to minimize sample loss, field data suggest that sample loss does occur.

MDN site operators complete an MDN Observer Form (MOF) for each weekly sample to document sampling conditions and sample integrity. A review of MOFs for the period March 1996-November 2010 revealed that some sample bottles were empty at the end of the 7-day sampling period. In other cases, liquid was present at the end of the sampling period, but the volume of liquid was less than $20 \mathrm{~mL}$. In many instances this occurred during weeks with neither precipitation nor collector cycles (that is, collector not opening and closing again). These occurrences prompted investigation of the extent and cause(s) of MDN sample evaporation.

The NADP PO and USGS BQS conducted a multi-phase study during 2010-2012 to: (1) assess the extent of MDN sample loss, (2) identify factors that impact MDN 
sample loss for both types of MDN collectors, modified ACM and N-CON Systems, Inc. $(\mathrm{N}-\mathrm{CON})$, and (3) determine the impact of sample volume loss on total $\mathrm{Hg}$ concentrations. Results from each phase of this study are presented in this report.

\section{Phase 1 of Study_Extent of MDN Sample Loss}

The objective of this phase was to evaluate the extent of sample loss in MDN samples across the network. The MDN database was initially considered to determine the number of samples where volume was less than $20 \mathrm{~mL}$. Samples met the following criteria:

- No leaks reported during transport from the laboratory to the site,

- No leaks reported during transport from the site to the laboratory,

- Precipitation sensor and collector motor operated properly,

- No precipitation reported during the sample period, and

- No quality assurance samples.

Evaporation probably occurs with all MDN samples, not just those that meet the criteria described above. However, the volumes of liquids in the sample bottles are not monitored during the course of the sampling period. In order to estimate potential effects on field samples, this study evaluated loss of preservative volume during dry weeks. Sample preservative loss cannot be quantified when precipitation occurs and is collected.

For Phase 1, samples collected between March 1996 and November 2010 were considered. During that time 5,185 samples met the criteria of the study. Table 2 lists the number and the percentage of samples that had volumes less than $20 \mathrm{~mL}$, the initial volume of preservative. Values shown are based on the amount of sample loss during the 7-day, Tuesday to Tuesday, sampling period. Because at least some evaporation is demonstrated in over 84 percent of the samples meeting the study criteria, Phase 2 of the study was implemented to identify causes for the observed evaporation.

Having determined the existence of MDN preservative loss, the next step was to evaluate the factors that contribute to evaporation of actual field samples. Identification of the factors was needed for NADP to take actions to help reduce sample loss. Toward this end, the following questions were evaluated:

- Are the two versions of the modified-ACM collector and the N-CON collector affected equally?

- Does geographic location contribute to sample loss?

- Does collector interior temperature contribute to sample loss?

- Does integrity of the lid seal contribute to sample loss?

- Does airflow through the collector contribute to sample loss?

To address the first two questions, the Phase 1 data were screened for preservative volume loss (4,380 samples) and evaluated with respect to collector type: modified ACM versus N-CON. The N-CON MDN collector was approved for network use in October 2006. As such, fewer sites have the N-CON collector, and fewer samples were collected with the N-CON collector. It is unknown whether equal use (that is, number of sites, and duration of use) of the two collectors would have yielded the same results. Figures 9 and 10 illustrate the number and percentage of samples with measureable preservative evaporation loss at each site, respectively, by collector type. 


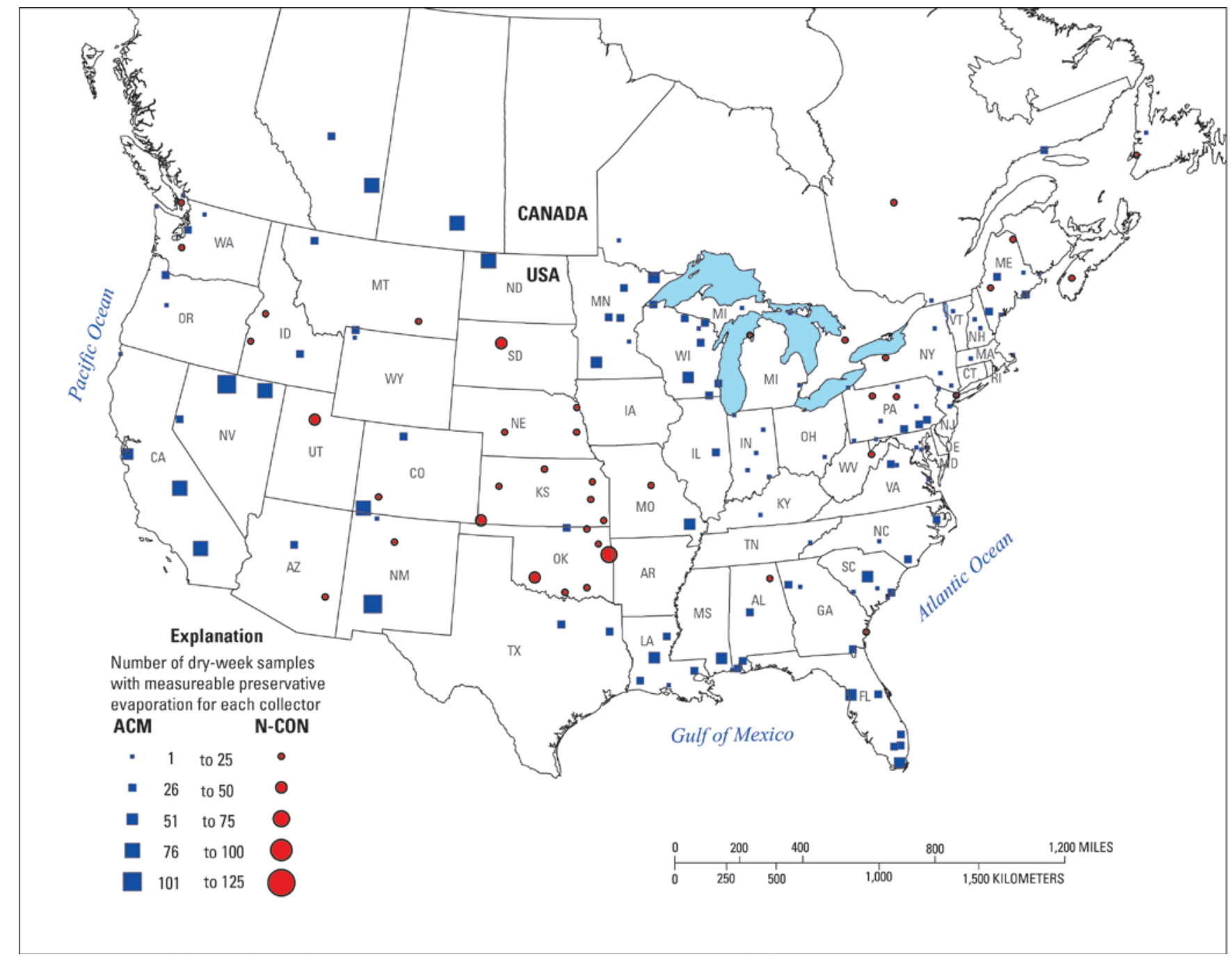

Figure 9. Mercury Deposition Network samples with preservative volume loss in modified ACM and N-CON precipitation collectors during weeks with no precipitation, March 1996-November 2010. 


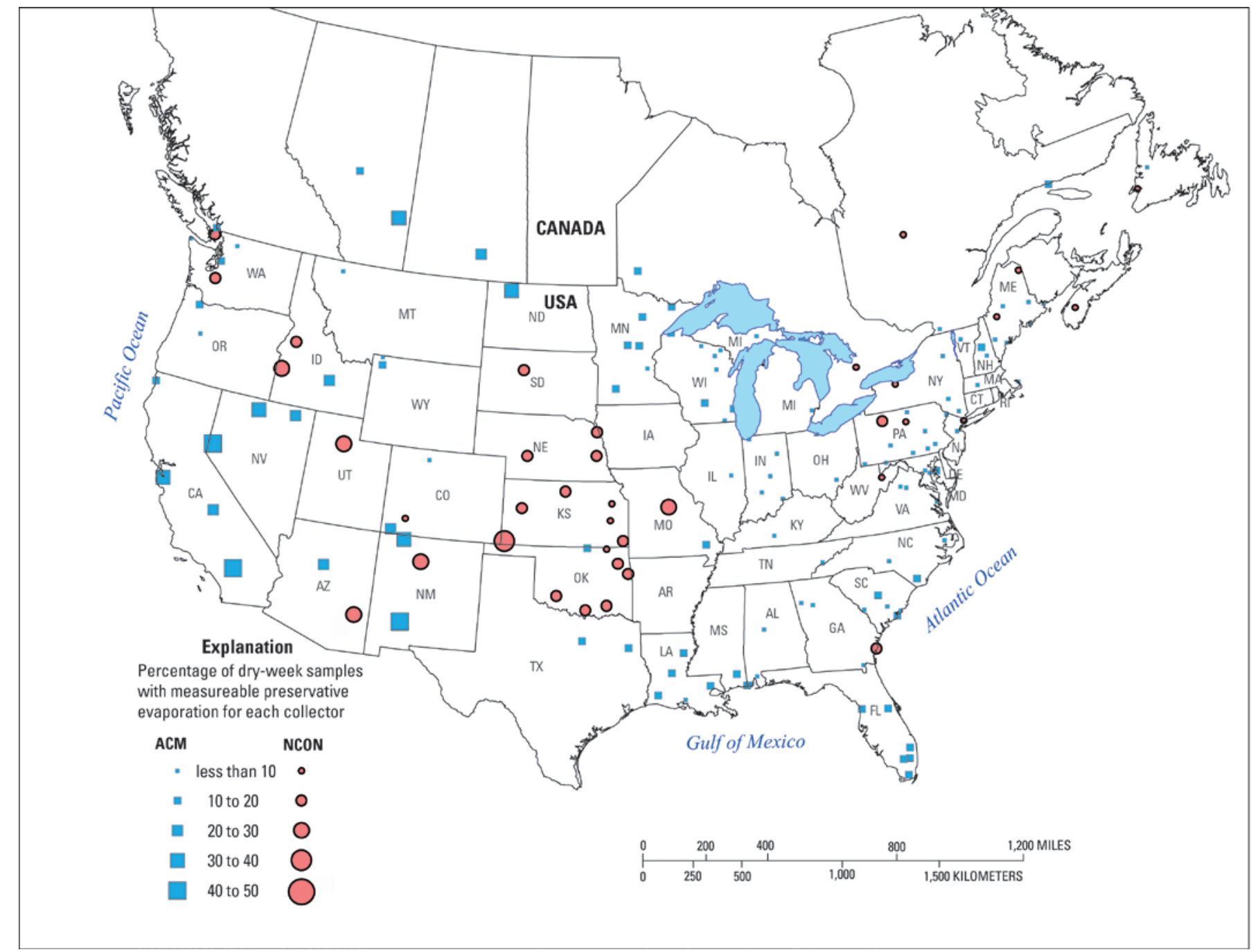

Figure 10. Mercury Deposition Network percent preservative volume loss in modified ACM and N-CON precipitation collectors during weeks with no precipitation, March 1996-November 2010. 
Data in figures 9 and 10 indicate greater preservative loss with the modified ACM than with the N-CON collector. The greatest preservative volume loss occurred in the southwestern U.S. suggesting that geographic location affects sample loss. However, the majority of collectors used at these sites are the modified ACM type. Additional field experimentation is required to determine whether the increased volume loss at these sites is due to the collector characteristics or climatic conditions, such as wind speed, temperature, and relative humidity.

\section{Phase 2 of Study-Factors that Affect MDN Sample Loss}

Having demonstrated preservative loss in Phase 1, Phase 2 examined collector influence on field-sample evaporation. One modified ACM collector and one N-CON collector were specially configured for testing purposes and located outside the PO facility in Champaign, Illinois. Testing began on December 9, 2009, and continued through March 1, 2011.

\section{Phase 2 Methodology}

Phase 2 field testing included:

- 1 modified ACM collector without a precipitation sensor to ensure no openings,

- $1 \mathrm{~N}-\mathrm{CON}$ (standard, single-chimney version) collector without a precipitation sensor,

- 2 sample bottles, one for each collector containing an initial $500 \mathrm{~mL}$ of preservative, and

- a sampling period of 7 days.

The collectors were deployed to the field with the lids tied in the closed position using bungee cords. This prevented the collectors from exposing the sample train and bottle during the course of the sampling period. It is likely that the bungee cords improved the seal between the lid pad and funnel. Therefore, actual evaporation observed in the field would likely be greater. Sample bottles were weighed at the start of each 7day sampling period (initial mass) and again at the end of the sampling period (final mass). Sample volume loss was determined as the difference between the initial mass and the final mass; assuming a density of 1 gram per cubic centimeter $\left(1 \mathrm{~g} / \mathrm{cm}^{3}\right.$ or $\left.1 \mathrm{~g} / \mathrm{mL}\right)$ for water. All testing included the measurement of daily minimum and maximum temperatures inside each collector, visual observation of the collector lid seal, and recording whether the collector cooling fans were operational or not. During winter, the collector heaters ran continuously. Thus, internal temperature of the collector is not a reflection of ambient conditions.

Figure 11 shows each of the two MDN collector types configured to have a poor lid seal. For this configuration, a spacer was placed between the lid pad and the funnel, creating a gap between the two. Though the sample remains protected by the sample train, the gap likely allows a more direct path for evaporation.

Figures 12,13, and 14 illustrate the sample loss data obtained for each of the parameters tested. Data in figure 12 suggest that field sample evaporation is not related to air temperature inside the collectors because measured evaporation amounts are generally constant over the range of measured maximum temperatures with the exception of four 
measurements for the modified ACM. More evaporation was observed from the modified ACM samples than from the N-CON samples.

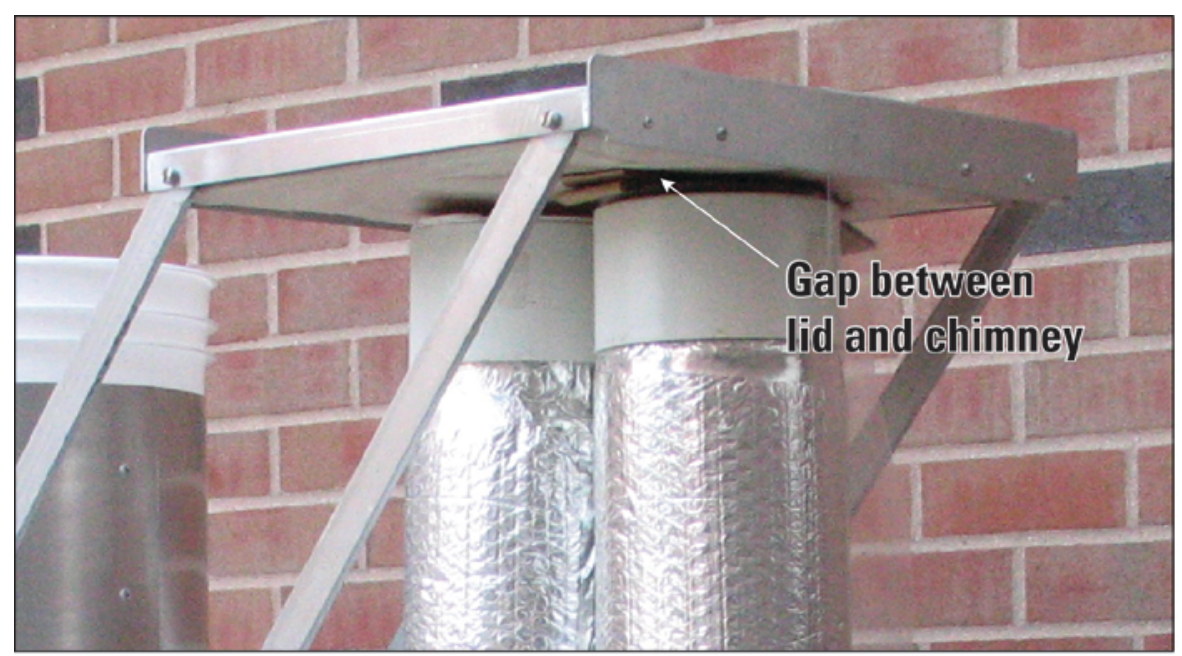

\section{Modified Aerochem Metrics Collector}

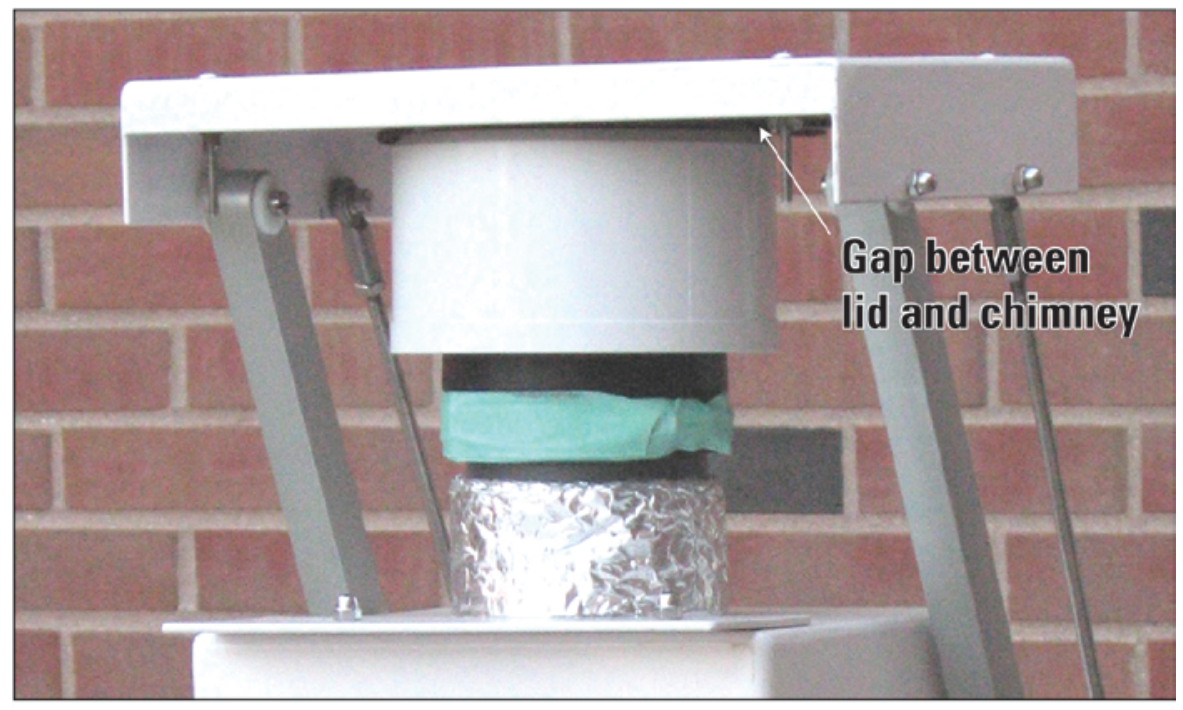

\section{N-CON Collector}

Figure 11. Photographs of bad lid seal configuration for the modified ACM collector (top) and the $\mathrm{N}-\mathrm{CON}$ collector (bottom). 


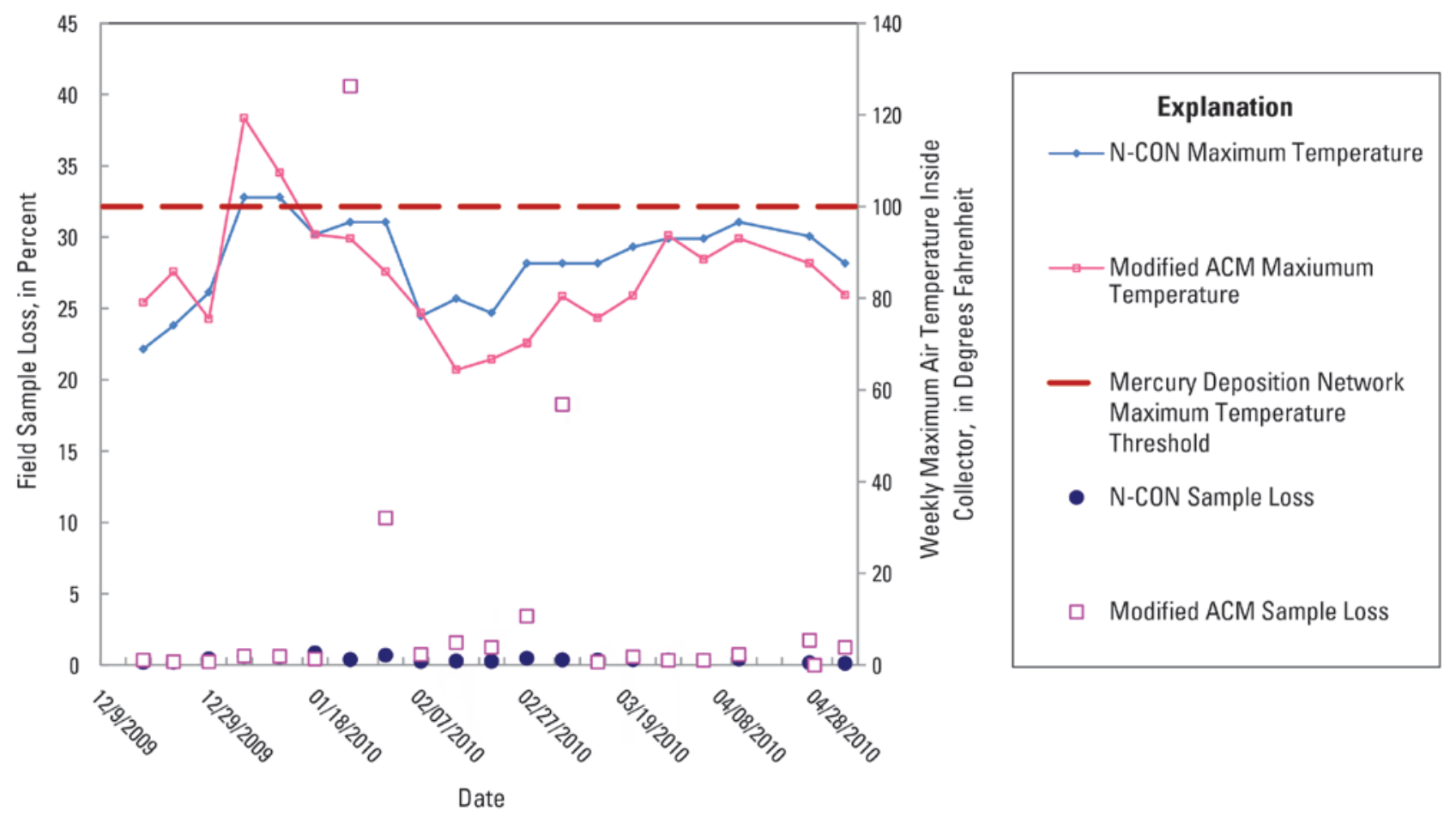

Figure 12. Field sample volume lost (percent) over weekly periods in N-CON and modified Aerochem Metrics (ACM) precipitation collectors and maximum weekly temperatures of the air inside the collectors, December 1, 2009-May 7, 2010.

Data in figure 13 indicate that sample evaporation might have increased for 4 of 15 weekly measurements for the modified ACM when the lid seal was compromised. However, the same effect was not observed for the N-CON. 


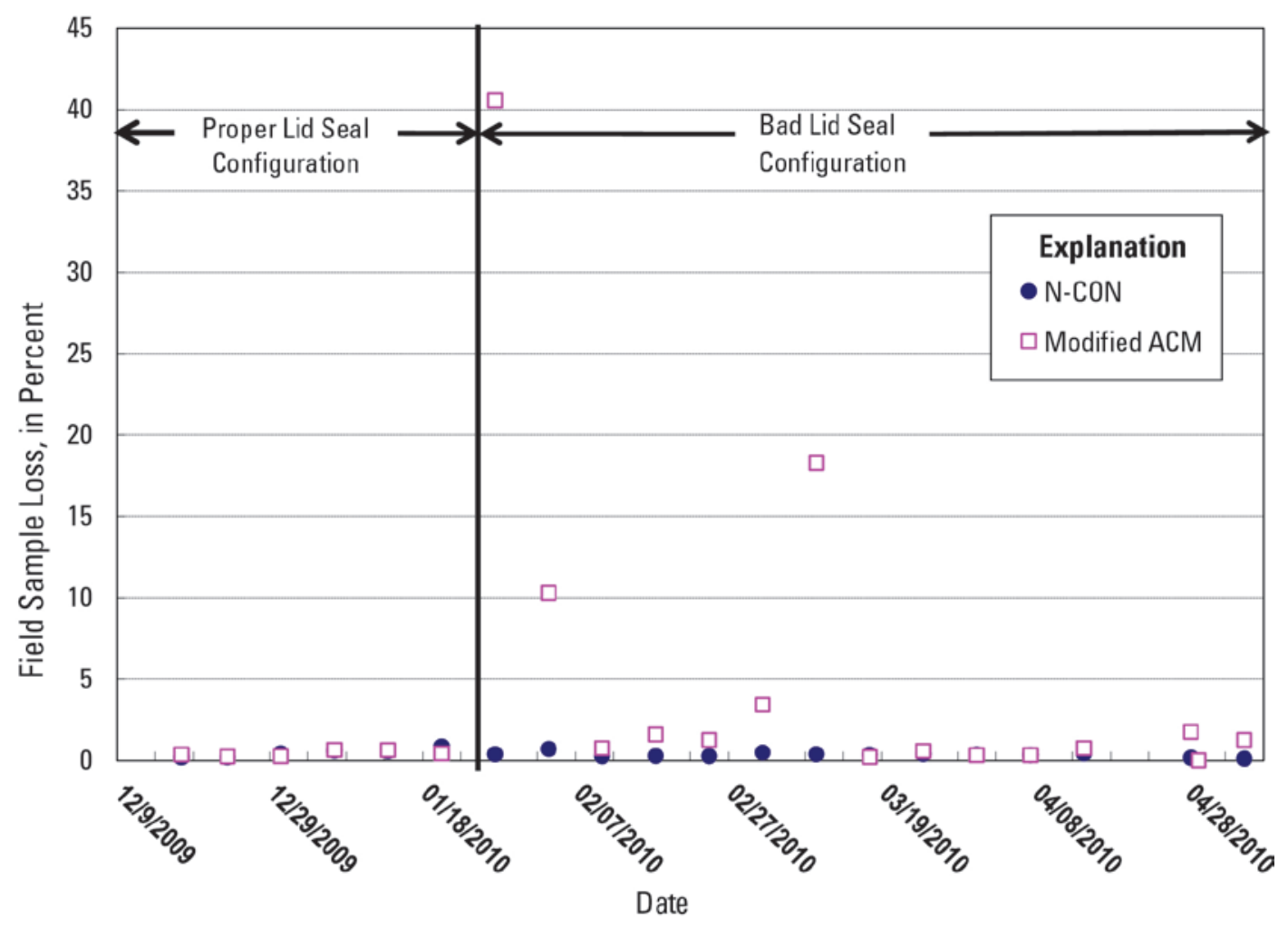

Figure 13. Percentages of initial sample volumes lost over weekly periods in N-CON and modified Aerochem Metrics (ACM) precipitation collectors and corresponding integrity of collector-lid seals, December 1, 2009-May 7, 2010. 


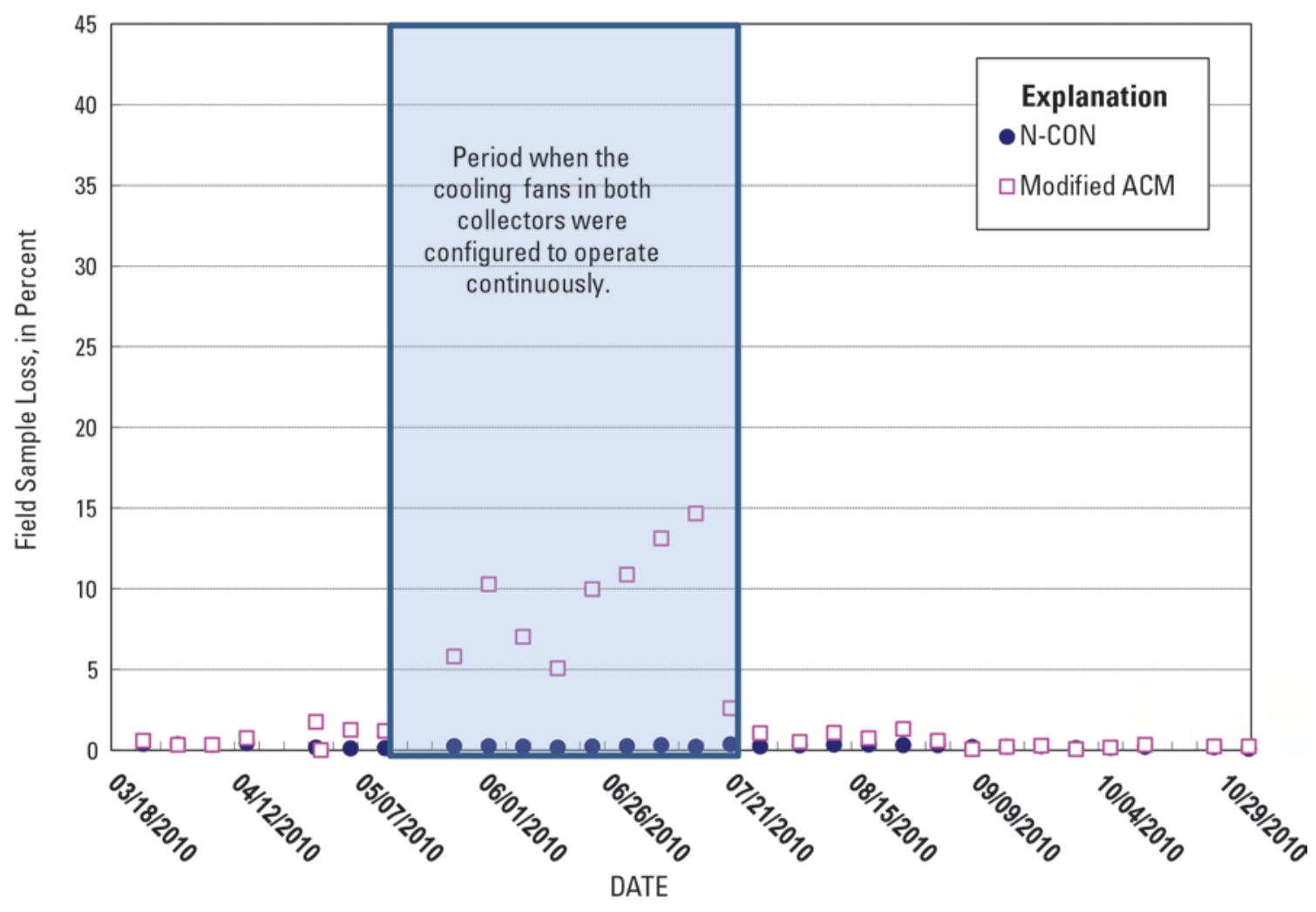

Figure 14. Percentages of initial sample volumes lost over weekly periods in N-CON and modified Aerochem Metrics (ACM) precipitation collectors and corresponding configurations of air flow inside the collectors, March 1, 2010-October 29, 2010.

Results in figure 14 indicate that field-sample evaporation was higher from samples in the modified ACM collector when the cooling fan was operated continuously. When both collectors were configured so that the cooling fans operated continuously, sample loss was consistently greater with the modified ACM collector (5 to 15 percent sample loss). Figure 15 is a composite of figures 12, 13, and 14. Two conclusions may be drawn from the results of these tests. First, samples in the modified ACM collector are affected to a greater extent than samples in the N-CON collector. Second, air flow within the collector is the most consistent factor affecting sample loss through evaporation. Having made these conclusions, the study entered into Phase 3 to evaluate the effect of field sample volume loss on actual $\mathrm{Hg}$ concentrations. 


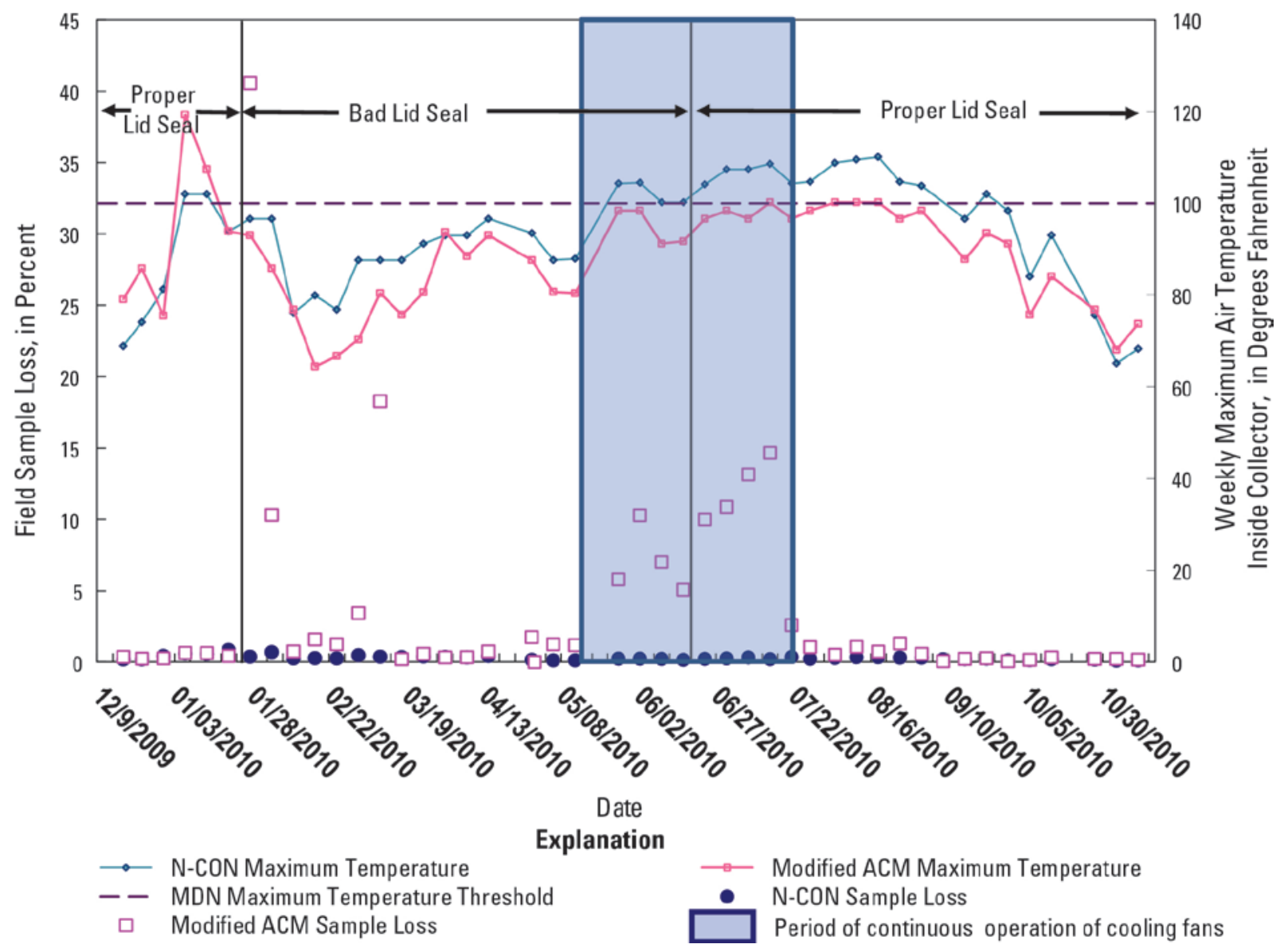

Figure 15. Percentages of initial sample volumes lost over weekly periods in N-CON and modified Aerochem Metrics (ACM) precipitation collectors and corresponding internal collector temperature, lid seal integrity, and internal air flow configurations for the collectors, December 1, 2009-November 17, 2010.

\section{Phase 3 of Study_Effects of Sample Loss on Mercury Concentrations}

The following experimental design was used for Phase 3 of the field study on the effects of sample volume loss on Hg concentrations:

- 2 collectors (1 modified ACM collector, $1 \mathrm{~N}-\mathrm{CON}$ collector),

- 2 cooling fans (1 ACM cooling fan, 1 Loda Electronics cooling fan),

- Weekly pairs of sample bottles, one for each collector, each containing an initial $20 \mathrm{~mL}$ of preservative,

- Quality Control (QC) samples of known total Hg concentration,

- A sampling period of 7 days, and

- Total $\mathrm{Hg}$ analysis by the HAL

Clean glassware and sample bottles containing preservative were provided by the $\mathrm{HAL}$ on a weekly basis. The HAL provides glassware, sample bottles, and all total $\mathrm{Hg}$ analyses by Cold Vapor Atomic Fluorescence for the MDN. 
At the start of each sampling period, the sample bottles were weighed. Then approximately $100 \mathrm{~mL}$ of a QC sample of known $\mathrm{Hg}$ concentration was added to each bottle, and the sample bottles were weighed again before being installed in the collectors with clean glassware (that is, funnel and thistle tube). The collectors were configured without sensors, and the collector lids were secured to prevent them from cycling during the sampling period. At the end of the sampling period the bottles were re-weighed to determine the mass loss during the sampling period, and were then shipped to the HAL for analysis.

In most cases, the sampling period was 7 days. In some cases, a longer sampling period was used due to the availability of personnel and clean glassware to support the study. As with Phase 2 of this study, samples were deployed using one modified ACM collector and one N-CON collector. One month into the study, the cooling fan in the modified ACM collector was replaced with a more powerful fan as used in the Loda Electronics version of the ACM collector due to failure of the original ACM fan. Table 4 contains specifications for the cooling fans used in the 2 versions of the ACM collector. Consistent with the Phase 2 experimental results, sample volume loss from the modified ACM collector was higher for the collector with a Loda Electronics cooling fan, which has a higher speed and moves more air through the collector. Results from the testing are presented for the modified ACM in tables 5 and 6 and for the N-CON collector in table 7. Figure 16 illustrates the results with "modified ACM1" being the Aerochem Metrics version of the modified ACM collector and "Loda Electronics ACM" being the Loda Electronics version of the collector.

The QC samples used in this phase of the study were provided by the USGS and are from the USGS MDN Interlaboratory-Comparison Program (Wetherbee and others, 2010). The chemistry of these samples is well defined. Nine different laboratories participate in the Interlaboratory-Comparison Program, including the HAL. Results from each of the participating laboratories were used to determine the most probable value (MPV) for $\mathrm{Hg}$ concentration in each of the QC solutions. The QC samples were preserved with 1-percent $\mathrm{HCl}$ and have $\mathrm{Hg}$ concentrations ranging from approximately 6 to 22 nanograms per liter $(\mathrm{ng} / \mathrm{L})$. The concentration range was chosen as it spans the interquartile range of MDN field sample concentrations. Most probable value concentrations for each QC sample were provided by USGS after the chemical analysis was complete. $\mathrm{Hg}$ concentrations for each the QC solutions were unknown to both PO staff and staff of the HAL during the study. As the samples evaporate, the acidity and associated preservation of the $\mathrm{Hg}$ in the samples can change. However, the acidity of the QC samples was not monitored. Tables 5-7 present the results from each of the three collectors tested in Phase 3 of the study. Figures 16 and 17 illustrate these results. Hg concentration differences were calculated as measured-minus-most probable value (MPV) for the QC solutions. Percent $\mathrm{Hg}$ mass gained (fig. 17) is probably from various sources including laboratory and field contamination. 


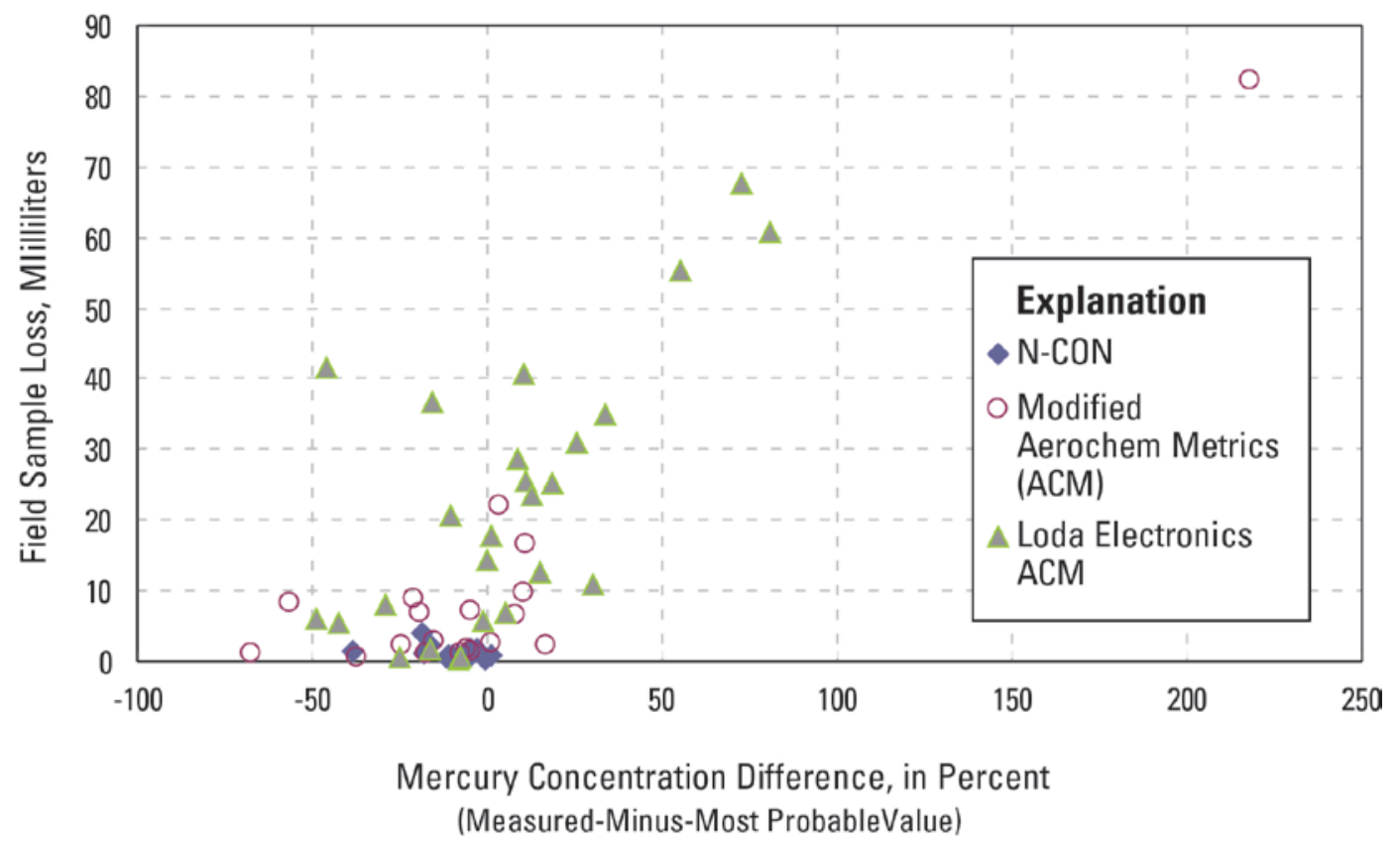

Figure 16. Relation of percent sample volume loss and mercury concentration difference for three MDN collector types: N-CON, modified Aerochem Metrics (ACM), and Loda Electronics ACM.

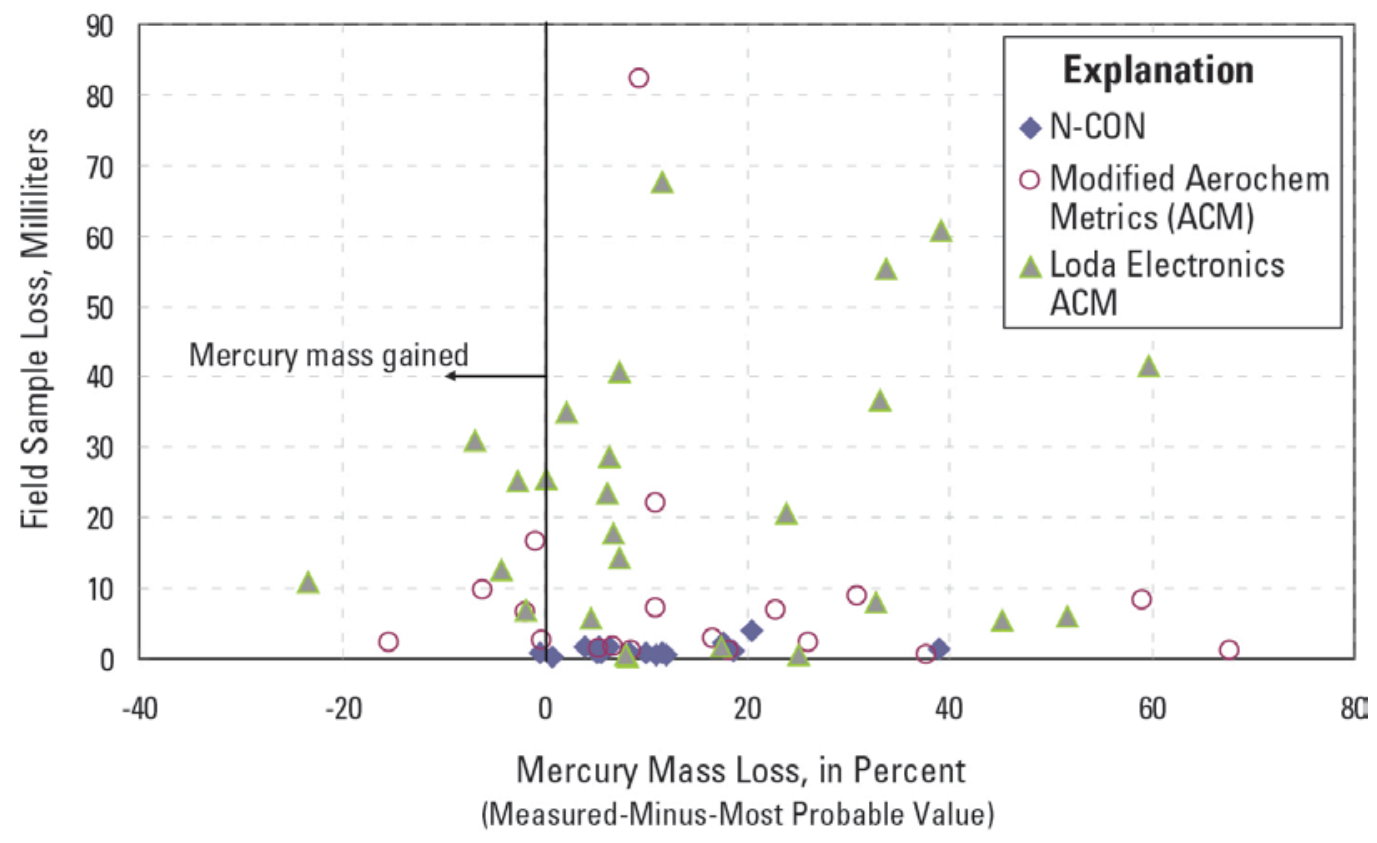

Figure 17. Relation of sample volume loss to percent mercury mass loss for three MDN collector types: N-CON, modified Aerochem Metrics (ACM), and Loda Electronics ACM. 


\section{Conclusions}

The following conclusions can be made from the three phases of this study:

- MDN samples in modified ACM collectors are subject to greater volume loss than those in an $\mathrm{N}-\mathrm{CON}$ collector.

- MDN sample-volume loss occurs more frequently in low relative humidity regions of the USA, such as the western and southwestern regions of the country.

- Air flow through the collector housing increases MDN volume loss due to operation of the cooling fan.

- MDN samples deployed with the Loda Electronics version of the modified ACM collector undergo greater volume loss than those deployed with the original (Aerochem Metrics) version of the modified ACM collector. This difference is due to differences in the cooling fan used with the two versions of the collector.

- Sample chemistry is affected by MDN volume loss. In some instances $\mathrm{Hg}$ is lost thus decreasing the total $\mathrm{Hg}$ concentration in the sample. In other instances, $\mathrm{Hg}$ is concentrated in the sample resulting in higher total $\mathrm{Hg}$ concentrations.

- The rates of loss of sample volume, preservative volume, and Hg are not consistently proportional.

This study demonstrates that MDN sample evaporation has important implications for MDN data and field operations. Remediation of the modified ACM evaporation problem, including potential reconfiguration of the modified ACM collector's glass sample train, could improve representativeness of MDN samples. Additional testing using an N-CON type thistle tube in the modified ACM collector and other potential solutions are needed.

\section{Study 3. Mercury Adsorption in MDN Sample Trains}

\section{Background and Methods}

MDN sample bottles are deployed containing $20 \mathrm{~mL}$, 1-percent (volume/volume) $\mathrm{HCl}$ preservative pre-charge to prevent adsorption of $\mathrm{Hg}$ onto the glassware. Glass has the lowest adsorption rate (0.026-1.13 micrograms per square meter $\left.\left(\mu \mathrm{g} / \mathrm{m}^{2}\right)\right)$ of commonly used materials for sample containers (Rosain and Wai, 1973). Adsorption can also be reduced by using $\mathrm{HCl}$ as a preservative (Rong and others, 2001). While deployed, some of the 1-percent $\mathrm{HCl}$ preservative refluxes within the sample train (Bob Brunette, Frontier Global Sciences, Inc., oral commun., 2009), which helps prevent adsorption of $\mathrm{Hg}$ to the walls of the MDN glassware.

The Modified ACM and N-CON MDN collectors use different glass thistle tubes to collect the precipitation sample (fig. 18). Both sample trains consist of a borosilicate glass funnel, thistle tube, and sample bottle, but the N-CON thistle tube extends down into the sample bottle, while the Modified ACM thistle tube does not. As the sample droplets travel from the less acidic funnel to the more acidic sample bottle, there is a potential for loss of $\mathrm{Hg}$ to the walls of the thistle tube. Differences in the sample train 
configurations led to concern that $\mathrm{Hg}$ concentrations may be affected differently by adsorption between the two sample trains.
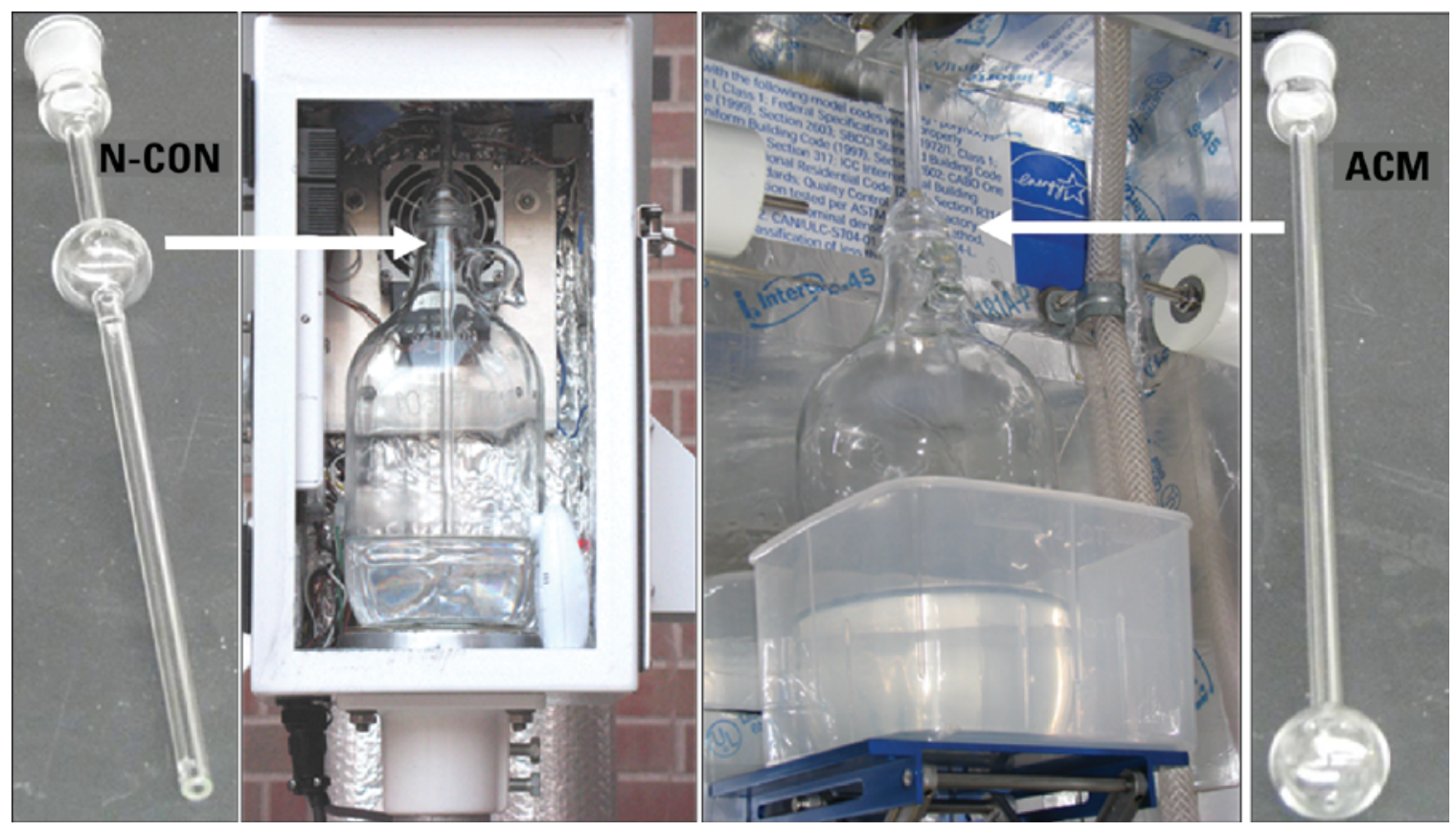

Figure 18. Thistle-tube configurations used with the modified N-CON collector (left) and the ACM collector (right).

To address these concerns, adsorption of $\mathrm{Hg}$ to the Modified ACM and N-CON sample trains was compared at 18 sites. First, 5 Modified ACM collectors in Florida, Indiana, Oklahoma (2 sites), and South Carolina were compared to $5 \mathrm{~N}-\mathrm{CON}$ collectors in Georgia, Kansas, New York, Utah, and West Virginia for rain events. Then, 4 Modified ACM collectors in Indiana, Minnesota, and Pennsylvania (2 sites) were compared to $4 \mathrm{~N}-\mathrm{CON}$ collectors in Nebraska, New York, Idaho, and Utah for snow events. Results were used to evaluate the dependence of precipitation type on $\mathrm{Hg}$ absorption.

USGS provided each site operator with a cooler containing two standard MDN glass sample bottles and a 1-liter Teflon bottle. One of the MDN glass sample bottles was a "trip blank" sample containing either $170 \mathrm{~mL}$ or $320 \mathrm{~mL}$ of 1-percent $\mathrm{HCl}$. The different volumes were used to help conceal the control sample. The "trip blank" remained sealed until it was analyzed by the HAL. The second glass MDN sample bottle contained the standard $20 \mathrm{~mL} \mathrm{HCl}$ pre-charge only. This bottle was used to collect rinseate from the used sample train. The 1-L Teflon bottle contained 1-percent $\mathrm{HCl}$ in a volume of either $250 \mathrm{~mL}$ or $500 \mathrm{~mL}$, a portion of which was used to rinse the sample train in the field. The $\mathrm{HCl}$ remaining in the Teflon bottle was also analyzed for total $\mathrm{Hg}$ concentration and is referred to as the "bottle sample."

After a week during which precipitation occurred, the field sample bottle was processed as usual, but the used sample train was left in place. This is different from standard MDN protocol whereby the complete sample train is replaced weekly. The 
second MDN sample bottle containing $20 \mathrm{~mL}$ of $\mathrm{HCl}$ was installed into the collector, and half of the 1-percent $\mathrm{HCl}$ solution in the 1-L Teflon bottle was poured through the glass sample train to create the "sample-train sample." Both the sample-train sample and the bottle sample in the 1-L Teflon bottle were capped and placed in the cooler with the "trip blank". All three test samples, plus the composite MDN sample from the previous week, were shipped to the HAL for total $\mathrm{Hg}$ analysis. The identities of the sample-train and control samples were not revealed to the HAL and were known only by USGS and the site operators. The flowchart in figure 19 illustrates the study design. 
Flow Chart for Phase I of Proposed USGS Sample Train Study

(protocol agreed to by NADP / PO, USGS, and HAL on 3/18/09)

\section{HAL ships 10 coolers to USGS which contain 3 bottles per each as follows:}

2 - 2-Liter glass MDN sample bottles each preserved with 20 milliliters

1-percent (volume/volume) hydrochloric acid ( $\mathrm{HCl})$ pre-charge

1 - 1-Liter Teflon bottle with 250 to $500 \mathrm{~mL}$ of 1-percent $\mathrm{HCl}$

USGS: Pours approximately $1 / 3$ of volume of $\mathrm{HCl}$ from 1 -L Teflon into 1 of the 2-L MDN bottles $=$ Trip Blank (a.k.a. control sample)

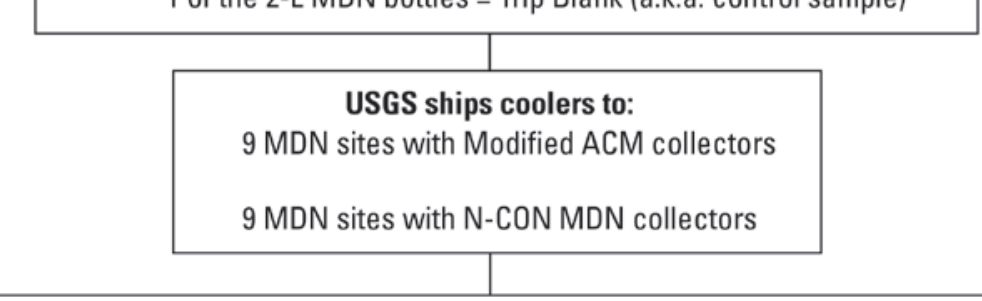

After a week with "normal" precipitation, site operators:

1) Leave collector closed and remove week's composite sample for normal shipment to HAL.

2) Leaving collector closed with used ("dirty") sample train in place, install USGS-designated MDN sample bottle = sample-train bottle.

3) Open the collector and pour half of the volume of $\mathrm{HCl}$ from the 1-L Teflon bottle through the sample train and into the sample-train bottle, then cap and remove.

\section{Post-processing protocol:}

1) Place control bottle, sample-train bottle, and original 1-L Teflon $\mathrm{HCl}$ sample into cooler along with HAL Chain-of-Custody form (already filled out by USGS) for the 3 bottles.

2) Remove used sample train to ship back to HAL with the previous week's composite sample and MOF.

3) Install new MDN bottle and clean sample train for next week's sample.

4) Ship both coolers to HAL.

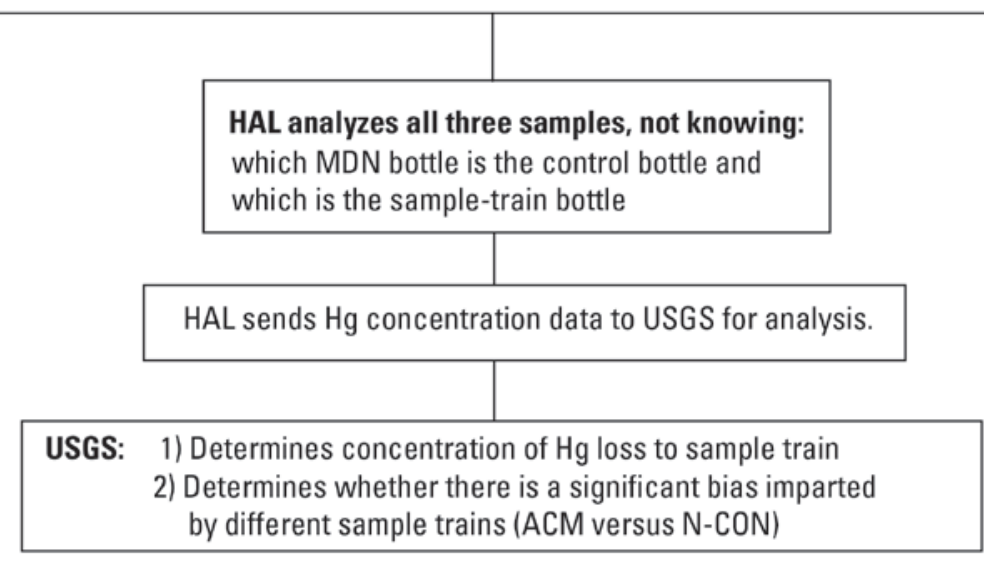

\section{Explanation}

HAL-Mercury Deposition Network, Mercury Analytical Laboratory at Frontier Geosciences, Inc.1 USGS-United States Geological Survey, Branch of Quality Systems, Precipitation Quality Assurance Project Modified ACM-Modified Aerochem Metrics Precipitaiton Collector

MDN-Mercury Deposition Network

MOF-Mercury Observer Form

NADP / PO-National Atmospheric Deposition Program / Program Office

$\mathrm{N}-\mathrm{CON}-\mathrm{N}-\mathrm{CON}$ Systems Inc. MDN precipitation collector

Figure 19. Flowchart of the sample-train study for the Mercury Deposition Network. 


\section{Results and Discussion}

Average $\mathrm{Hg}$ concentrations were calculated for the $\mathrm{HCl}$ solutions remaining in the original Teflon bottles. Hg adsorption to the sample trains is estimated by the median sample-train-minus-average control $\mathrm{Hg}$ concentration differences in table 8 . The results indicate that there is a measureable amount of $\mathrm{Hg}$ that adsorbs to the glass sample trains in both the modified ACM and N-CON wet-deposition collectors.

There is no statistically significant difference between the collectors with respect to $\mathrm{Hg}$ adsorption as represented by $\mathrm{Hg}$ concentration differences per the Wilcoxon signed-rank test at the $\alpha=0.05$ significance level. $\mathrm{Hg}$ concentration differences are significantly $(\alpha=0.05)$ higher for rain than for snow per the Wilcoxon rank sum test. Negative $\mathrm{Hg}$ concentration differences for GA33 and NE15 indicate potential contamination of the control samples with trace amounts of $\mathrm{Hg}$, but the negative differences could also be due to analytical variability. Negative differences are interpreted as zero values for the purposes of this study.

No correlation was observed between the mass of $\mathrm{Hg}$ collected in the previous week's precipitation samples and the mass of $\mathrm{Hg}$ adsorbed to the sample trains (Kendall's $\mathrm{Tau}=0.238, p=0.17$ ). However, the KS03 sample collected for the previous week (June $10-16,2009)$ had the largest mass $(18,154 \mathrm{ng})$ of $\mathrm{Hg}$ among all sites included in this study, and it also exhibited the largest amount of adsorbed $\mathrm{Hg}$ to the sample train (1.384 $\mathrm{ng} / \mathrm{L})$. The results indicate that there is a small mass of $\mathrm{Hg}$ that absorbs to the sample trains during sample collection.

\section{Study 4. Sensitivity of NTN and MDN Collector Sensors}

\section{Background and Methods}

Sensors for ACM wet-deposition collectors are used to expose the collection bucket to the atmosphere at precipitation onset and then cover it again at cessation of precipitation events. The representativeness of the samples decreases with delay between precipitation onset and collector openings due to missed aerosol washout at precipitation onset (Raynor and McNiel, 1979; Pellett and others, 1984; Schroeder and others, 1986 and 1987). Sample representativeness also decreases when collectors remain open after cessation of precipitation as contamination may be introduced from dry deposition or other foreign materials (Sisterson and others, 1985; Tang, 1987). Open collectors also increase the potential to affect sample integrity. Consequently, the sensitivity of the precipitation sensor is important for representative collection of wet-deposition samples.

NADP ACM wet-deposition collectors use two types of grid-design precipitation sensors: a 7-grid model for NTN and an 11-grid model for MDN (fig. 20). The MDN began deployment of modified ACM collectors using the 11-grid sensor instead of the 7grid NTN sensor in 1999. NTN continued to use the 7-grid sensor out of concern that a change to the 11-grid sensor might cause a shift in sample concentration bias. This study is part of renewed efforts to increase consistency between NTN and MDN field instrumentation. NADP approved optical sensors as an alternative to grid sensors in 2006. As N-CON collectors with optical sensors replace ACM collectors at NTN and MDN sites, differences in grid sensor performance also will need to be considered along with differences in optical and grid sensor performance. For this study, comparison of 7-grid 
and 11-grid sensor performance was accomplished by monitoring openings and closings of collector lid cycles recorded by a Campbell Scientific, Inc. data logger internal to a colocated ETI model NOAH-IV electronic rain gage (ETI Instrument Systems, Inc., Fort Collins, Colo.).

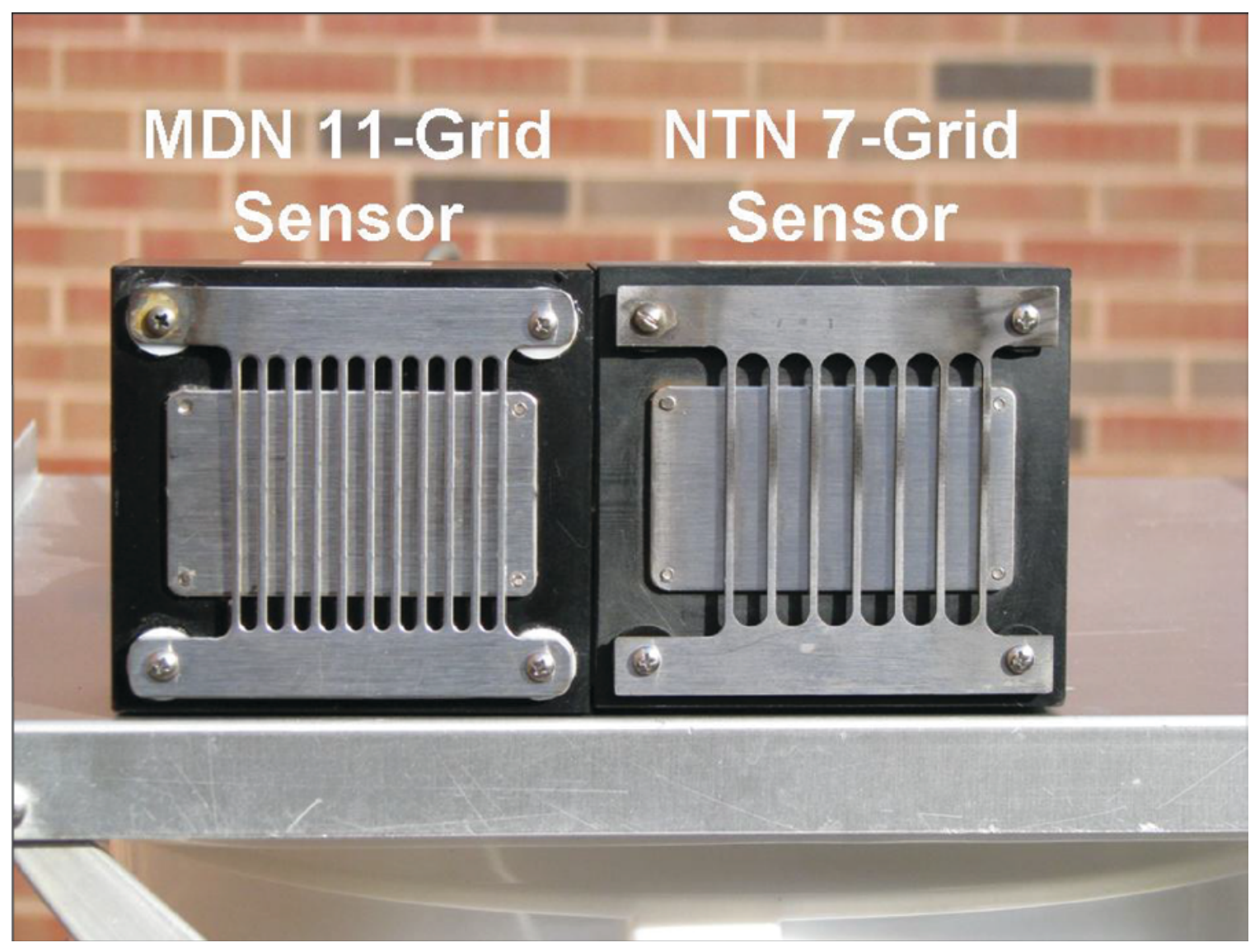

Figure 20. Mercury Deposition Network 11-grid sensor and National Trends Network 7-grid sensor for Aeorchem Metrics precipitation collectors.

NADP NOAH-IV rain gages are programmed to report precipitation when the gage's optical sensor counts a minimum of 16 particles falling into the gage per minute. The data loggers count and store the number of seconds within each quarter hour when precipitation is detected and the collector lid is open. This parameter is called "wet exposure". The number of seconds within each 15-minute period during which precipitation is not detected but the lid remains open is reported as "dry exposure".

A third NADP parameter, "missed exposure" is the number of seconds within the quarter hour when precipitation is detected, but the collector is closed. "Missed exposure" is arguably a more subjective parameter because the gage's detection of precipitation is not confirmed by the collector sensor, which is triggered by precipitation completing an electrical circuit. Similarly, the rain gage's optical sensor might detect particles that are not precipitation, such as blowing snow, dust, insects, and pollen.

Comparison of the sensitivity of 7- and 11-grid sensors was done using data obtained from NADP sites with co-located NTN and MDN equipment. That is, ACM 
collectors with 7-grid sensors, and modified ACM collectors with 11-grid sensors, respectively. Data for the period May 22, 2007 to February 24, 2009 were obtained from the NADP website, http://nadp.isws.illinois.edu/precip/, on February 28, 2011. Table 9 is a list of the sites used in the analysis, and the associated periods of record.

Sensitivity of the 7-grid and 11-grid sensors to precipitation onset and cessation was compared. For each storm event in the record, the NTN or MDN collector that opened first and closed first was determined. The times of day when wet exposure began to be recorded at the beginning of an event and when it stopped being recorded for the same event were compared for the co-located NTN and MDN collectors. This information is reported for each co-located NTN/MDN site.

\section{Results and Discussion}

The 11-grid sensors opened the collectors sooner than did the 7-grid sensors at 16 of the 20 sites (fig. 21) after precipitation onset. The results in figure 21 also indicate that 7 -grid sensors closed the collectors sooner than did the 11-grid sensors at 12 of the 20 sites. 

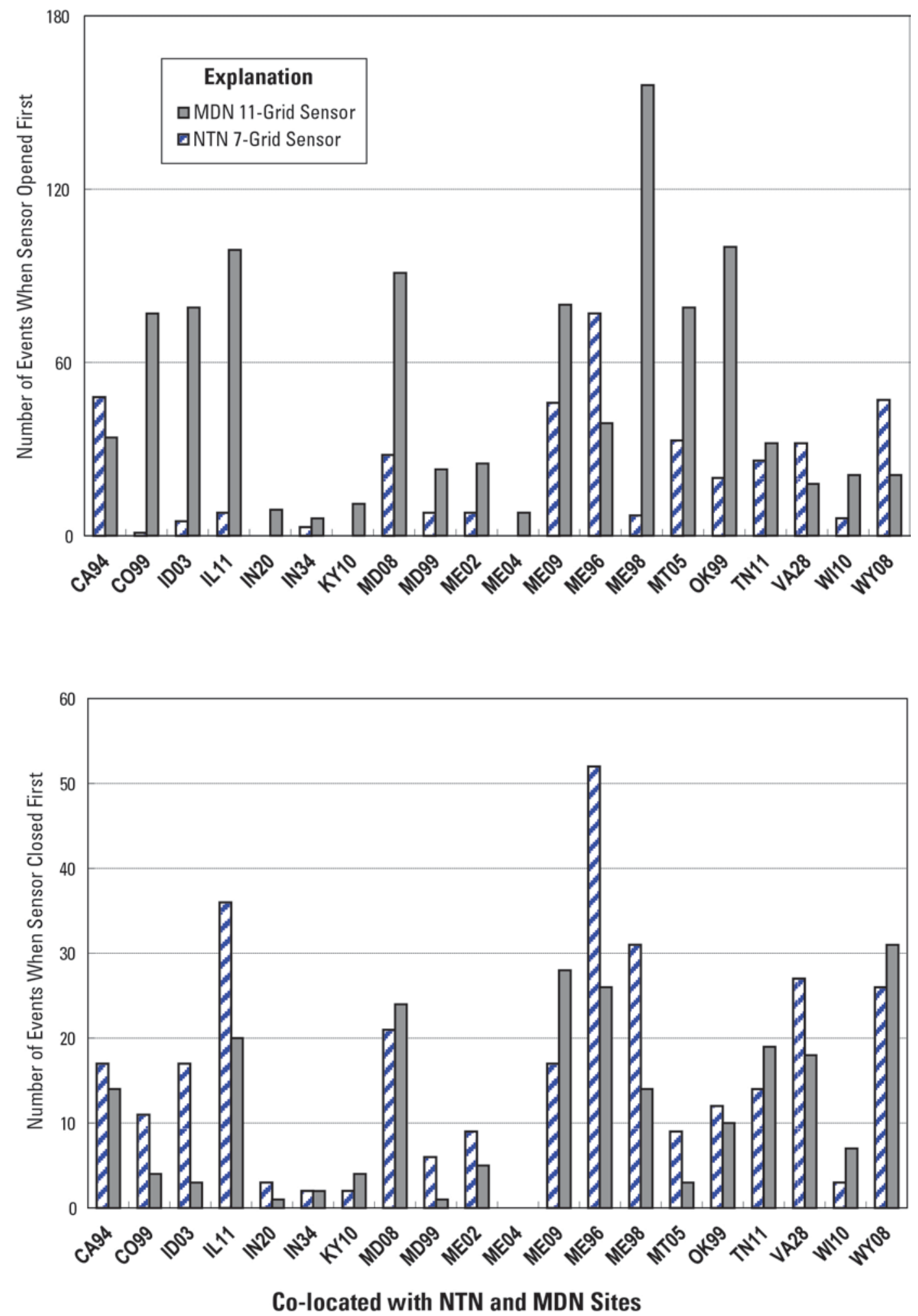

Figure 21. Comparison of number of precipitation events when 7-and 11-grid sensors opened and closed their respective collectors first at 20 co-located National Trends Network (NTN) and Mercury Deposition Network (MDN) sites. 
Daily wet-, dry-, and missed-exposure times were summed for each collector in the study, and 7-grid -minus- 11-grid differences were calculated for each of the three exposure times. Figure 22 shows mean 7-grid-minus- 11-grid exposure differences on a monthly basis. More wet exposure was recorded for the 11-grid sensors than for the 7grid sensors for 10 months of the year, especially during the winter months of November -December. More dry exposure was recorded for the 11-grid sensors than for the 7-grid sensors for 7 months of the year. The 7-grid sensors caused the collector lids to cycle more during precipitation events than did the 11-grid sensors for all months except during February (fig. 22). 

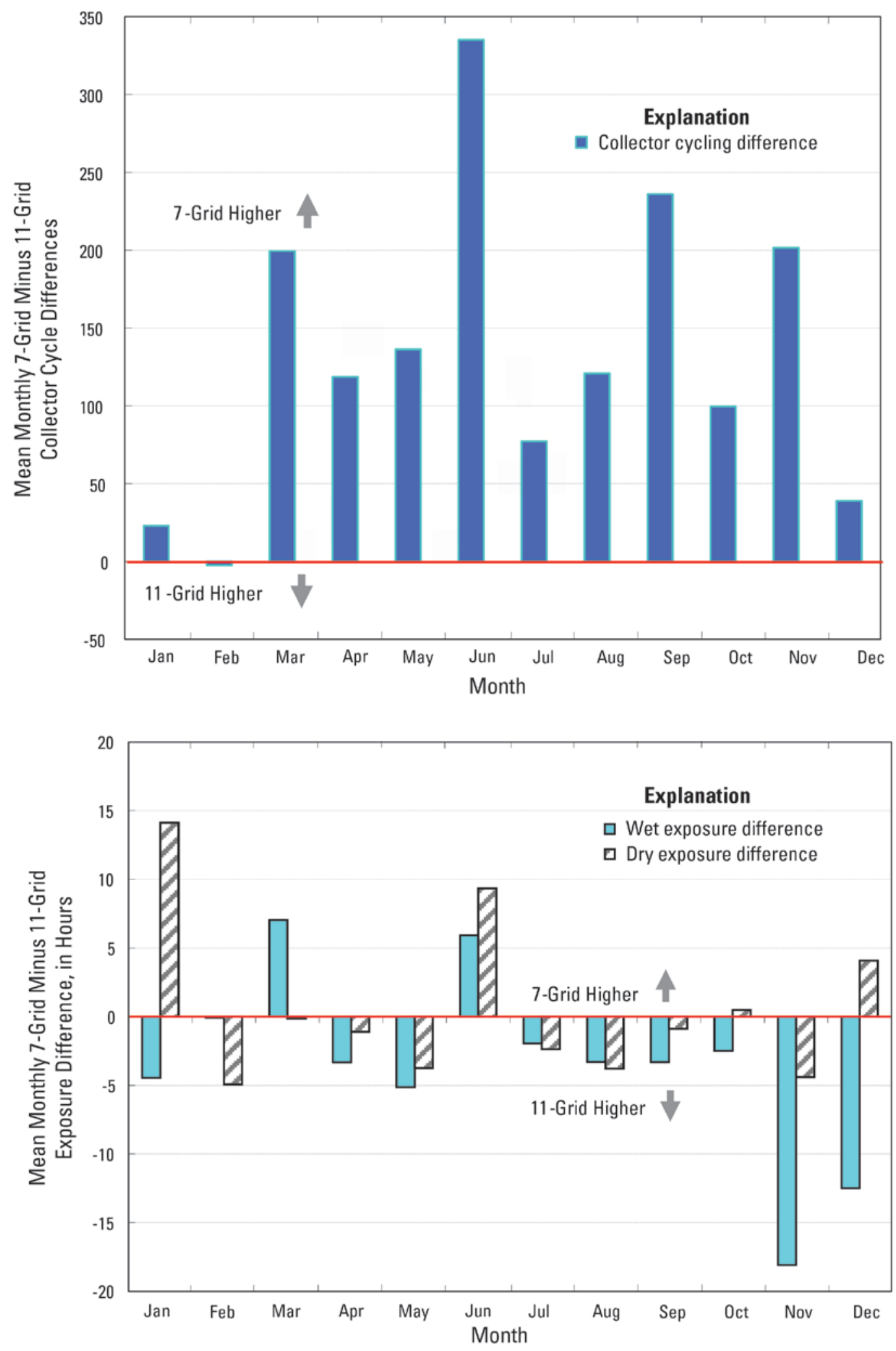

Figure 22. Comparison of wet- and dry-exposure differences and collector cycle differences for 7- and 11-grid sensors at 20 co-located National Trends Network and Mercury Deposition Network sites. 
The data obtained indicate that the 11-grid sensor, used with the MDN modified ACM collector, opens the collector sooner and keeps it open longer than does the 7-grid sensor, used with the NTN ACM collector. The 7-grid sensors cycle the collector lids more than does the 11-grid sensor, which could be advantageous for limiting dry exposure.

Retrofit of NTN collectors with 11-grid sensors could be expected to increase constituent concentrations in NTN samples because the collectors would open sooner and catch more atmospheric washout at early onset of precipitation. The 11-grid sensor would also be expected to keep the NTN collectors open longer during periods with no precipitation. This could promote sample loss from evaporation or contamination from dry deposition. Retrofit of NTN ACM collectors with 11-grid sensors would lessen lid cycling by the motor and thus lower power consumption and save wear of the motor. This might be advantageous for sites that use direct current (DC) power, where power conservation can be important. A retrofit of 7-grid sensors with 11-grid sensors for NTN ACM collectors is not planned by NADP as of this writing.

\section{Study 5. Catch Efficiency of NTN Collector with Wind Shield}

\section{Background and Methods}

Wind-blown precipitation causes under-representation of precipitation depth measurements by precipitation gages, especially for snow (Alter, 1937; Weiss, 1961, Brown and Peck, 1962; Bigelow and Denning, 1990; Yang and others, 1998 and 1999). Various wind shielding devices have been used to improve the catch of precipitation gages, such as the Alter wind shield, which is currently used at many NADP sites (Alter, 1937). Wind shields are required for rain gages at NADP sites that receive at least 20 percent of their annual precipitation as snow (see http://nadp.sws.uiuc.edu/newissues/newgages/windshields.aspx, accessed July 23, 2012). Similar types of wind shields have not been approved for use with precipitation collectors, due to concerns of potential sample contamination from rain splash from the surface of the wind shield. There is also the potential for birds to perch on the shields, thus creating another potential source of contamination.

This study assessed a wind shield for ACM precipitation collectors at the National Center for Atmospheric Research (NCAR) Marshall Field Site near Marshall, Colorado (fig. 23). The wind shield was designed in consultation with NCAR personnel experienced in testing various wind shields (Scott Landolt, NCAR, personal commun., 2008). Made from materials commonly available in hardware stores, the wind shield is plastic construction mesh supported by 0.75 -inch diameter electrical metal conduit poles attached to the ACM body using metal flagpole holders and self-tapping screws. The mesh is attached to the poles using locking plastic electrical ties. The flagpole holders keep the mesh shield angled away from the collector buckets. The wind shield is similar in shape to the Wyoming-type shield used with precipitation gages (Yang and others, 2000).

The porous wind shield creates self-canceling turbulent conditions over the top of the collector and prevents the shield from acting as a sail and catching too much wind, even though collectors are anchored to the ground with rebar stakes. From October 31, 2007 to December 23, 2008, two ACM collectors were operated independently, each with 
its own standard NTN 7-grid sensor (see Study 4). One collector was shielded and the other was not. The ACM sensor is located inside and within a few inches of the shield. From December 23, 2008 to April 6, 2009, both collectors were operated by the same sensor on the unshielded collector so that both collectors opened within a few seconds of each other. The later configuration provided an additional control on the study so that the effects of the wind shield could be evaluated without shielding the sensor. 

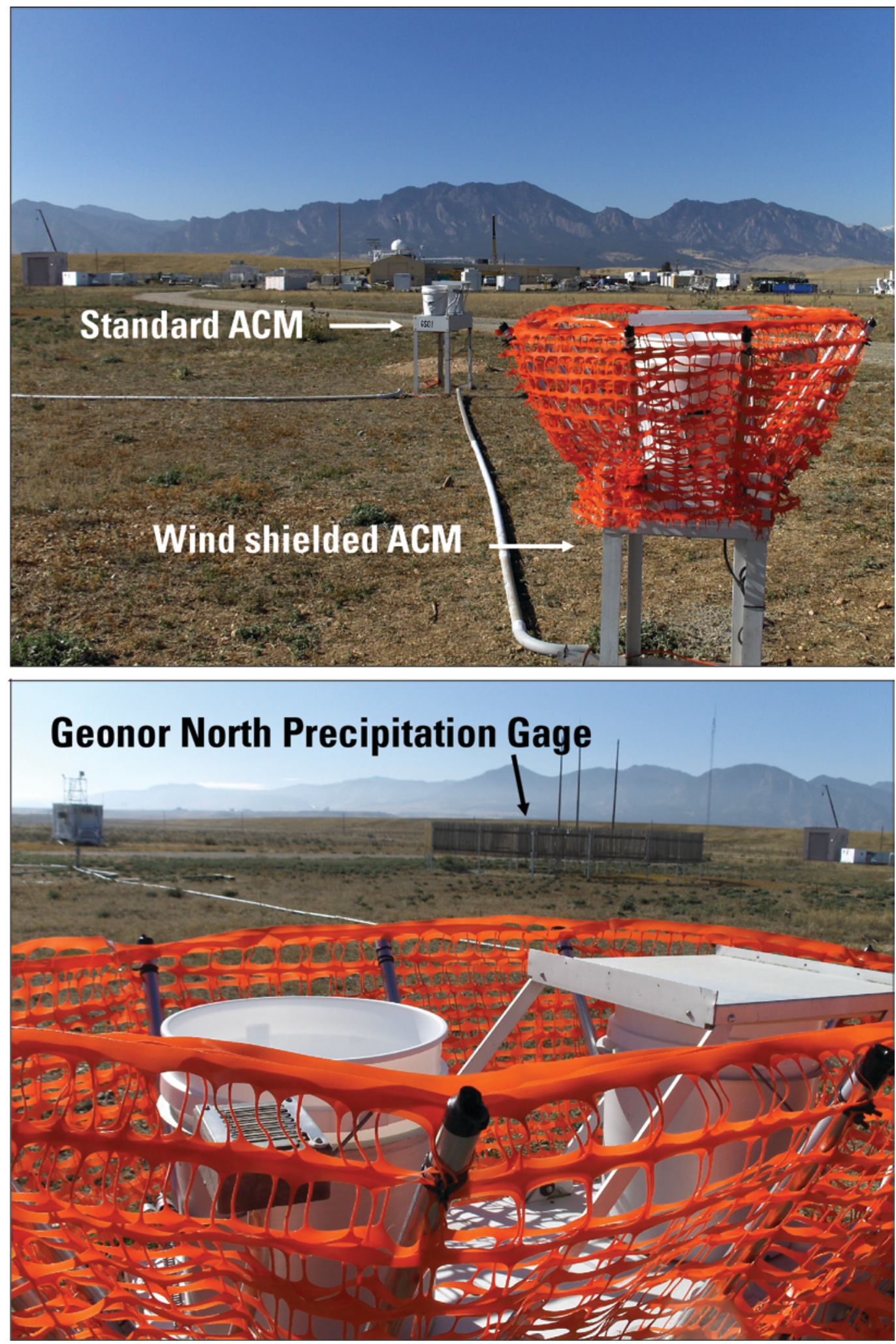

Figure 23. Co-located sampler installation at Marshall Field, Colorado showing placement of standard and wind-shielded ACM collectors and location of precipitation gage. 
The two collectors were installed at Marshall Field; a windy, easily accessed, and secure site with many continuously operating meteorological instruments. Official precipitation depth is measured by the "Geonor North" gage installed inside a dual fence inter-comparison reference (DFIR) shield at Marshall Field (fig. 23). Meteorological data are collected at 2 meters above the land surface every minute and include air temperature, wind speed and direction, and relative humidity. Precipitation depth and meteorological data for Marshall Field were obtained from Scott Landolt of NCAR, (oral and written communs., 2009). Meteorological data for the site can also be obtained from the NCAR, Marshall Field web site at

http://www.rap.ucar.edu/projects/winter/sites/marshall/?e10i4rljob9nfdsbdk4m4meud3, accessed February 28, 2011.

Meteorological data were extracted from the continuous records for the 1-minute intervals during which precipitation was recorded by the Geonor North gage. It was assumed that the wet-side buckets on the collectors were most likely exposed to the atmosphere during these periods. Mean, minimum, and maximum values of temperature, wind speed, wind direction, and wind direction standard deviation for the periods with precipitation were computed for the weekly sample-collection intervals.

Weekly samples were collected from both the shielded and standard, unshielded ACM collectors for November 20, 2007, to March 25, 2008, and October 17, 2008, to April 6, 2009. Samples sealed in the original, pre-weighed collection buckets with preweighed lids were transported to the PCQA laboratory at the Denver Federal Center (DFC), where they were weighed on a balance. The previously determined empty bucket and lid weights were subtracted from the total weight to calculate the mass and volume of precipitation collected during the previous week. Shielded-minus-unshielded collector sample-volume differences were calculated. The mass of precipitation was converted to depth by equation (2), which incorporates the area of the bucket orifice $\left(678.9 \mathrm{~cm}^{2}\right)$ :

$$
\begin{gathered}
\text { Depth (inches) }=\text { mass of liquid precipitation }(\text { grams }) \bullet 0.00058,(2) \\
\text { where: } 0.00058=\left(1 \mathrm{gram} / \mathrm{cm}^{3} \times 678.9 \mathrm{~cm}^{2} \times 2.54 \mathrm{~cm} / \text { inch }\right)^{-1} .
\end{gathered}
$$

The ability of a precipitation collector to catch a representative portion of the entire precipitation depth is characterized by catch efficiency. Catch efficiency is computed as the ratio of the precipitation depth measured by the collector, to the rain gage precipitation depth at the same location (equation 3).

$$
\text { Catch efficiency }=\frac{\text { weekly collector catch depth (inches) }}{\text { weekly rain gage precipitation depth (inches) }}
$$

Weekly samples were measured for $\mathrm{pH}$ and specific conductance in the PCQA laboratory in Building 95 at the DFC. Solution $\mathrm{pH}$, a measure of acidity, is the negative base-10 logarithm of the hydrogen-ion concentration in equivalents per liter. $\mathrm{pH}$ was measured with a Beckman Phi-11 pH meter and ion-specific electrode calibrated with Orion low-ionic strength $\mathrm{pH} 4.0$ and 7.0 buffers. Specific conductance was measured with a Radiometer CDM3 conductivity meter and type CDC 314 cell calibrated using a 50 microSiemens per centimeter $(\mu \mathrm{S} / \mathrm{cm})$ aqueous potassium chloride standard. These measurements provided data to imply how potential differences in catch efficiency might 
affect sample chemistry without obtaining complete chemical analyses of solute concentrations in the samples. Only complete paired data, whereby sufficient volume was obtained for analysis by both collectors, were compared statistically. The unshielded collector did not obtain sufficient volume for analysis of specific conductance and $\mathrm{pH}$ for 4 and 6 weekly samples, respectively.

\section{Results and Discussion}

During water year 2008 (October 1, 2007-September 30, 2008, WY08), 15 paired, weekly samples were collected, and an additional 4 weekly samples were collected by the shielded collector that were missed by the unshielded collector. During water year 2009 (WY09), 13 paired, weekly samples were collected, and an additional 2 weekly samples were collected only by the shielded collector (fig. 24). Collector catch was significantly $(\alpha=0.05)$ greater for the shielded collector per the Wilcoxon Signed Rank Test on the paired sample volumes $(p<0.0001)$. There was no significant difference $(\alpha=0.05)$ in shielded-minus-unshielded collector catch differences for the two different sensor configurations, independent versus single-sensor modes, per the Wilcoxon Rank Sum Test $(p=0.1728)$. Excluding weeks with zero standard ACM collector catch, the shielded collector exhibited a +39 percent (median) increase in catch efficiency over the unshielded collector (fig. 25).

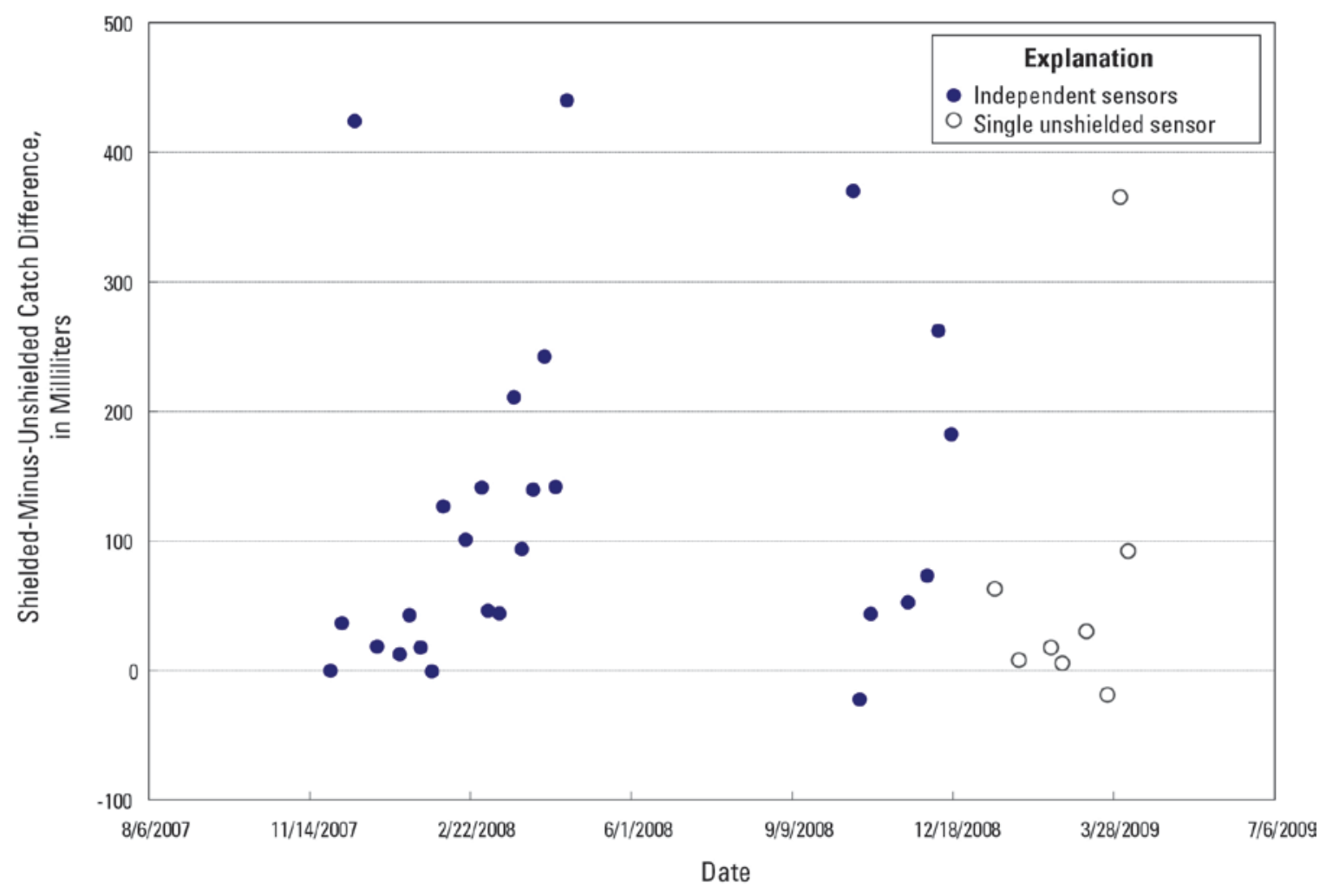

Figure 24. Time series of unshielded-minus-shielded collector catch differences for co-located wet-deposition collectors operated at Marshall Field, Colorado during water years 2008-09 (WY08-WY09). 


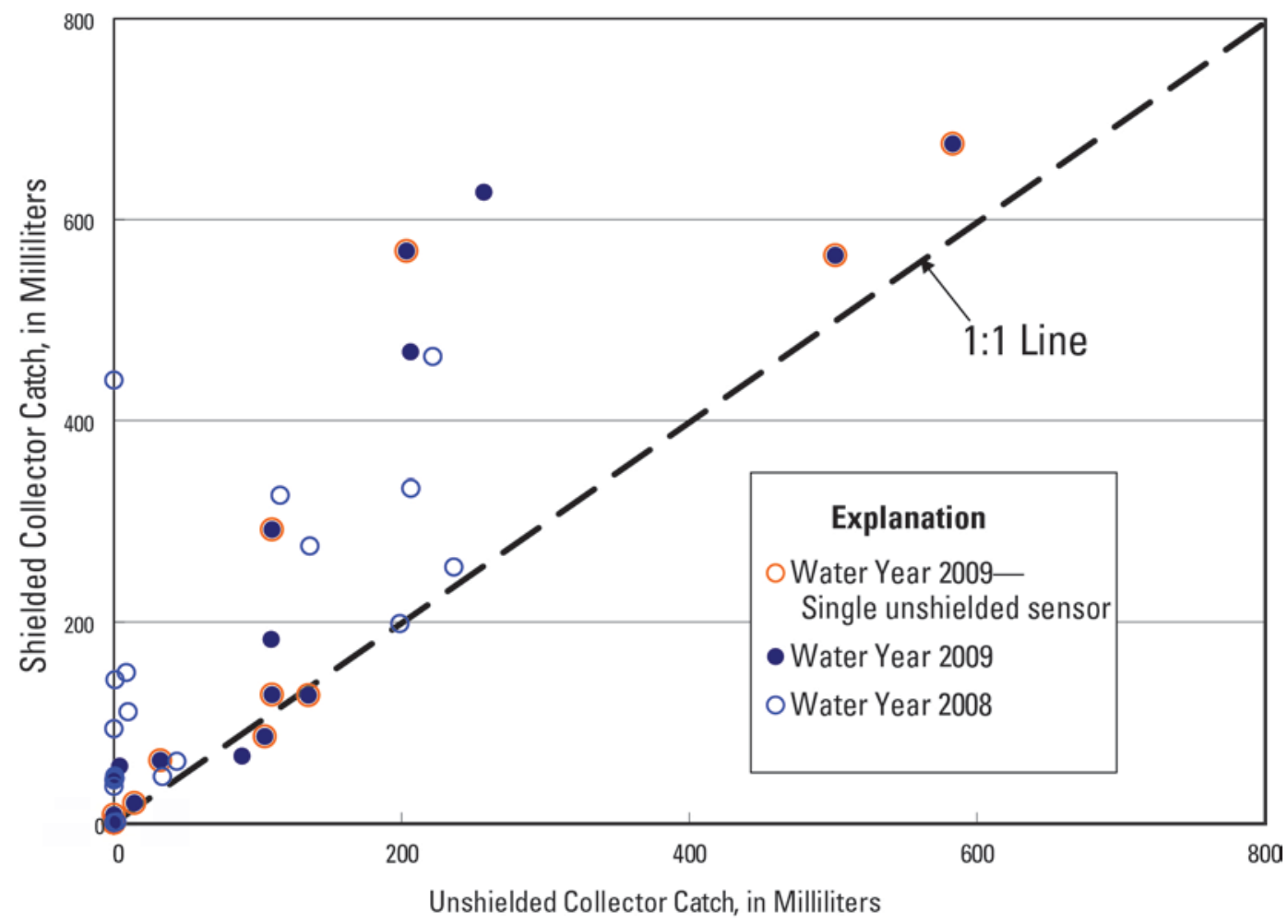

Figure 25. Relation of shielded and unshielded collector catch for co-located wet-deposition collectors operated at Marshall Field, Colorado during water years 2008-09 (WY08-WY09).

Results in figure 26 indicate no statistical correlation between shielded-minusunshielded collector catch difference and average or maximum wind speed during precipitation (Kendall's Tau $=-0.011$ and 0.183 , respectively). However, the distribution of the data indicate increasing effectiveness of the shield with increasing wind speed up to a maximum effectiveness at a mean wind speed of $5 \mathrm{~m} / \mathrm{s}$ (meters per second). Then, the wind shield's effectiveness decreases with further increasing wind speed to approximately $9 \mathrm{~m} / \mathrm{s}$ where the wind shield ceases to be effective. Collector catch efficiency tended to be greater when the 2-meter elevation wind direction was from the northeast to southwest. Mean relative standard deviation of wind direction (wind direction variability, also known as Sigma theta) during precipitation and shielded-minusunshielded collector catch difference are weakly correlated (Kendall's Tau $=0.35, p=$ 0.0103), but this is not evident in the scatterplot of the data in figure 27. 

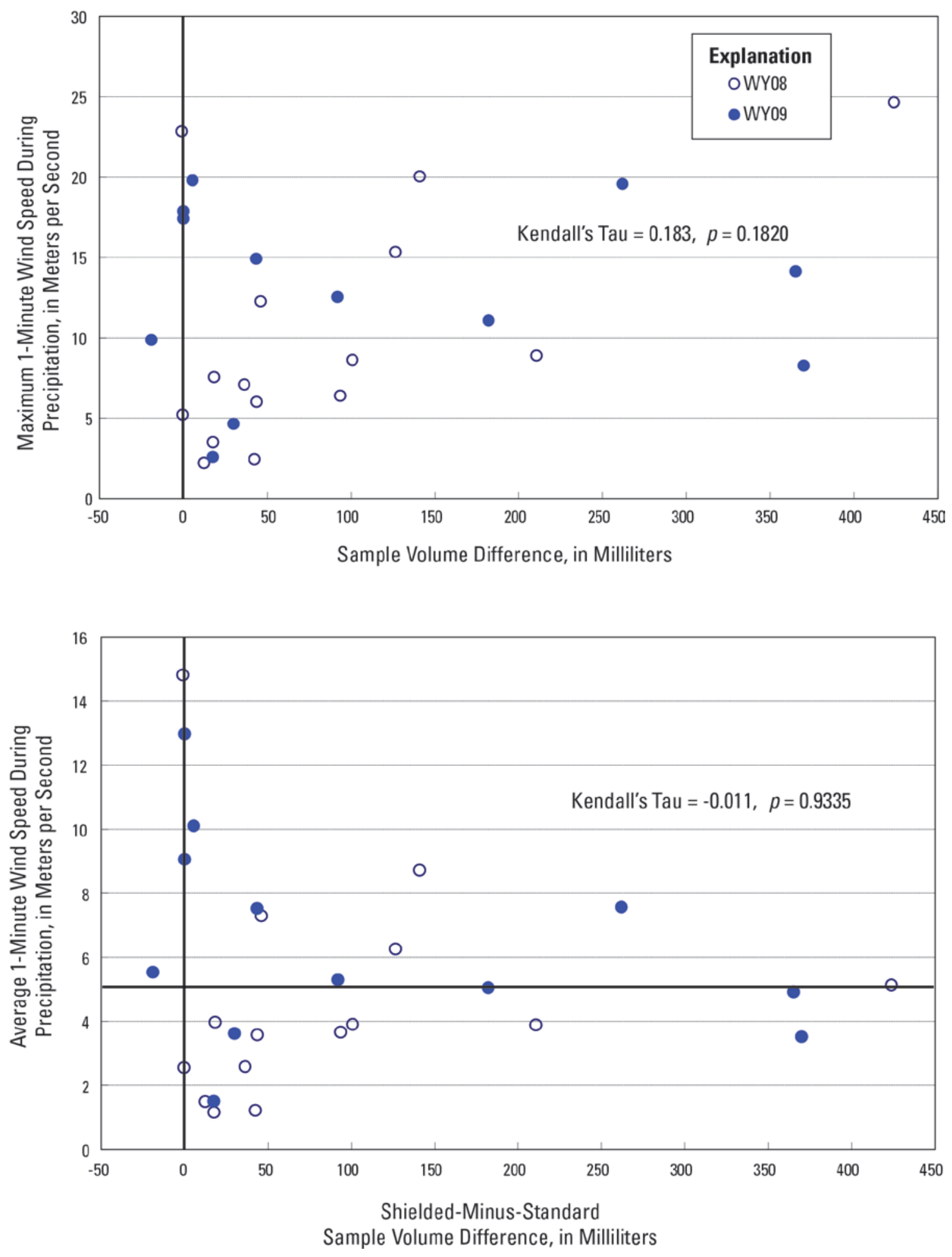

Figure 26. Sample-volume differences for co-located standard and wind-shielded wet-deposition collectors, with maximum and average wind speed during precipitation at Marshall Field, Colorado during water years 2008-2009 (WY08-WY09). 

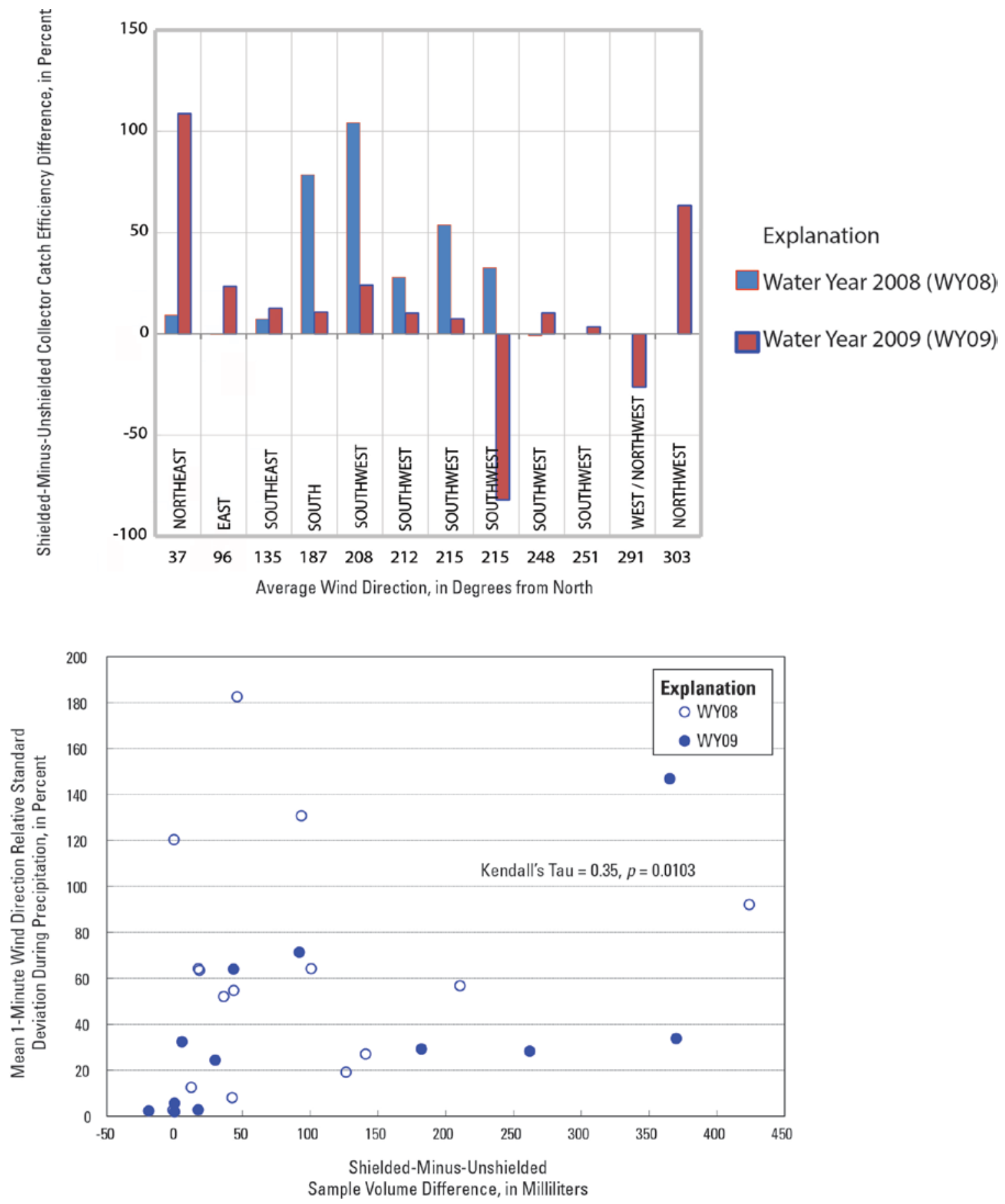

Figure 27. Catch efficiency and sample-volume differences, for co-located wind-shielded and standard wet-deposition collectors, related to average wind direction and wind direction relative standard deviation during precipitation at Marshall Field, Colorado during water years 20082009. 
The wind shield's effect on snow catch is indicated by a weak negative correlation (Kendall's Tau $=-0.2796, p=0.041$ ) between minimum temperature during precipitation and shielded-minus-unshielded catch difference (fig. 28). This implies that shielded-minus-unshielded collector catch differences are greater for frozen precipitation than for liquid precipitation. The catch differences are plotted versus mean temperature during precipitation in figure 28 for comparison. Additionally, there were 6 weeks when the shielded collector obtained a sample when the unshielded collector did not, and 5 of these samples were for snow. 

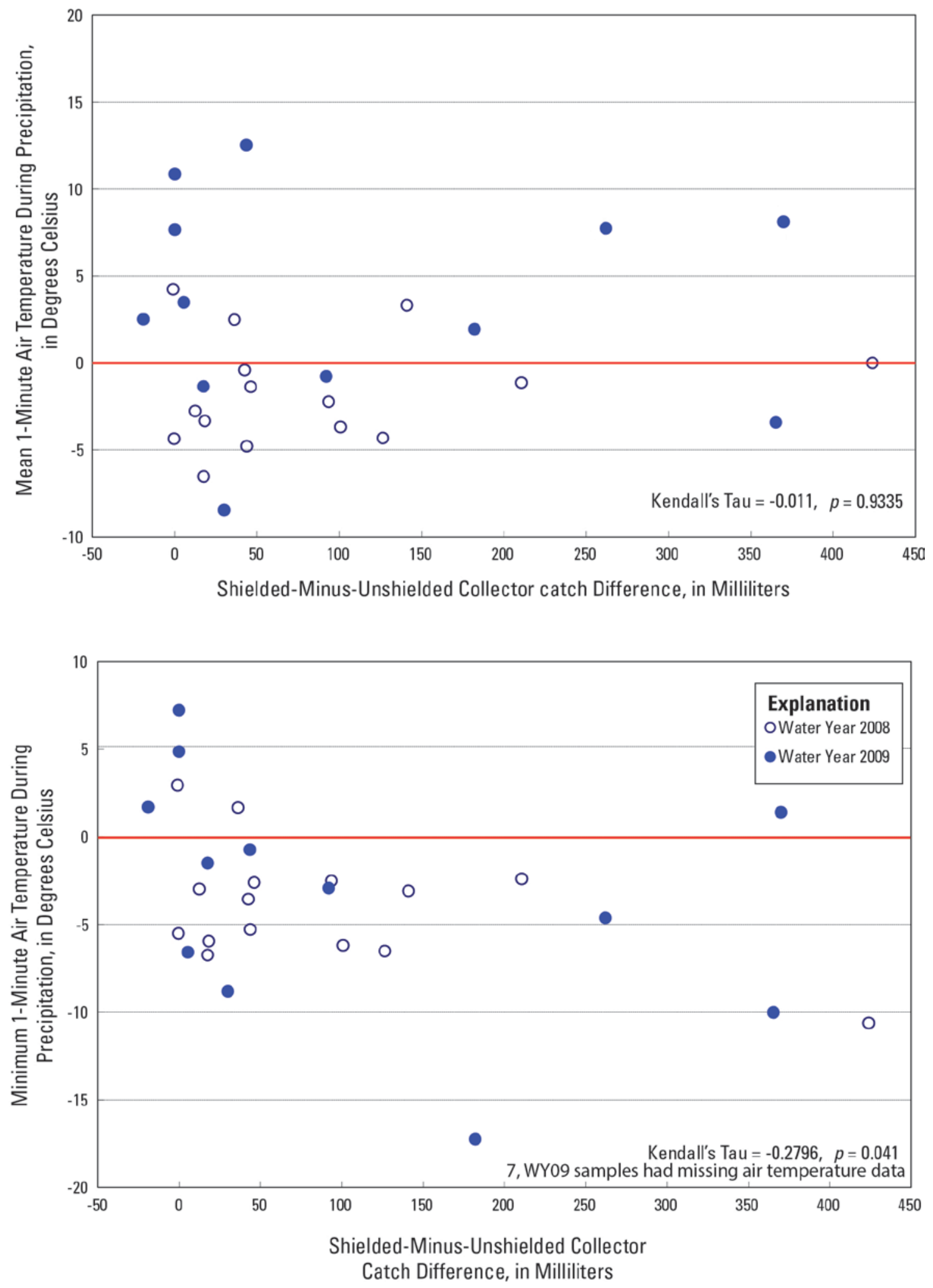

Figure 28. Sample-volume differences for co-located standard and wind-shielded wet-deposition collectors related to average and minimum air temperature during precipitation at Marshall Field, Colorado during water years 2008-2009 (WY08-WY09). 
Specific conductance was significantly $(\alpha=0.05)$ lower for samples from the shielded collector compared to the unshielded collector per the Wilcoxon Signed Ranks test $(p=0.004)$. Results in figure 29 show that the shielded collector had lower specific conductance for 15 of 18 weekly sample pairs. The median shielded-minus-unshielded specific conductance difference is $-2.6 \mu \mathrm{S} / \mathrm{cm}$.

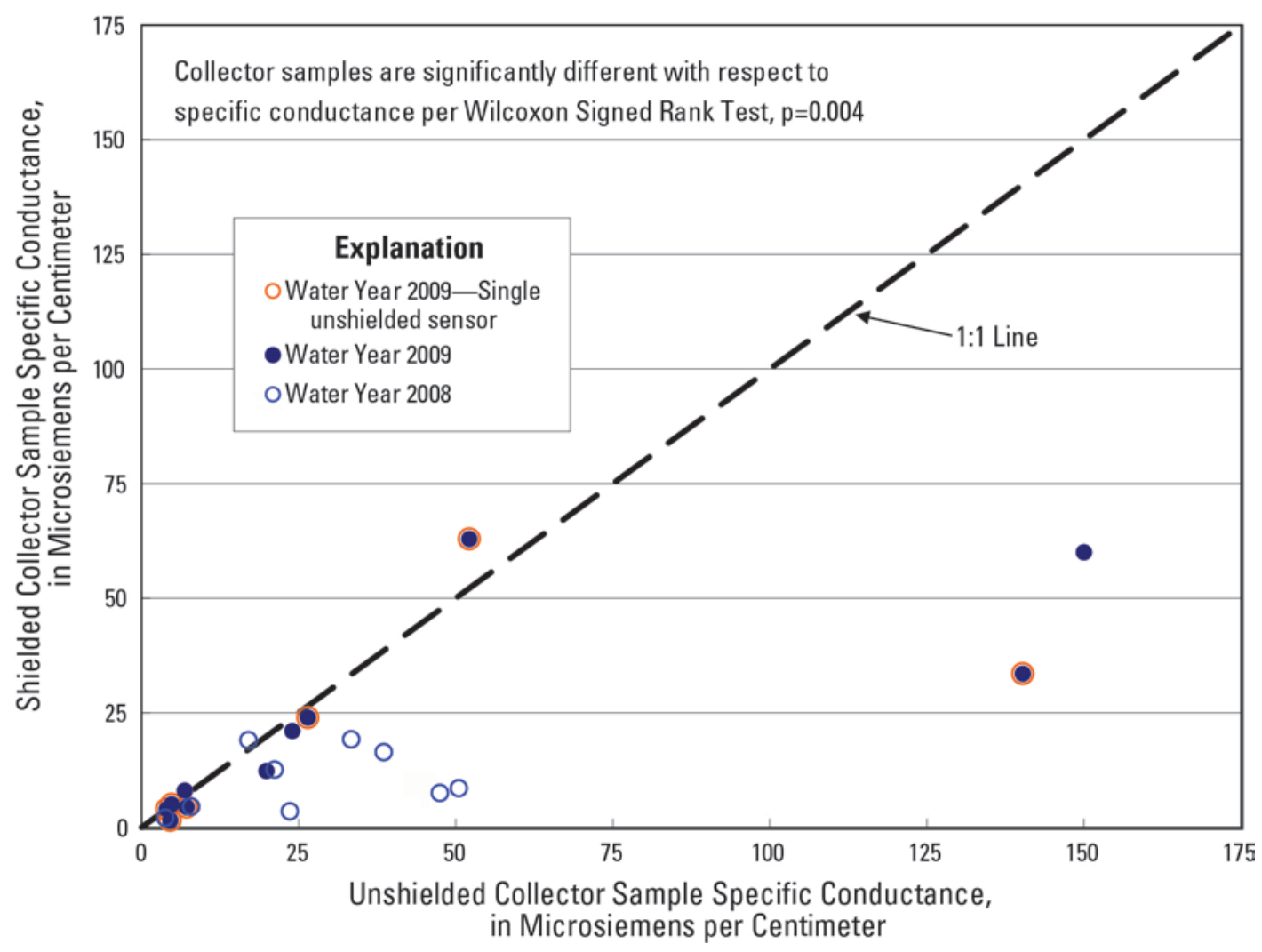

Figure 29. Specific conductance of precipitation samples obtained by co-located wind-shielded and standard wet-deposition collectors at Marshall Field, Colorado, during water years 20082009.

Results in figure 30 show that 13 of 17 samples from the shielded collector had higher $\mathrm{pH}$ than the unshielded collector. However, $\mathrm{pH}$ of the samples from the shielded and unshielded collectors were not significantly $(\alpha=0.05)$ different per the Wilcoxon Signed Ranks test ( $p=0.1475)$. The median shielded-minus-unshielded hydrogen-ion concentration difference (calculated from $\mathrm{pH})$ is -0.08 microequivalents per liter $(\mu \mathrm{eq} / \mathrm{L})$. 


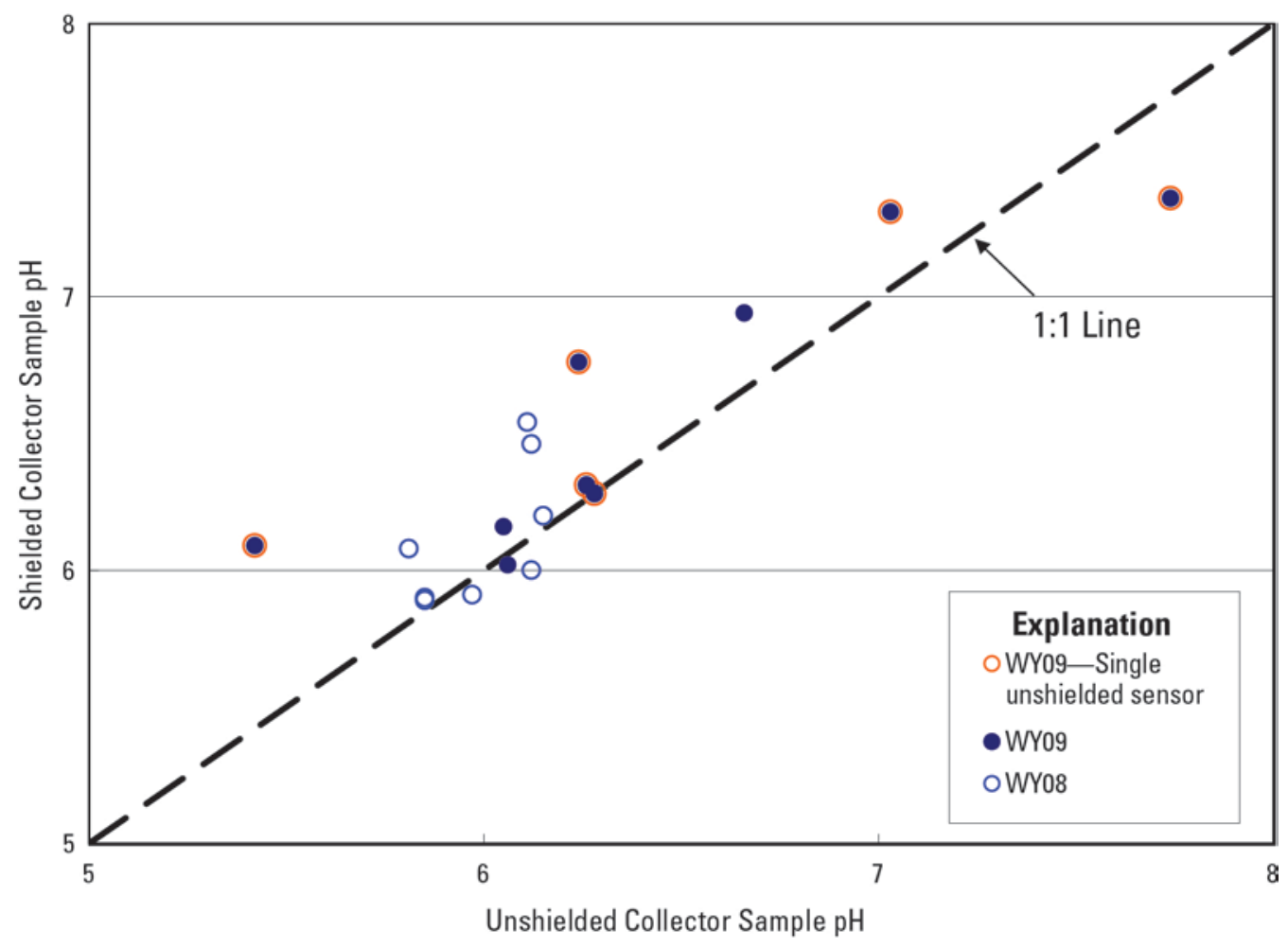

Figure 30. $\mathrm{pH}$ of precipitation samples obtained by co-located wind-shielded and unshielded wetdeposition collectors at Marshall Field, Colorado during water years 2008-2009 (WY08 to WY09).

The results indicate that sample $\mathrm{pH}$ and specific conductance are potentially affected by the wind shield in three ways: (1) the shielded collector could open later than the unshielded collector, thereby missing acidic atmospheric deposition at the onset of precipitation, (2) the unshielded collector could catch more dry deposition or windblown particulates that increase the specific conductance of the sample, or (3) the shielded collector could catch more dry deposition or windblown particulates that buffer sample acidity and thereby lower the specific conductance attributed to hydrogen ion. Collector lid actuation was only logged for the shielded collector. Therefore, data are incomplete for determination of how the wind shield affects sensitivity of the precipitation sensor.

\section{Summary and Conclusions}

USGS/BQS and the NADP/PO conducted five studies to assess the effects of monitoring equipment performance on the quality of NADP/NTN and MDN measurements. Each study's objectives and results are summarized.

Results of an NTN sample evaporation study indicate that weekly NTN samplevolume evaporated from ACM collector buckets ranged between 1.1-33 percent with a median of 4.7 percent. The results suggest that weekly NTN sample evaporation is small relative to sample volume. Effects of evaporation on sample solute concentrations were not evaluated. Sample evaporation was consistent with co-located pan evaporation measurements and was statistically correlated with relative humidity, but not sample volume, air temperature, wind speed, or wind direction. 
Results of a study on weekly MDN sample evaporation and associated changes in $\mathrm{Hg}$ concentrations revealed that MDN sample evaporation is more prevalent in the western and southern portions of the United States, and the problem occurs more frequently with modified ACM collectors than with N-CON collectors. Field testing of MDN collectors revealed that airflow through the modified ACM is the dominant factor that influences sample evaporation. Modified ACM collectors with cooling fans manufactured by Loda Electronics are even more susceptible to sample evaporation, which was measured to be as high as 47.5 percent per week. Median evaporation was 5 percent.

MDN Hg concentrations are affected by evaporation. In some instances $\mathrm{Hg}$ is lost from the sample and in other instances $\mathrm{Hg}$ is concentrated in the sample, with both scenarios resulting in changes to $\mathrm{Hg}$ concentrations in MDN samples. The rates of loss of sample volume, preservative volume, and $\mathrm{Hg}$ are not consistently proportional.

Results of a field evaluation of MDN glass sample trains in both modified ACM and $\mathrm{N}-\mathrm{CON}$ collectors indicate that a small amount of $\mathrm{Hg}$ can be removed from MDN samples by adsorption to the glass sample trains. No statistically significant difference between the two collector types with respect to $\mathrm{Hg}$ adsorption was found. Median summer time $\mathrm{Hg}$ loss ranged from $0.238 \mathrm{ng} / \mathrm{L}$ to $0.489 \mathrm{ng} / \mathrm{L}$ for the $\mathrm{N}-\mathrm{CON}$ and modified $\mathrm{ACM}$, respectively. Median winter time $\mathrm{Hg}$ loss ranged from $0.056 \mathrm{ng} / \mathrm{L}$ to $0.076 \mathrm{ng} / \mathrm{L}$ for the modified ACM and N-CON, respectively.

A comparison of the relative sensitivity of 2 different ACM collector grid-type precipitation sensors indicates that the 11-grid MDN sensors open the collectors sooner than the 7-grid NTN sensors. The 7-grid sensors closed the collectors sooner than did the 11-grid sensors. The 7-grid sensor also causes the collector lid to cycle more than the 11grid sensor. Retrofit of NTN ACM collectors with 11-grid sensors could reduce wear on collector motors. However, solute concentrations in NTN samples could be expected to increase because the collector would open earlier at the onset of precipitation with an 11grid sensor, and it would be more likely to stay open after precipitation stops.

Evaluation of a collector wind shield demonstrated that precipitation catch was significantly increased by the shield without significant differences in $\mathrm{pH}$, and specific conductance was significantly lower for samples collected by the shielded collector. The results demonstrate that collector shields could be used to enhance the catch efficiency of the collector while preserving the integrity of sample chemistry. However, NADP has only approved the use of wind shields on precipitation gages, not collectors. Collector wind shields are typically prohibited by NADP and only approved on a case-by-case basis. This study is intended to inform and guide changes to this policy.

\section{References Cited}

Alter, J.C., 1937, Shielded storage precipitation gages, in Monthly Weather Review, July 1937,65 , p. 262-265.

Bigelow, D.S., and Denning, A.S., 1990, Differences between Nipher and Alter shielded universal Belfort precipitation gages at two Colorado deposition monitoring sites:

Environmental Science and Technology, v. 24, p. 758-760.

Brown, M.J., and Peck, E.L., 1962, Reliability of precipitation measurements as related to exposure: Journal of Applied Meteorology, June 1962, v. 1, p. 203-207. 
Citizen Weather Observer Program, 2011, site AR893: Citizen Weather Observer program, accessed on March 4, 2011 at http://weather.gladstonefamily.net/site/AR893.

Gordon, J.D., 1999, External quality-assurance results for the National Atmospheric Deposition Program/National Trends Network, 1995-96: U.S. Geological Survey Water-Resources Investigations Report 99-4072, 69 p.

Gordon, J.D., Nilles, M.A., Polacsek, D.K., and Ratcliff, M.E., 1997, External qualityassurance results for the National Atmospheric Deposition Program/National Trends Network during 1994: U.S. Geological Survey Water-Resources Investigations Report 97-4201, 42 p.

Graham, R.C., and Robertson, J.K., 1990, An assessment of performance of wet atmospheric deposition samplers: U.S. Geological Survey Water-Resources Investigations Report 90-4042, 101 p.

Graham, R.C., Robertson, J.K., and Obal, J., 1987, An assessment of the variability in performance of wet atmospheric deposition samplers: U.S. Geological Survey WaterResources Investigations Report 87-4125, 152 p.

Helsel, D.R., and Hirsch, R.M., 1992, Statistical methods in water resources: New York, Elsevier Science Publishing Company, Inc., 522 p.

Latysh, N.E., and Gordon, J.D., 2004, Investigation of differences between field and laboratory $\mathrm{pH}$ measurements of National Atmospheric Deposition Program/National Trends Network precipitation samples: Water, Air, and Soil Pollution, v. 154, p. 249270.

Latysh, N.E., and Wetherbee, G.A., 2005, External quality-assurance programs managed by the U.S. Geological Survey in support of the National Atmospheric Deposition Program/National Trends Network: U.S. Geological Survey Open-File Report 20051024, 76 p.

Latysh, N.E., and Wetherbee, G.A., 2007. External Quality Assurance Programs Managed by the U.S. Geological Survey in Support of the National Atmospheric Deposition Program/Mercury Deposition Network: U.S. Geological Survey Open-file Report 2007-1170.

National Atmospheric Deposition Program (NADP), 2011:Accessed on Mar. 4, 2011at http://nadp.isws.illinois.edu/newissues/newgages/windshields.aspx.

National Center for Atmospheric Research (NCAR), 2011:, Accessed on Feb. 28, 2011at http://www.rap.ucar.edu/projects/winter/sites/marshall/?7b4701fa4bc533451f192615e aa0263d.

Nilles, M.A., 2000, Atmospheric Deposition Program of the U.S. Geological Survey: U.S. Geological Survey Fact Sheet 112-00.

Pellett, G.L., Bustin, R.A., and Harris, R.C., 1984, Sequential sampling and variability of acid precipitation in Hampton, Virginia: Water, Air, and Soil Pollution, v. 21, p. 33-49.

Raynor, G.S., and Hayes, J.V., 1982, Variation in chemical wet deposition with meteorological conditions: Atmospheric Environment, v. 16, no. 7, p. 1647-1656.

Raynor, G.G., and McNeil, J.P., 1979, An automatic sequential precipitation sampler, in Atmospheric Environment, v. 13, pp. 149-155.

Rong, X., Waite, D., Huang, G.H., Tong, L., and Kybett, B., 2001, Materials selection for a dry atmospheric mercury deposits sampler, in Chemosphere, vol. 45, pp 1045-1051.

Rosain, R.M., and Wai, C.M., 1973, The rate of loss of mercury from aqueous solution when stored in various containers, in Analytical Chimica Acta, vol. 65, pp 279-284. 
Schroeder, L.J., Brooks, M.H., and Garbarino, J.R., 1987, The influence of an urban environment in the chemical composition of precipitation, in Chemical Quality of Water and Hydrologic Cycle, chap. 3, Averett, R.C., and McKnight, D.M., eds.,: Chelsea, Mich., Lewis Publishers, Inc.

Schroeder, L.J., and Hedley, A.G., 1986, Variation in precipitation quality during a 40hour snowstorm in an urban environment-Denver, Colorado: International Journal of Environmental Studies, v. 28, p. 131-138.

See, R.B., Schroder, L.J., and Willoughby, T.C., 1989, A quality-assurance assessment for constituents reported by the National Atmospheric Deposition Program and the National Trends Network: Atmospheric Environment, v. 23, no. 8, p. 1801-1806.

Sisterson, D.L., Wurfel, B.E., and Lesht, B.M., 1985, Chemical differences between event and weekly precipitation samples in northeastern Illinois: Atmospheric Environment, v. 19, no. 9, p. 1453-1469.

Tang, A.J.S., Chan, W.H., Orr, D.B., Bardswick, W.S., and Lusis, M.A., 1987, An evaluation of the precision, and various sources of error, in daily and cumulative precipitation chemistry sampling: Water, Air, and Soil Pollution, v. 36, p 91-102.

Vermette, S.J., Lindberg, S.E., and Bloom, N., 1995, Field tests for a regional mercury deposition network-sampling design and preliminary test results: Atmospheric Environment, v. 29, no. 11, p. 1247-1251.

Weiss, L.L., 1961, Relative catches of snow in shielded and unshielded gages at different wind speeds: Monthly Weather Review, October 1961, p. 397-400.

Wetherbee, G.A., Latysh, N.E., and Chesney, T.A., 2010, U.S. Geological Survey External Quality-Assurance Project Report to the National Atmospheric Deposition Program / National Trends Network and Mercury Deposition Network, 2007-08: NADP QA Report 2010-01, ISWS Miscellaneous Publication 190, University of Illinois, Institute of Natural Resource Sustainability, Illinois State Water Survey, 82 p.

Wetherbee, G.A., Latysh, N.E., Greene, S.M., and Chesney, T.A., 2009, U.S. Geological Survey external quality-assurance program results reported to the National Atmospheric Deposition Program / National Trends Network, and Mercury Deposition Network for 2005-06: NADP QA Report 2009-01, ISWS DCS 2009-01, Illinois State Water Survey, Champaign, Ill., 54 p.

Wetherbee, G.A., Latysh, N.E., and Gordon, J.D., 2005, Spatial and temporal variability of the overall error of National Atmospheric Deposition Program measurements determined by the USGS co-located-sampler program, water years 1989-2001:

Environmental Pollution, v. 135, p. 407-418.

Wetherbee, G.A., Latysh, N.E., and Gordon, J.D., 2004, External quality-assurance results for the National Atmospheric Deposition Program / National Trends Network, 2000-2001, U.S. Geological Survey Scientific Investigations Report 2004-5034, Denver, CO, $59 \mathrm{p}$.

Wetherbee, G.A., Latysh, N.E., and Greene, S.M., 2006, External quality-assurance results for the National Atmospheric Deposition Program / National Trends Network, and Mercury Deposition Network, 2004: U.S. Geological Survey Scientific Investigations Report 2006-5067, 52 p.

Willoughby, T.C., Schroder, L.J., and See, R.B., 1990, Chemical stability of wetdeposition samples subsampled daily for one week: U.S. Geological Survey WaterResources Investigations Report 90-4003, 19 p. 
Willoughby, T.C., See, R.B., and Schroder, L.J., 1989, Stability of nitrate-ion concentrations in simulated deposition samples used for quality-assurance activities by the U.S. Geological Survey: U.S. Geological Survey Water-Resources Investigations Report 89-4042, 15 p.

Yang, D., Goodison, B.E., and Metcalfe, J.R., 1998, Accuracy of NWS 8" standard nonrecording precipitation gauge - Results and application of WMO intercomparison: Journal of Atmospheric and Oceanic Technology, v. 15, p. 54-68.

Yang, D., Goodison, B.E., Metcalfe, J.R., Louie, P., Leavesley, G.L., Emerson, D., Hanson, C.L., Golubev, E.E., Gunther, T., Pangburn, T., Kang, E., and Milkovic, J., 1999, Quantification of precipitation measurement discontinuity induced by wind shields on national gauges: Water Resources Research, v. 35, no. 2, p. 491-508.

Yang, D., Kane, D.L., Hinzman, L.D., Goodison, B.E., Metcalfe, J.R., Louie, P.Y.T., Leavesley, G.H., Emerson, D.G., and Hanson, C.L., 2000, An evaluation of the Wyoming gauge system for snowfall measurement: Water Resources Research, v. 36, no. 9 , p. 2665-2677.

Table 1. Kendall's Tau and associated statistical significance for correlation of meteorological data and weekly evaporation of synthetic precipitation samples sealed in an Aerochem Metrics Model 301 precipitation collector in Arvada, Colorado, May 16-September 5, 2006.

[mm, millimeters; $\mathrm{p}$-values, probability of correctly deciding that two variables are not correlated; m/s, meters per second; deg. $\mathrm{C}$, degrees Celsius; $\mathrm{mmHg}$, millimeters of mercury; $\mathrm{mL}$, milliliters ]

\begin{tabular}{lcccc}
\hline & \multicolumn{2}{c}{$\begin{array}{c}\text { Weekly sample evaporation } \\
\text { depth, } \mathbf{~ m m}\end{array}$} & \multicolumn{2}{c}{$\begin{array}{c}\text { Weekly sample evaporation, } \\
\text { in percent }\end{array}$} \\
\cline { 2 - 5 } \multicolumn{1}{c}{ Parameters and units } & Kendall's Tau & p-values & Kendall's Tau & p-values \\
\hline Weekly pan evaporation, mm & 0.69 & 0.0003 & 0.30 & 0.157 \\
Weekly mean wind direction & 0.07 & 0.757 & 0.08 & 0.690 \\
Weekly mean wind speed, $\mathrm{m} / \mathrm{s}$ & 0.45 & 0.015 & 0.40 & 0.033 \\
Weekly mean air temperature, deg. C & 0.10 & 0.626 & -0.12 & 0.564 \\
Weekly mean relative humidity, percent & -0.77 & 0.00001 & - & - \\
Weekly mean barometric pressure, $\mathrm{mmHg}$ & -0.37 & 0.059 & - & - \\
Initial sample volume, $\mathrm{mL}$ & 0.23 & 0.228 & -0.38 & 0.041 \\
\hline
\end{tabular}


Table 2. Preservative volume loss for MDN samples collected between March 1996 and November 2010.

\begin{tabular}{ccc}
\hline $\begin{array}{c}\text { Preservative volume loss }{ }^{1} \\
\text { (milliliters) }\end{array}$ & Number of samples & $\begin{array}{c}\text { Percentage of samples } \\
\text { (Percent) }\end{array}$ \\
\hline 0 (no loss) & 805 & 15.5 \\
$0-1$ & 1,052 & 20.3 \\
$1-2$ & 801 & 15.4 \\
$2-5$ & 1,072 & 20.7 \\
$5-10$ & 670 & 12.9 \\
$10-15$ & 293 & 5.7 \\
$15-19.9$ & 336 & 6.5 \\
20 & 156 & 3.0 \\
\hline
\end{tabular}

${ }^{1}$ Volume loss based on sampling period with no precipitation, no bottle leaks during shipment, and proper operation of both the collector's motor and sensor.

${ }^{2}$ Based on the number of samples $(5,185)$ that met the study criteria.

Table 3. Weekly Mercury Deposition Network (MDN) samples with preservative volume loss and individual MDN sites where sample loss was observed, March 1996 - November 2010.

\begin{tabular}{lcc}
\hline \multicolumn{1}{c}{ Collector type } & $\begin{array}{c}\text { Number of samples with preservative } \\
\text { volume loss }{ }^{1}\end{array}$ & Number of sites $^{2}$ \\
\hline Modified ACM & 3,820 & 125 \\
N-CON & 560 & 39 \\
\hline
\end{tabular}

1 Total number $(4,380)$ based on sampling periods with no precipitation, no bottle leaks during shipment, proper operation of both the motor and sensor, and preservative volume loss greater than 0 milliliters.

${ }^{2}$ Includes both presently and formerly active sites, and sites that changed collector type.

Table 4. Specifications of the cooling fan used in the original modified Aerochem Metrics (ACM) collector and the Loda Electronics version of the ACM collector.

$\left[\mathrm{ft}^{3} / \mathrm{min}\right.$, cubic feet per minute; rpm, revolutions per minute; $\mathrm{dB}$, decibels]

\begin{tabular}{lcc}
\hline \multirow{2}{*}{ Parameter } & \multicolumn{2}{c}{ Manufacturer } \\
\cline { 2 - 3 } & Aerochem Metrics & Loda Electronics \\
\hline Air flow (ft $\left.{ }^{3} / \mathrm{min}\right)$ & 70 & 100 \\
Speed (rpm) & 2,000 & 2,900 \\
Power (Watts) & 11 & 18 \\
Noise (dB) & 36 & 48 \\
\hline
\end{tabular}


Table 5. Results from evaporation tests with Aerochem Metrics version of the modified ACM collector.

[\%, percent; ng/L, nanograms per liter; MPV, most probably value; Hg, mercury]

\begin{tabular}{|c|c|c|c|c|c|c|c|}
\hline $\begin{array}{c}\text { Dates } \\
\text { samples } \\
\text { deployed in } \\
\text { collectors }\end{array}$ & $\begin{array}{l}\text { Sampling } \\
\text { Period } \\
\text { (days) }\end{array}$ & $\begin{array}{l}\text { Mass } \\
\text { Loss } \\
\text { (grams) }\end{array}$ & $\begin{array}{l}\text { Volume } \\
\text { Loss } \\
(\%)\end{array}$ & $\begin{array}{c}\text { MPV } \\
\text { (ng/L) }\end{array}$ & $\begin{array}{c}\text { Measured total } \\
\mathrm{Hg} \\
\text { concentration } \\
\text { (ng/L) }\end{array}$ & $\begin{array}{c}\mathrm{Hg} \\
\text { concentration } \\
\text { difference }^{1} \\
(\%)\end{array}$ & $\begin{array}{c}\text { Hg mass } \\
\text { loss }^{2} \\
(\%)\end{array}$ \\
\hline $\begin{array}{l}8 / 24 / 10- \\
8 / 31 / 10\end{array}$ & 7 & 0.6 & 0.4 & 15.3 & 9.56 & -37.5 & 37.8 \\
\hline $\begin{array}{l}8 / 31 / 10- \\
9 / 15 / 10\end{array}$ & 15 & 1.1 & 0.8 & 21.7 & 7.08 & -67.4 & 67.7 \\
\hline $\begin{array}{l}11 / 11 / 10- \\
11 / 23 / 10\end{array}$ & 12 & 9.7 & 3.6 & 9.26 & 10.2 & 10.4 & -6.00 \\
\hline $\begin{array}{l}11 / 23 / 10- \\
12 / 02 / 10\end{array}$ & 9 & 2.6 & 1.0 & 9.26 & 9.38 & 1.3 & -0.20 \\
\hline $\begin{array}{l}12 / 02 / 10- \\
12 / 09 / 10\end{array}$ & 7 & 2.2 & 1.4 & 6.26 & 7.33 & 17.1 & -15.2 \\
\hline $\begin{array}{l}12 / 09 / 10- \\
12 / 16 / 10\end{array}$ & 7 & 16.7 & 9.4 & 9.26 & 10.3 & 10.9 & -0.80 \\
\hline $\begin{array}{l}12 / 16 / 10- \\
12 / 23 / 10\end{array}$ & 7 & 8.3 & 4.8 & 15.2 & 6.59 & -56.6 & 59.0 \\
\hline $\begin{array}{l}12 / 23 / 10- \\
12 / 30 / 10\end{array}$ & 7 & 1.3 & 0.7 & 6.26 & 5.96 & -4.80 & 5.50 \\
\hline $\begin{array}{l}12 / 30 / 10- \\
1 / 13 / 11\end{array}$ & 14 & 22.2 & 12.6 & 15.2 & 15.8 & 3.70 & 11.1 \\
\hline $\begin{array}{l}1 / 13 / 11- \\
1 / 25 / 11\end{array}$ & 12 & 2.8 & 1.7 & 15.2 & 12.9 & -15.0 & 16.6 \\
\hline $\begin{array}{l}1 / 25 / 11- \\
2 / 01 / 11\end{array}$ & 7 & 9.0 & 10.0 & 15.2 & 12.0 & -20.9 & 31.0 \\
\hline $\begin{array}{c}2 / 01 / 11- \\
2 / 08 / 11\end{array}$ & 7 & 82.4 & 60.9 & 21.6 & 68.7 & 218 & 9.50 \\
\hline $\begin{array}{l}2 / 08 / 11- \\
2 / 15 / 11\end{array}$ & 7 & 7.2 & 5.7 & 21.6 & 20.6 & -4.60 & 11.0 \\
\hline $\begin{array}{l}2 / 15 / 11- \\
2 / 22 / 11\end{array}$ & 7 & 6.8 & 4.2 & 21.6 & 17.5 & -19.0 & 22.9 \\
\hline $\begin{array}{l}2 / 22 / 11- \\
3 / 01 / 11\end{array}$ & 7 & 2.4 & 2.0 & 21.6 & 16.3 & -24.4 & 26.2 \\
\hline $\begin{array}{l}7 / 05 / 11- \\
7 / 12 / 11\end{array}$ & 7 & 6.6 & 4.9 & 15.2 & 16.4 & 8.10 & -1.80 \\
\hline $\begin{array}{l}7 / 12 / 11- \\
7 / 19 / 11\end{array}$ & 7 & 1.1 & 0.9 & 15.2 & 14.0 & -7.60 & 8.60 \\
\hline $\begin{array}{l}7 / 19 / 11- \\
7 / 26 / 11\end{array}$ & 7 & 1.2 & 0.7 & 20.8 & 17.1 & -17.6 & 18.2 \\
\hline $\begin{array}{l}7 / 26 / 11- \\
8 / 02 / 11\end{array}$ & 7 & 1.6 & 1.0 & 14.2 & 13.4 & -5.80 & 6.90 \\
\hline
\end{tabular}

${ }^{1}(($ Measured - MPV $) / \mathrm{MPV}) \times 100$

${ }^{2}(($ MPV-Measured $) /$ MPV $) \times 100$ 
Table 6. Results from evaporation tests with Loda Electronics version of the modified ACM collector. [\%, percent; ng/L, nanograms per liter; MPV, most probably value; $\mathrm{Hg}$, mercury]

\begin{tabular}{|c|c|c|c|c|c|c|c|}
\hline $\begin{array}{c}\text { Dates } \\
\text { samples } \\
\text { deployed in } \\
\text { collectors }\end{array}$ & $\begin{array}{l}\text { Sampling } \\
\text { Period } \\
\text { (days) }\end{array}$ & $\begin{array}{c}\text { Mass } \\
\text { Loss } \\
\text { (grams) }\end{array}$ & $\begin{array}{c}\text { Volume } \\
\text { Loss } \\
(\%)\end{array}$ & $\begin{array}{c}\text { MPV } \\
\text { (ng/L) }\end{array}$ & $\begin{array}{c}\text { Measured } \\
\text { total Hg } \\
\text { concentration } \\
\text { (ng/L) }\end{array}$ & $\begin{array}{c}\mathrm{Hg} \\
\text { concentration } \\
\text { difference }^{1} \\
(\%)\end{array}$ & $\begin{array}{c}\text { Hg mass } \\
\text { loss }^{2} \\
(\%)\end{array}$ \\
\hline $\begin{array}{l}8 / 24 / 10- \\
8 / 31 / 10\end{array}$ & 7 & 5.5 & 3.9 & 15.3 & 8.79 & -42.5 & 45.2 \\
\hline $\begin{array}{l}8 / 31 / 10- \\
9 / 15 / 10\end{array}$ & 15 & 6.0 & 4.2 & 21.7 & 11.0 & -49.1 & 51.6 \\
\hline $\begin{array}{l}11 / 11 / 10- \\
11 / 23 / 10\end{array}$ & 12 & 25.4 & 9.5 & 15.2 & 16.9 & 11.2 & 0.2 \\
\hline $\begin{array}{l}11 / 23 / 10- \\
12 / 09 / 10^{3}\end{array}$ & 16 & 40.7 & 15.2 & 15.2 & 16.8 & 10.6 & 7.5 \\
\hline $\begin{array}{l}12 / 09 / 10- \\
12 / 16 / 10\end{array}$ & 7 & 25.3 & 12.1 & 9.26 & 11.0 & 18.7 & -2.7 \\
\hline $\begin{array}{l}12 / 16 / 10- \\
12 / 23 / 10\end{array}$ & 7 & 41.7 & 22.7 & 15.2 & 8.25 & -45.7 & 59.6 \\
\hline $\begin{array}{l}12 / 23 / 10- \\
12 / 30 / 10\end{array}$ & 7 & 28.7 & 12.8 & 15.2 & 16.5 & 8.8 & 6.4 \\
\hline $\begin{array}{l}12 / 30 / 10- \\
1 / 13 / 11\end{array}$ & 14 & 35.1 & 23.2 & 15.2 & 20.3 & 33.5 & 2.3 \\
\hline $\begin{array}{l}1 / 13 / 11- \\
1 / 25 / 11\end{array}$ & 12 & 67.6 & 42.6 & 15.2 & 26.2 & 72.6 & 11.7 \\
\hline $\begin{array}{l}1 / 25 / 11- \\
2 / 01 / 11\end{array}$ & 7 & 20.7 & 13.1 & 15.2 & 13.6 & -10.5 & 23.9 \\
\hline $\begin{array}{l}2 / 01 / 11- \\
2 / 08 / 11\end{array}$ & 7 & 36.8 & 18.6 & 21.6 & 18.2 & -15.6 & 33.1 \\
\hline $\begin{array}{l}2 / 08 / 11- \\
2 / 15 / 11\end{array}$ & 7 & 60.7 & 54.4 & 21.6 & 39.1 & 81.0 & 39.1 \\
\hline $\begin{array}{l}2 / 15 / 11- \\
2 / 22 / 11\end{array}$ & 7 & 7.9 & 4.7 & 21.6 & 15.4 & -28.9 & 32.7 \\
\hline $\begin{array}{l}2 / 22 / 11- \\
3 / 01 / 11\end{array}$ & 7 & 55.3 & 47.5 & 21.6 & 33.6 & 55.5 & 33.7 \\
\hline $\begin{array}{l}8 / 02 / 11- \\
8 / 09 / 11\end{array}$ & 7 & 10.9 & 4.8 & 9.03 & 11.8 & 30.2 & -23.3 \\
\hline $\begin{array}{l}8 / 09 / 11- \\
8 / 16 / 11\end{array}$ & 7 & 5.6 & 3.1 & 9.03 & 8.92 & -1.2 & 4.6 \\
\hline $\begin{array}{l}8 / 16 / 11- \\
8 / 23 / 11\end{array}$ & 7 & 14.4 & 6.6 & 14.2 & 14.2 & -0.1 & 7.4 \\
\hline
\end{tabular}


Table 6. Results from evaporation tests with Loda Electronics version of the modified ACM collector-Continued

[\%, percent; ng/L, nanograms per liter; MPV, most probably value; $\mathrm{Hg}$, mercury]

\begin{tabular}{|c|c|c|c|c|c|c|c|}
\hline $\begin{array}{c}\text { Dates } \\
\text { samples } \\
\text { deployed in } \\
\text { collectors }\end{array}$ & $\begin{array}{l}\text { Sampling } \\
\text { Period } \\
\text { (days) }\end{array}$ & $\begin{array}{l}\text { Mass } \\
\text { Loss } \\
\text { (grams) }\end{array}$ & $\begin{array}{l}\text { Volume } \\
\text { Loss } \\
(\%)\end{array}$ & $\begin{array}{c}\text { MPV } \\
\text { (ng/L) }\end{array}$ & $\begin{array}{c}\text { Measured } \\
\text { total } \mathrm{Hg} \\
\text { concentratio } \\
\mathrm{n}(\mathrm{ng} / \mathrm{L})\end{array}$ & $\begin{array}{c}\mathrm{Hg} \\
\text { concentration } \\
\text { difference }{ }^{1} \\
(\%)\end{array}$ & $\begin{array}{c}\text { Hg mass } \\
\text { loss }^{2} \\
(\%)\end{array}$ \\
\hline $\begin{array}{l}8 / 23 / 11- \\
8 / 30 / 11\end{array}$ & 7 & 1.7 & 1.0 & 20.75 & 17.33 & -16.5 & 17.5 \\
\hline $\begin{array}{l}\text { 8/30/11 - } \\
9 / 06 / 11\end{array}$ & 7 & 23.5 & 14.7 & 9.03 & 10.16 & 12.5 & 6.3 \\
\hline $\begin{array}{l}\text { 9/06/11 - } \\
9 / 13 / 11\end{array}$ & 7 & 17.8 & 7.2 & 15.5 & 15.66 & 1.0 & 6.9 \\
\hline $\begin{array}{l}\text { 9/13/11 - } \\
\text { 9/20/11 }\end{array}$ & 7 & 0.4 & 0.2 & 14.2 & 13.05 & -8.1 & 8.3 \\
\hline $\begin{array}{l}\text { 9/20/11 - } \\
\text { 9/27/11 }\end{array}$ & 7 & 0.5 & 0.3 & 15.5 & 14.32 & -7.6 & 8.0 \\
\hline $\begin{array}{c}9 / 27 / 11- \\
10 / 04 / 11\end{array}$ & 7 & 0.7 & 0.4 & 15.5 & 11.66 & -24.8 & 25.1 \\
\hline $\begin{array}{l}10 / 04 / 11- \\
10 / 11 / 11\end{array}$ & 7 & 6.8 & 3.2 & 6.02 & 6.35 & 5.5 & -1.8 \\
\hline $\begin{array}{l}10 / 11 / 11- \\
10 / 18 / 11\end{array}$ & 7 & 12.5 & 8.2 & 6.02 & 6.96 & 15.1 & -4.3 \\
\hline $\begin{array}{l}10 / 18 / 11- \\
11 / 01 / 11\end{array}$ & 14 & 31.0 & 13.6 & 6.02 & 7.56 & 25.6 & -6.9 \\
\hline
\end{tabular}

${ }^{1}(($ Measured - MPV $) / \mathrm{MPV}) \times 100$

$2(($ MPV-Measured $) / M P V) \times 100$

${ }^{3}$ Sample bottle left in place for extended duration. Bottle for $2^{\text {nd }}$ week broke during shipment. 
Table 7. Results from evaporation tests with $\mathrm{N}-\mathrm{CON}$ single-chimney collector.

[\%, percent; ng/L, nanograms per liter; MPV, most probably value; $\mathrm{Hg}$, mercury]

\begin{tabular}{|c|c|c|c|c|c|c|c|}
\hline $\begin{array}{c}\text { Dates } \\
\text { samples } \\
\text { deployed in } \\
\text { collectors }\end{array}$ & $\begin{array}{l}\text { Sampling } \\
\text { Period } \\
\text { (days) }\end{array}$ & $\begin{array}{l}\text { Mass } \\
\text { Loss } \\
\text { (grams) }\end{array}$ & $\begin{array}{l}\text { Volume } \\
\text { Loss } \\
(\%)\end{array}$ & $\begin{array}{c}\text { MPV } \\
\text { (ng/L) }\end{array}$ & $\begin{array}{c}\text { Measured total } \\
\mathrm{Hg} \\
\text { concentration } \\
\text { (ng/L) }\end{array}$ & $\begin{array}{c}\mathrm{Hg} \\
\text { concentration } \\
\text { difference }{ }^{1} \\
(\%)\end{array}$ & $\begin{array}{c}\text { Hg mass } \\
\text { loss }^{2} \\
(\%)\end{array}$ \\
\hline $\begin{array}{l}7 / 05 / 11- \\
7 / 12 / 11\end{array}$ & 7 & 1.7 & 1.1 & 15.2 & 14.4 & -5.3 & 6.5 \\
\hline $\begin{array}{l}7 / 12 / 11- \\
7 / 19 / 11\end{array}$ & 7 & 2.4 & 1.6 & 15.2 & 12.7 & -16.2 & 17.7 \\
\hline $\begin{array}{l}7 / 19 / 11- \\
7 / 26 / 11\end{array}$ & 7 & 1.4 & 0.9 & 20.8 & 12.8 & -38.3 & 38.9 \\
\hline $\begin{array}{l}7 / 26 / 11- \\
8 / 02 / 11\end{array}$ & 7 & 0.9 & 0.5 & 14.2 & 13.5 & -5.1 & 5.6 \\
\hline $\begin{array}{l}8 / 02 / 11- \\
8 / 09 / 11\end{array}$ & 7 & 1.7 & 0.8 & 9.03 & 8.62 & -4.5 & 5.4 \\
\hline $\begin{array}{l}8 / 09 / 11- \\
8 / 16 / 11\end{array}$ & 7 & 0.8 & 0.5 & 9.03 & 8.16 & -9.6 & 10.1 \\
\hline $\begin{array}{l}8 / 16 / 11- \\
8 / 23 / 11\end{array}$ & 7 & 0.9 & 0.4 & 14.2 & 14.3 & 1.0 & -0.5 \\
\hline $\begin{array}{l}8 / 23 / 11- \\
8 / 30 / 11\end{array}$ & 7 & 0.9 & 0.5 & 20.8 & 19.8 & -4.8 & 5.3 \\
\hline $\begin{array}{l}8 / 30 / 11- \\
9 / 06 / 11\end{array}$ & 7 & 1.1 & 0.7 & 9.03 & 7.4 & -18.1 & 18.7 \\
\hline $\begin{array}{l}\text { 9/06/11 - } \\
\text { 9/13/11 }\end{array}$ & 7 & 0.8 & 0.4 & 15.5 & 14.3 & -7.9 & 8.4 \\
\hline $\begin{array}{l}\text { 9/13/11 - } \\
\text { 9/20/11 }\end{array}$ & 7 & 0.3 & 0.2 & 14.2 & 14.1 & -0.6 & 0.8 \\
\hline $\begin{array}{l}9 / 20 / 11- \\
9 / 27 / 11\end{array}$ & 7 & 0.7 & 0.4 & 15.5 & 13.8 & -10.8 & 11.1 \\
\hline $\begin{array}{c}9 / 27 / 11- \\
10 / 04 / 11\end{array}$ & 7 & 1.6 & 1.1 & 15.5 & 15.1 & -2.9 & 4.1 \\
\hline $\begin{array}{l}10 / 04 / 11- \\
10 / 11 / 11\end{array}$ & 7 & 4.1 & 2.2 & 6.02 & 4.91 & -18.4 & 20.5 \\
\hline $\begin{array}{l}10 / 11 / 11- \\
10 / 18 / 11\end{array}$ & 7 & 0.6 & 0.5 & 6.02 & 5.32 & -11.6 & 12.1 \\
\hline $\begin{array}{l}10 / 18 / 11- \\
11 / 01 / 11\end{array}$ & 14 & 0.8 & 0.4 & 6.02 & 5.34 & -11.3 & 11.7 \\
\hline
\end{tabular}

${ }^{1}(($ Measured - MPV $) / \mathrm{MPV}) \times 100$

${ }^{2}(($ MPV-Measured $) / M P V) \times 100$ 
Table 8. Total mercury concentration analyses for sample-train study samples processed after a week with rain or snow at selected Mercury Deposition Network sites.

[Hg, mercury; ng, nanograms; ng/L, nanograms per liter; \%, percent; $\mathrm{HCl}$, hydrochloric acid; N-CON, NCON Systems, Inc.; Mod-ACM, Modified Aerochem Metrics; dry, no precipitation recorded for previous week; $<0.005$, less than detection value reported as 0.000 by laboratory; mean $\mathrm{HCl}$ control concentration= $0.1 \mathrm{ng} / \mathrm{L} ;]$

\begin{tabular}{|c|c|c|c|c|c|c|}
\hline $\begin{array}{c}\text { MDN site } \\
\text { ID }\end{array}$ & $\begin{array}{l}\text { Hg wet- } \\
\text { deposition } \\
\text { collector type }\end{array}$ & $\begin{array}{l}\text { Hg mass } \\
\text { collected in } \\
\text { previous } \\
\text { week's sample } \\
\text { (ng) }\end{array}$ & $\begin{array}{l}\text { Sample train } \\
\text { total } \mathrm{Hg} \\
\text { concen- } \\
\text { tration }(\mathrm{ng} / \mathrm{L})\end{array}$ & $\begin{array}{l}\text { Control } \\
\text { sample total } \\
\text { Hg concen- } \\
\text { tration } \\
\text { (ng/L) }\end{array}$ & $\begin{array}{l}\text { Sample-train- } \\
\text { minus-control } \\
\text { total Hg } \\
\text { concentration } \\
\text { difference1 } \\
\text { (ng/L) }\end{array}$ & $\begin{array}{l}\text { Sample-train- } \\
\text { minus-control } \\
\text { total Hg } \\
\text { concentration } \\
\text { median } \\
\text { difference } \\
\text { (ng/L) }\end{array}$ \\
\hline \multicolumn{7}{|c|}{ Rain Samples } \\
\hline GA33 & $\mathrm{N}-\mathrm{CON}$ & 4,514 & 1.553 & 2.082 & -0.530 & \multirow{5}{*}{0.238} \\
\hline KS03 & $\mathrm{N}-\mathrm{CON}$ & 18,154 & 1.397 & 0.013 & 1.384 & \\
\hline NY06 & $\mathrm{N}-\mathrm{CON}$ & 999 & 0.557 & 0.320 & 0.238 & \\
\hline UT97 & $\mathrm{N}-\mathrm{CON}$ & 2,185 & 0.293 & 0.116 & 0.177 & \\
\hline WV99 & $\mathrm{N}-\mathrm{CON}$ & 1,397 & 0.666 & 0.007 & 0.659 & \\
\hline FL34 & Mod-ACM & 16,025 & 0.545 & $<0.005$ & 0.545 & \multirow{5}{*}{0.489} \\
\hline IN26 & Mod-ACM & 3,162 & 0.624 & 0.539 & 0.085 & \\
\hline OK04 & Mod-ACM & 3,069 & 0.601 & 0.010 & 0.590 & \\
\hline OK06 & Mod-ACM & 1,288 & 0.206 & $<0.005$ & 0.206 & \\
\hline SC03 & Mod-ACM & 8,981 & 0.529 & 0.039 & 0.489 & \\
\hline \multicolumn{7}{|c|}{ Snow Samples } \\
\hline NE15 & $\mathrm{N}-\mathrm{CON}$ & dry & 0.004 & 0.012 & -0.008 & \multirow{4}{*}{0.076} \\
\hline NY06 & $\mathrm{N}-\mathrm{CON}$ & 272 & 0.170 & 0.063 & 0.107 & \\
\hline ID98 & $\mathrm{N}-\mathrm{CON}$ & 805 & 0.046 & $<0.005$ & 0.046 & \\
\hline UT97 & $\mathrm{N}-\mathrm{CON}$ & 103 & 0.460 & $<0.005$ & 0.460 & \\
\hline $\mathrm{IN} 28$ & Mod-ACM & dry & 0.269 & 0.051 & 0.217 & \multirow{4}{*}{0.056} \\
\hline MN23 & Mod-ACM & 37 & 0.059 & $<0.005$ & 0.059 & \\
\hline PA52 & Mod-ACM & 91 & 0.052 & $<0.005$ & 0.052 & \\
\hline PA60 & Mod-ACM & 3,339 & 0.077 & 0.061 & 0.016 & \\
\hline
\end{tabular}

\footnotetext{
${ }^{1}$ Negative difference values are interpreted as zero for purposes of this study.
} 
Table 9. Co-located National Trends Network (NTN) and Mercury Deposition Network (MDN) sites and periods of record for comparison of 7- and 11-grid AeroChem Metrics precipitation sensors.

\begin{tabular}{ccc}
\hline $\begin{array}{c}\text { NTN/MDN } \\
\text { site }\end{array}$ & Period of record & $\begin{array}{c}\text { Months of } \\
\text { record } \\
\text { evaluated }\end{array}$ \\
\hline CA94 & $6 / 24 / 08-2 / 17 / 09$ & 8 \\
CO99 & $8 / 27 / 08-2 / 01 / 09$ & 5 \\
ID03 & $12 / 05 / 07-2 / 17 / 09$ & 14 \\
IL11 & $8 / 24 / 07-2 / 24 / 09$ & 18 \\
IN20 & $12 / 30 / 08-2 / 17 / 09$ & 2 \\
IN34 & $12 / 30 / 08-2 / 17 / 09$ & 1.5 \\
KY10 & $1 / 09 / 09-2 / 17 / 09$ & 1.2 \\
MD08 & $7 / 03 / 08-1 / 20 / 09$ & 6.5 \\
MD99 & $10 / 23 / 08-1 / 21 / 09$ & 3 \\
ME02 & $9 / 18 / 08-2 / 17 / 09$ & 5 \\
ME04 & $5 / 08 / 08-12 / 03 / 08$ & 7 \\
ME09 & $1 / 22 / 08-2 / 17 / 09$ & 13 \\
ME96 & $6 / 12 / 08-2 / 17 / 09$ & 8 \\
ME98 & $5 / 20 / 08-2 / 17 / 09$ & 8 \\
MT05 & $6 / 24 / 08-2 / 17 / 09$ & 8 \\
OK99 & $5 / 22 / 07-2 / 17 / 09$ & 16 \\
TN11 & $10 / 07 / 08-2 / 24 / 09$ & 4.5 \\
VA28 & $7 / 01 / 08-2 / 17 / 09$ & 7 \\
WI10 & $10 / 29 / 08-2 / 10 / 09$ & 4 \\
WY08 & $6 / 05 / 08-2 / 17 / 09$ & 8 \\
\hline
\end{tabular}

